\title{
2008
}

Brookhaven National Laboratory

Annual Illness and Injury

Surveillance Report

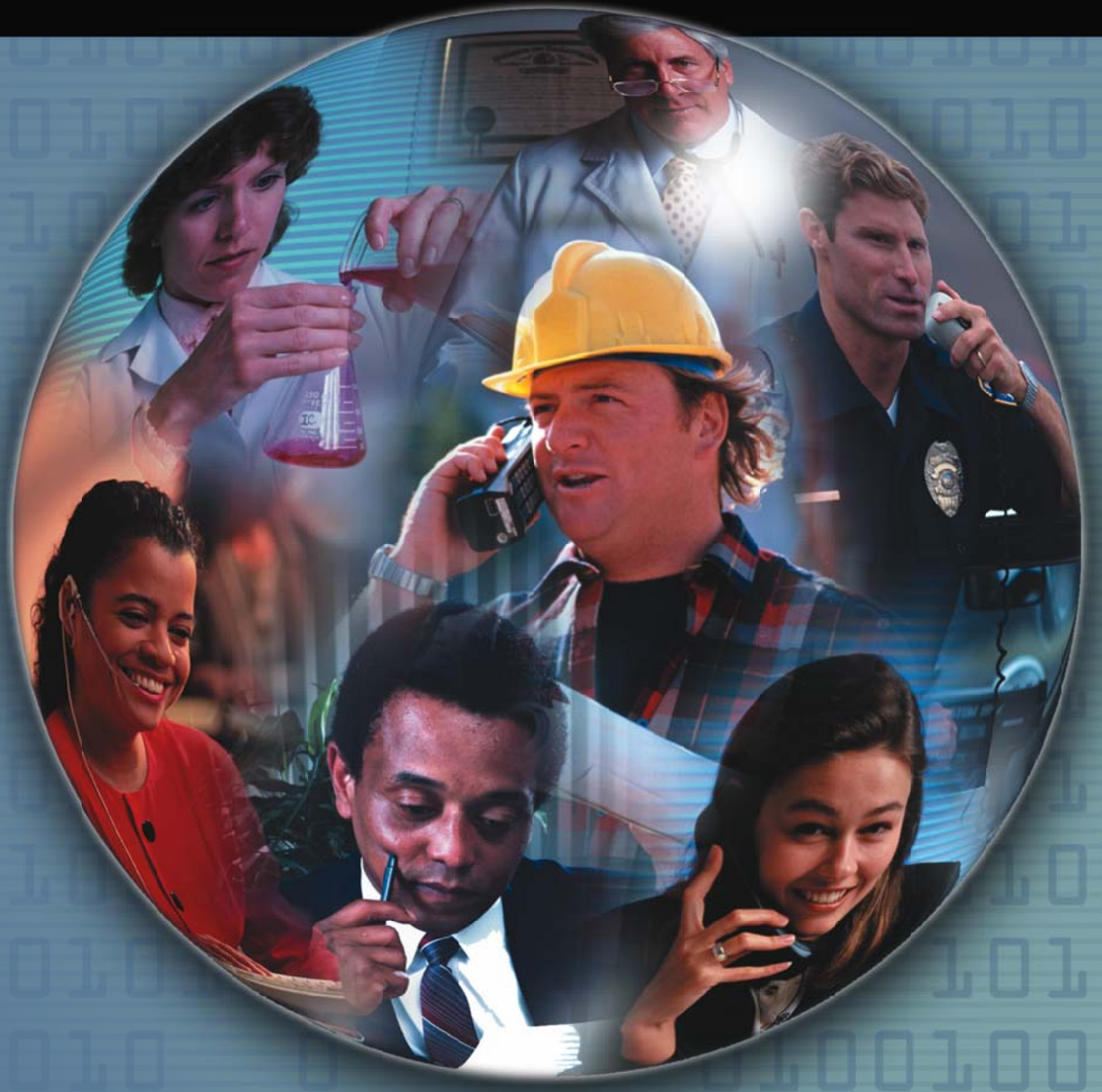




\section{Brookhaven National Laboratory 2008 Illness and Injury Surveillance Report}

Questions or comments about this report or the Illness and Injury Surveillance Program (IISP) may be directed to:

E-mail:

Dr. Cliff Strader at cliff.strader@hq.doe.gov or Dr. Bonnie Richter at bonnie.richter@hq.doe.gov

or direct letters to:

Mail Stop HS-13 / 270CC

U.S. Department of Energy

1000 Independence Avenue, S.W.

Washington, DC 20585-0270

Additional information about the Department of Energy's Office of Illness and Injury Prevention Programs, the IISP, and annual reports for DOE sites participating in this program can be found at:

http://www.hss.energy.gov/healthsafety/WSHP/epi/surv/

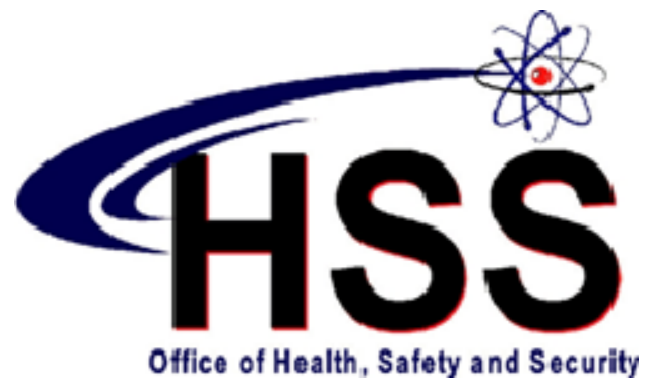

ACKNOWLEDGEMENT

LifeART images copyright 2000 Lippincott Williams \& Wilkins. All rights reserved.

This document was produced under contract number DE-AC05-06OR23100 between the

U.S. Department of Energy and Oak Ridge Associated Universities. 


\section{Brookhaven National Laboratory 2008 Illness and Injury Surveillance Report}

\section{At A Glance}

The BNL work force totaled 2,916 workers in 2008, a slight increase from 2,840 workers in 2007. After declining from 2003 to 2006, the number of workers at BNL increased in both 2007 and 2008.

The mean age of the work force has remained the same since 2005 for men (48 years). The mean age for women increased from 46 to 47 years in 2008.

There were a total of 149 absences among 110 women, a rate of 18.7 per 100 workers. Among 240 men, there were 320 absences, a rate of 15.1 per 100 workers. This is only the second year since 2003 that the absence rate for women has been higher than the rate for men. The trend in absence rates at BNL is different than other DOE sites. Among the DOE sites participating in the Illness and Injury Surveillance Program (IISP), the absence rates for women were at least 40 percent higher than those of men each year from 1998 to 2007.

Conditions of the musculoskeletal and respiratory systems, injuries, and unspecified symptoms have been the most common diagnoses each year since 2003 for both men and women.

Service workers had the highest rate for all diagnoses combined among women and men in 2008. The rate for women in 2008 decreased 27 percent from 2007, while the rate for men increased 76 percent during the same time. These rate changes were due to the reporting of musculoskeletal disorders in both men and women.

Injury rates, which declined from 2004 to 2006, increased in 2007 and remained steady for both men and women through 2008. The rate of musculoskeletal conditions decreased for women in 2008, but the rate has exhibited wide annual variation over the period 2003 through 2008. The rate of musculoskeletal conditions remained stable for men over the period. The rate of nervous system disorders increased sharply to the highest level since 2003 for women due to an increase in diagnoses for nerve disorders of the forearm and disorders of the ear and the eye. The rate of nervous system disorders remained steady for men. Chronic respiratory conditions for men and women have remained fairly steady since 2003. 
BNL reported 44 definite and 10 possible occupational sentinel health event (SHEO) diagnoses in 2008. Musculoskeletal conditions (25 diagnoses) and injuries (16 diagnoses) accounted for most of the SHEO diagnoses. Six SHEO diagnoses were carpal tunnel syndrome, 4 of which were reported by 2 women in the Professional job category.

Accidents were the cause of 24 of the 27 OSHA-recordable events in 2008. The most common type of accident was overexertion and strenuous movements, which accounted for 42 percent of the accidents; falls were the second most common. Twenty-four of the 34 illness and injury diagnoses reported for OSHA events were injuries.

The rate of OSHA events was less than 1 event per 100 workers in 2008, the lowest rate of OSHA events since 2003. Crafts and Security and Fire workers had the highest rate of OSHA events in 2008 ( 4.7 per 100 workers). Crafts workers have had the highest rate of OSHA events since 2004. Among sites participating in the IISP, the rates for Crafts and Security and Fire workers were among the highest throughout most of the period from 1998 through 2007. 


\section{The Brookhaven National Laboratory Work Force - 2008}

The Work Force by Gender and Age ............ 1

The Work Force by Gender and Job

Category 1

Number and Length of Absences

Absence Rate by Gender and Age 2

Number of Days Absent by

Gender and Age

Absence Rate by Job Category

and Gender 3

Average Duration of Absence by

Job Category and Gender. .. 3

\section{Diagnostic Categories}

Number of Diagnoses and Lost Calendar Days by Diagnostic Category

(Categorized by ICD-9-CM) and Gender . .4

Common Diagnoses Among Female

Workers in 2008 .. 5

Common Diagnoses Among Male

Workers in 2008 6

Number of Most Frequently Reported Diagnoses by Job Category and Gender 7

\section{Rates of Disease Occurrence}

Rates for All Illnesses and Injuries Combined by Job Category, Gender, and Age

Rates for Selected Diagnostic Categories by Job Category, Gender, and Age .. 8

\section{Time Trends}

Age-Adjusted Rates for All Diagnoses Combined Among Women and Men from 2003 to 2008
Age-Adjusted Rates for Selected Diagnostic Categories Among Women and Men from 2003 to 2008

Age-Adjusted Rates for All Diagnoses

Combined Among Women and Men by Job

Category from 2003 to $2008 \ldots \ldots \ldots \ldots \ldots \ldots \ldots \ldots . \ldots 12$

\section{Sentinel Health Events for Occupations (SHEOs)}

Characteristics of SHEOs by Gender 13

SHEO Diagnoses by Gender 13

Occupational Safety and Health Administration (OSHA)-Recordable Events

OSHA-Recordable Events by Gender and Age. 14

OSHA-Recordable Events by Job

Category and Gender 14

\section{Diagnostic and Accident Categories for OSHA-Recordable Events}

OSHA-Recordable Diagnoses by

Diagnostic Category and Gender

OSHA-Recordable Accidents by Type

and Gender

Rates of OSHA-Recordable Events

OSHA-Recordable Rates by Age and Job

Categories Among Women, All Diagnoses

Combined

OSHA-Recordable Rates by Age and Job

Categories Among Men, All Diagnoses

Combined

Time Trends for OSHA-Recordable Events

Age-Adjusted Rates for All OSHA-Recordable Diagnoses Combined Among Women and Men by Job Category from 2003 to 2008 .

\section{Appendices}

Appendices A-W 19 
The Brookhaven National Laboratory Work Force - 2008

Figure 1. The Work Force by Gender and Age

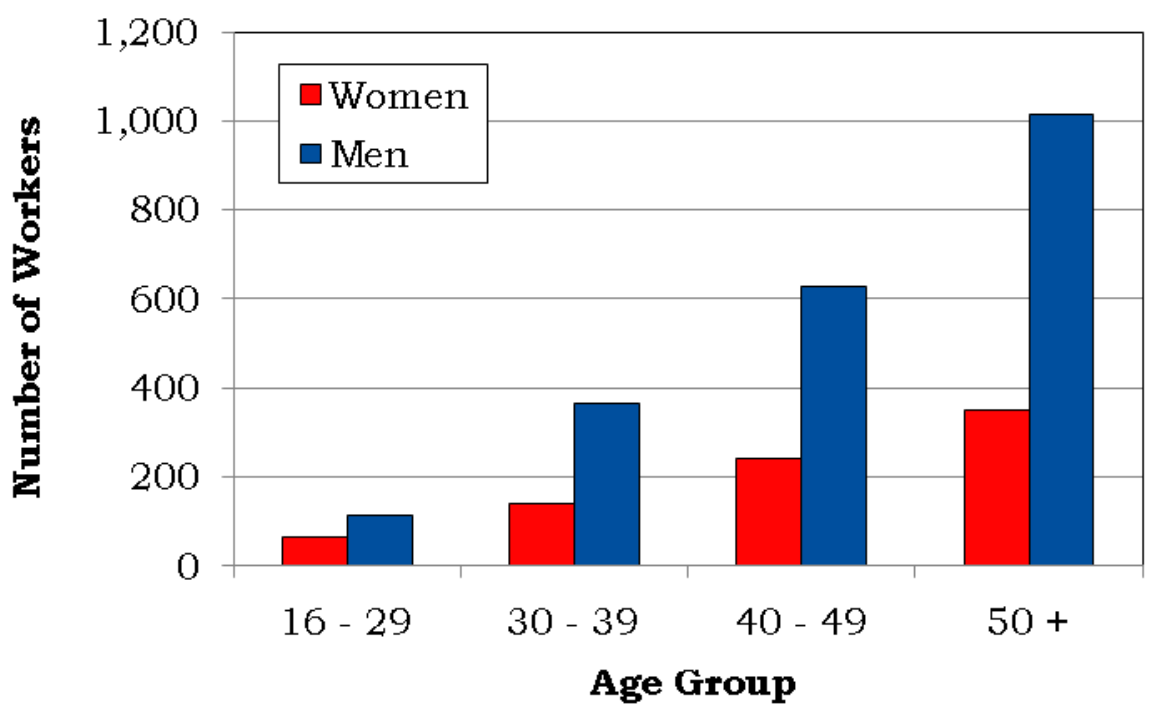

Figure 2. The Work Force by Gender and Job Category

\begin{tabular}{|c|c|c|}
\hline Job Category & Women & Men \\
\hline \multirow{2}{*}{ Professional } & 387 & 1,350 \\
\hline & $49 \%$ & $64 \%$ \\
\hline \multirow{2}{*}{ Administrative Support } & 311 & 49 \\
\hline & $39 \%$ & $2 \%$ \\
\hline \multirow{2}{*}{ Technical Support } & 43 & 355 \\
\hline & $5 \%$ & $17 \%$ \\
\hline \multirow{2}{*}{ Service } & 49 & 180 \\
\hline & $6 \%$ & $8 \%$ \\
\hline \multirow{2}{*}{ Security and Fire } & 5 & 59 \\
\hline & $1 \%$ & $3 \%$ \\
\hline \multirow{2}{*}{ Crafts } & 0 & 128 \\
\hline & $0 \%$ & $6 \%$ \\
\hline \multirow{2}{*}{ Line Operators } & 0 & $\mathbf{0}$ \\
\hline & $0 \%$ & $0 \%$ \\
\hline \multirow{2}{*}{ Total } & 795 & 2,121 \\
\hline & $100 \%$ & $100 \%$ \\
\hline
\end{tabular}




\section{Number and Length of Absences}

Figure 3. Absence Rate by Gender and Age

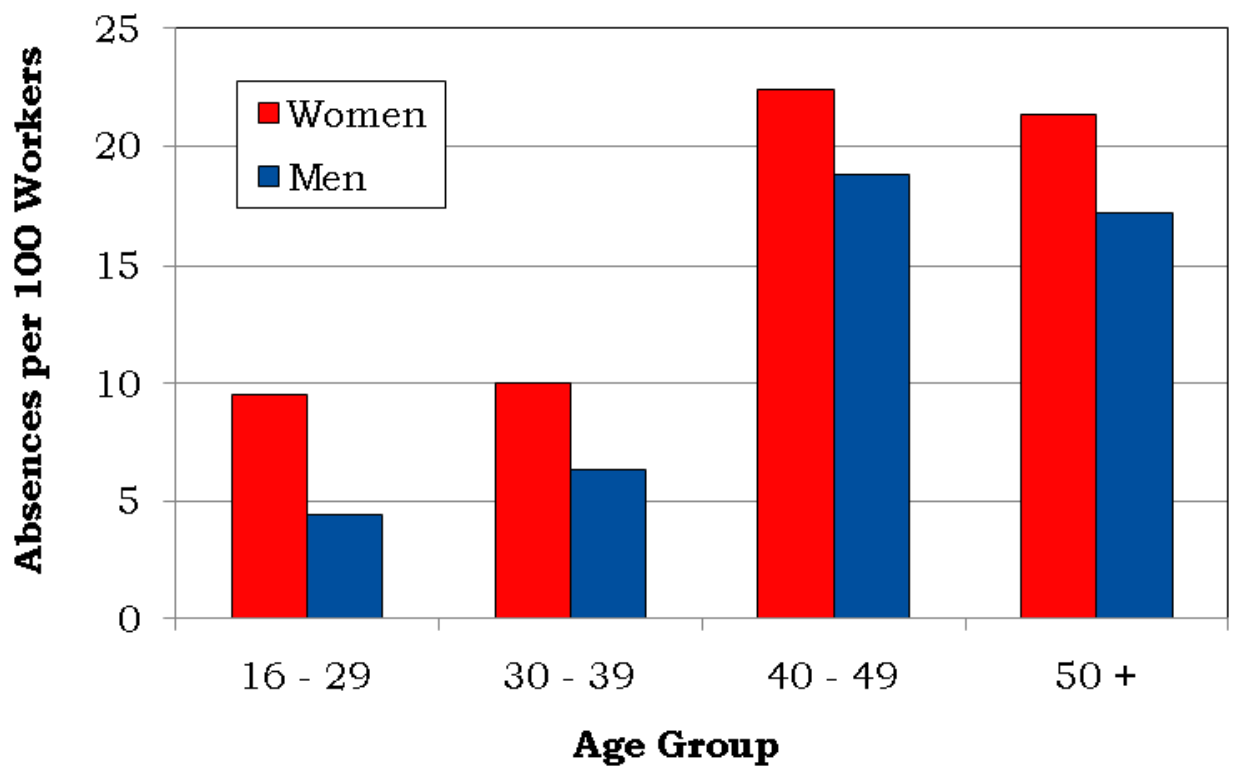

Figure 4. Number of Days Absent by Gender and Age

\begin{tabular}{|c|c|c|c|c|}
\hline \multirow{3}{*}{ Gender } & \multirow{2}{*}{ Age } & Number of & \multicolumn{2}{|c|}{ Number of Days Absent } \\
\cline { 3 - 5 } & & Absences & Total & Average \\
\hline \multirow{4}{*}{ Women } & $16-29$ & 6 & 25 & 4 \\
\cline { 2 - 5 } & $30-39$ & 14 & 244 & 17 \\
\cline { 2 - 5 } & $40-49$ & 54 & 1,001 & 19 \\
\cline { 2 - 5 } & $50+$ & 75 & 1,046 & 14 \\
\cline { 2 - 5 } & Total & 149 & 2,316 & 16 \\
\hline \multirow{4}{*}{ Men } & $16-29$ & 5 & 64 & 13 \\
\cline { 2 - 5 } & $30-39$ & 23 & 203 & 9 \\
\cline { 2 - 5 } & $40-49$ & 118 & 2,320 & 20 \\
\cline { 2 - 5 } & $50+$ & 174 & 4,324 & 25 \\
\cline { 2 - 5 } & Total & 320 & 6,911 & 22 \\
\hline
\end{tabular}


Figure 5. Absence Rate by Job Category and Gender

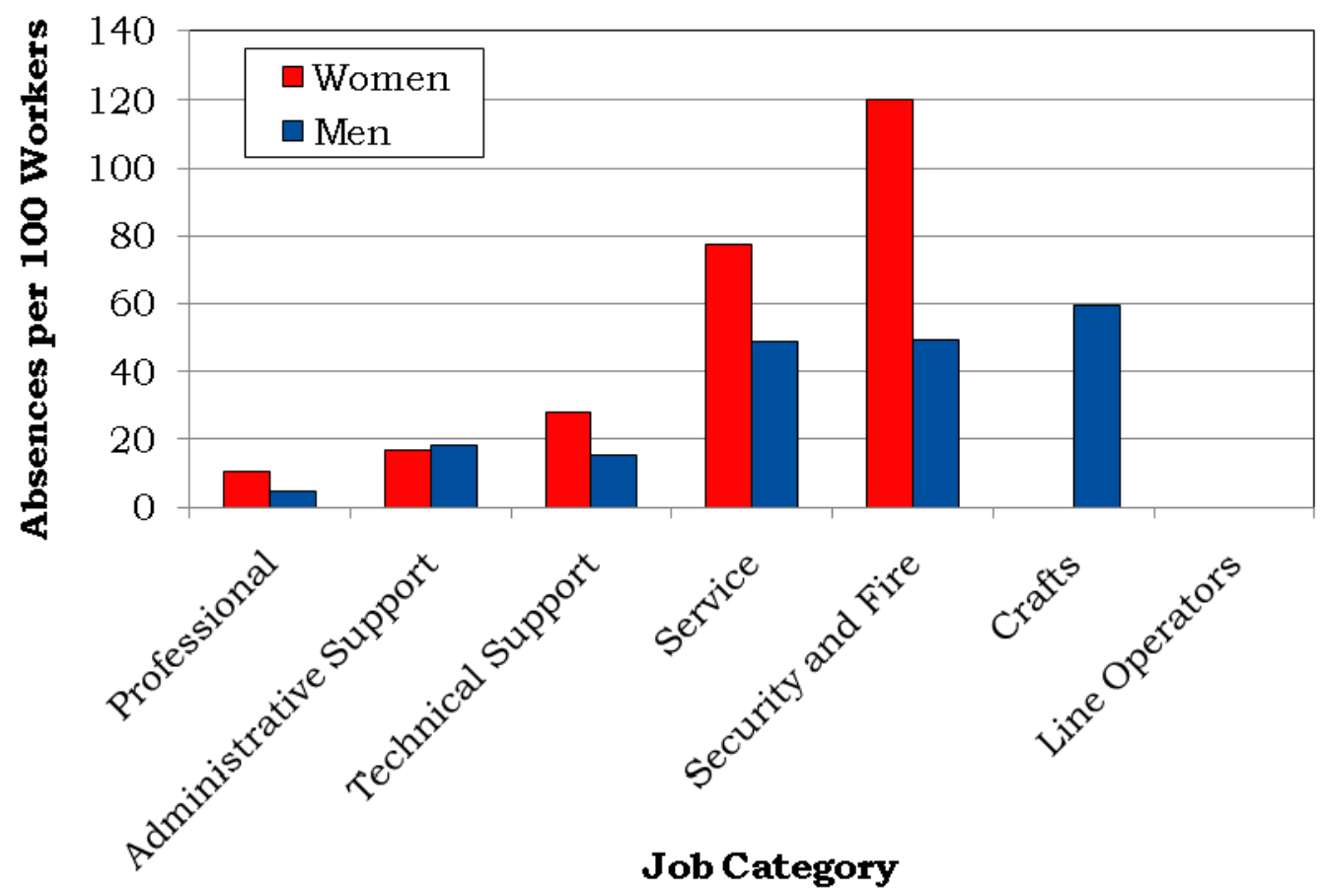

Figure 6. Average Duration of Absence by Job Category and Gender

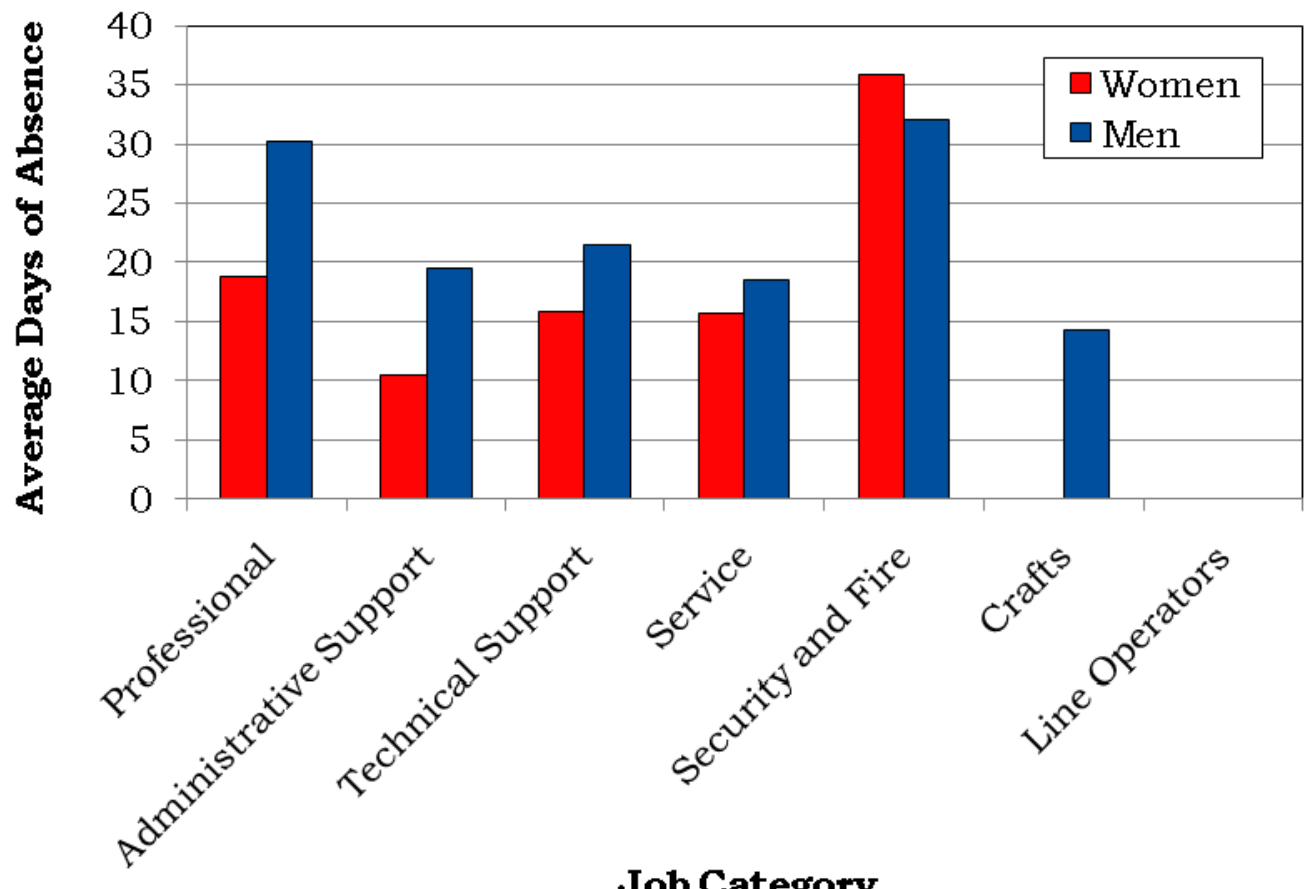

Job Category 


\section{Diagnostic Categories}

Figure 7. Number of Diagnoses and Lost Calendar Days by Diagnostic Category (Categorized by ICD-9-CM) and Gender

\begin{tabular}{|c|c|c|c|c|}
\hline \multirow[b]{2}{*}{ Diagnostic Category } & \multicolumn{2}{|c|}{ Women } & \multicolumn{2}{|c|}{ Men } \\
\hline & $\begin{array}{l}\text { Number of } \\
\text { Diagnoses }\end{array}$ & $\begin{array}{c}\text { Number } \\
\text { of Lost } \\
\text { Calendar } \\
\text { Days }\end{array}$ & $\begin{array}{l}\text { Number of } \\
\text { Diagnoses }\end{array}$ & $\begin{array}{c}\text { Number } \\
\text { of Lost } \\
\text { Calendar } \\
\text { Days }\end{array}$ \\
\hline Benign Growths & 3 & 99 & 6 & 103 \\
\hline Blood & 0 & 0 & 2 & 26 \\
\hline Cancer & 4 & 27 & 16 & 587 \\
\hline Digestive & 13 & 257 & 33 & 522 \\
\hline Endocrine / Me tabolic & 3 & 199 & 10 & 137 \\
\hline Existing Birth Condition & 0 & 0 & 1 & 477 \\
\hline Genitourinary & 14 & 218 & 8 & 100 \\
\hline Heart/Circulatory & 14 & 246 & 39 & 764 \\
\hline Infections/Parasites & 8 & 88 & 17 & 245 \\
\hline Injury & 24 & 454 & 65 & 1,861 \\
\hline Miscarriage & 0 & 0 & NA & NA \\
\hline Musculoskeletal & 50 & 725 & 146 & 2,811 \\
\hline Nervous System & 20 & 439 & 17 & 704 \\
\hline Psychological & 2 & 12 & 5 & 260 \\
\hline Respiratory & 43 & 310 & 81 & 572 \\
\hline Skin & 2 & 20 & 12 & 143 \\
\hline Unspecified Symptoms & 40 & 130 & 48 & 342 \\
\hline
\end{tabular}

Note: Lost calendar days for each absence are counted more than once when multiple diagnoses occur in different diagnostic categories for the same absence. 
Figure 8. Common Diagnoses Among Female Workers in 2008

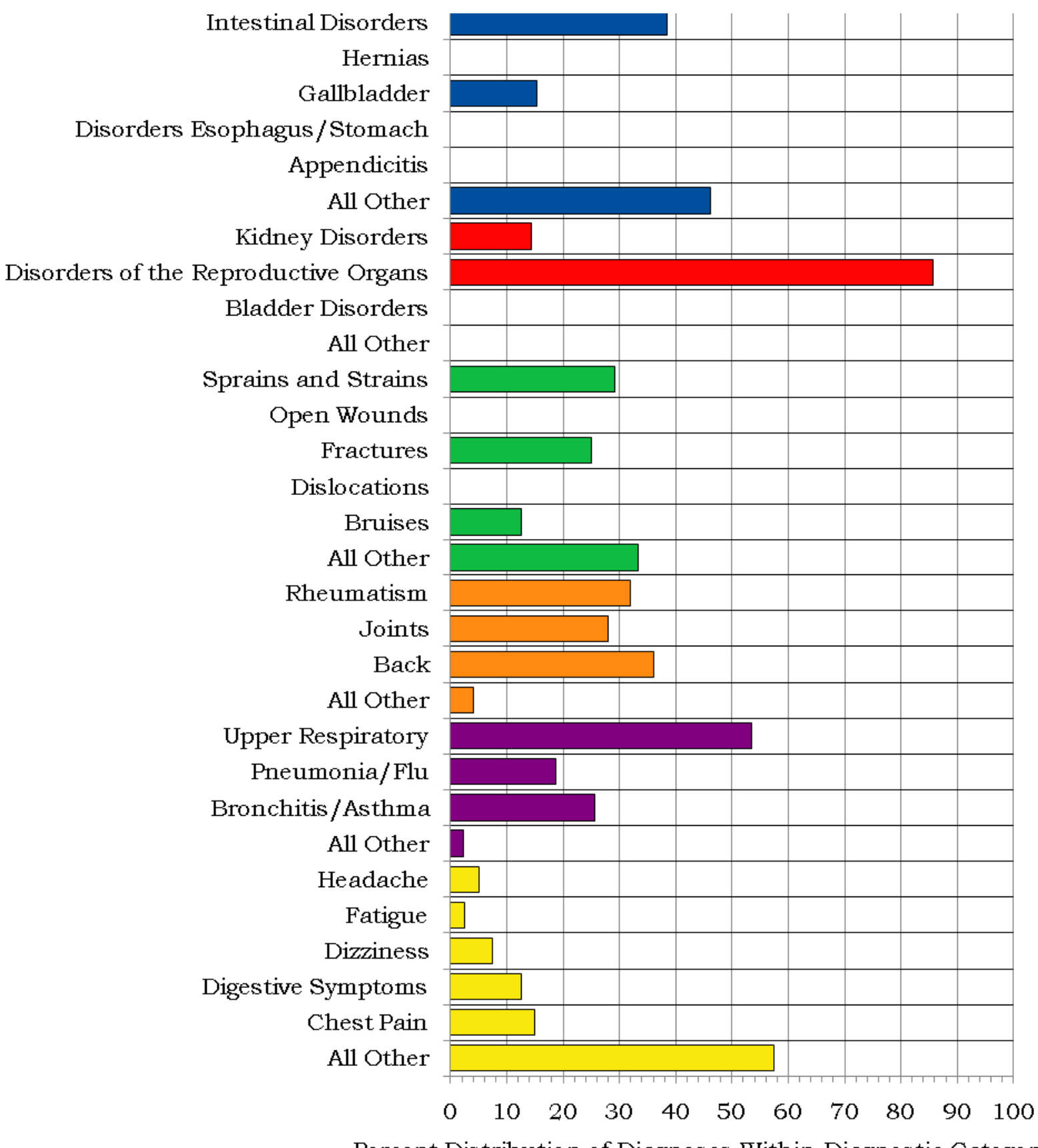

Percent Distribution of Diagnoses Within Diagnostic Category

Digestive, 13 Diagnoses

Genitourinary, 14 Diagnoses

Injury, 24 Diagnoses
Musculoskeletal, 50 Diagnoses

Respiratory, 43 Diagnoses

Unspecified Symptoms, 40 Diagnoses 
Figure 9. Common Diagnoses Among Male Workers in 2008

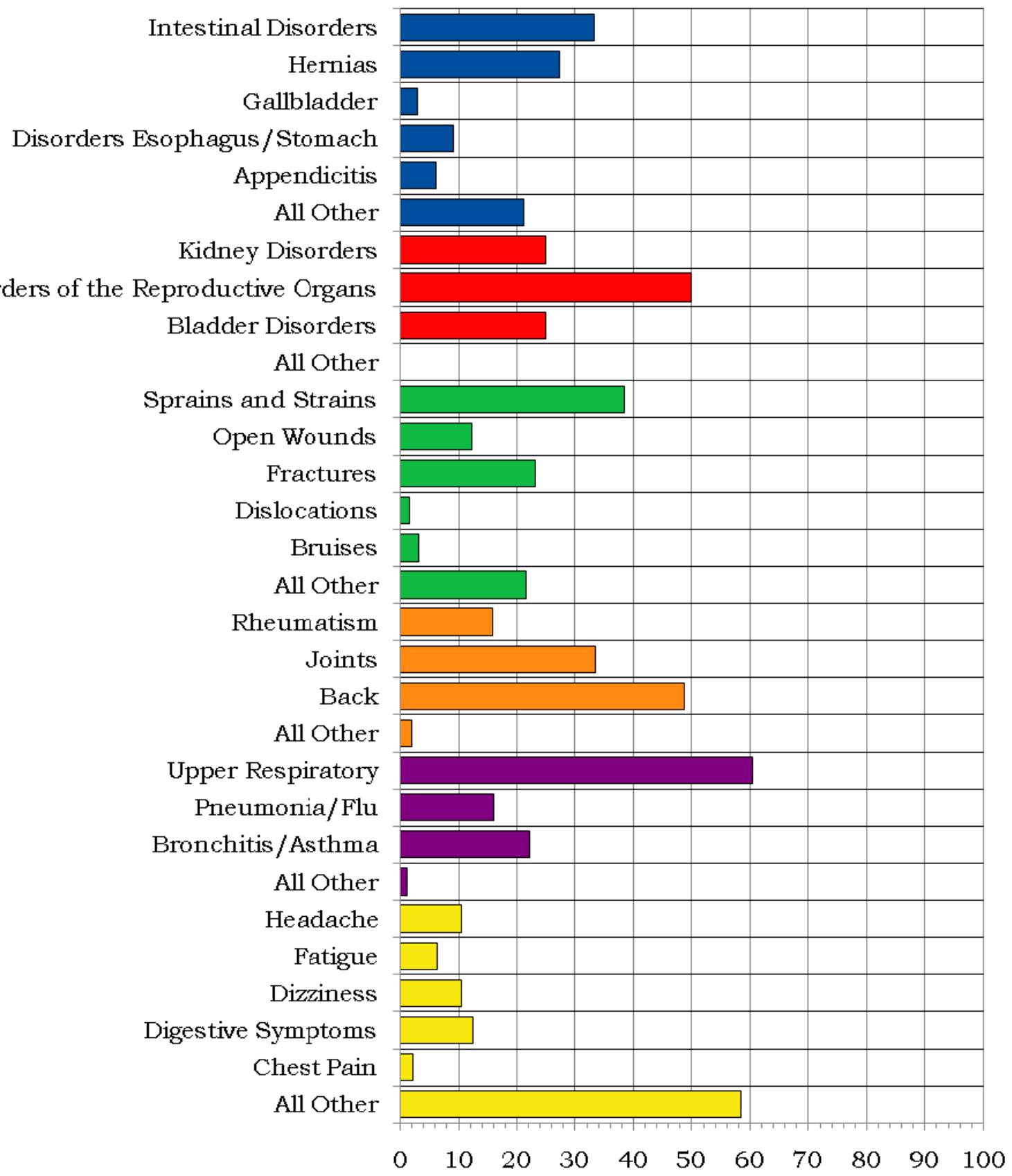

Percent Distribution of Diagnoses Within Diagnostic Category

Dige stive, 33 Diagnoses

Genitourinary, 8 Diagnoses

Injury, 65 Diagnoses
Musculoskeletal, 146 Diagnoses

Respiratory, 81 Diagnoses

Unspecified Symptoms, 48 Diagnoses 


\section{Figure 10. Number of Most Frequently Reported Diagnoses by Job Category and Gender}

\begin{tabular}{|c|c|c|c|c|}
\hline Job Category & Men & & Women & \\
\hline \multirow{4}{*}{ Professional } & Heart/Circulatory & 17 & M usculoskeletal & 16 \\
\hline & Injury & 15 & Nervous System & 9 \\
\hline & M usculoskeletal & 13 & Injury & 9 \\
\hline & Respiratory & 13 & & \\
\hline \multirow{3}{*}{ Administrative Support } & Respiratory & 4 & Respiratory & 22 \\
\hline & M usculoskeletal & 2 & Unspecified Symptoms & 21 \\
\hline & Unspecified Symptoms & 2 & M usculoskeletal & 18 \\
\hline \multirow{3}{*}{ Technical Support } & M usculoskeletal & 26 & Unspecified Symptoms & 7 \\
\hline & Respiratory & 17 & Respiratory & 4 \\
\hline & Injury & 10 & Nervous System & 3 \\
\hline \multirow{3}{*}{ Service } & Musculoskeletal & 50 & M usculoskeletal & 14 \\
\hline & Respiratory & 20 & Respiratory & 12 \\
\hline & Injury & 15 & Injury & 8 \\
\hline \multirow{6}{*}{ Security and Fire } & M usculoskeletal & 25 & Unspecified Symptoms & 3 \\
\hline & Respiratory & 5 & Nervous System & 2 \\
\hline & Unspecified Symptoms & 5 & M usculoskeletal & 1 \\
\hline & & & Genitourinary & 1 \\
\hline & & & Respiratory & 1 \\
\hline & & & Endocrine/M etabolic & 1 \\
\hline \multirow{3}{*}{ Crafts } & M usculoskeletal & 30 & & 0 \\
\hline & Respiratory & 22 & & \\
\hline & Injury & 20 & & \\
\hline Line Operators & & 0 & & 0 \\
\hline
\end{tabular}




\section{Rates of Disease Occurrence}

Figure 11. Rates for All Illnesses and Injuries Combined by Job Category, Gender, and Age

\begin{tabular}{|c|c|c|c|c|}
\hline \multirow{2}{*}{$\begin{array}{c}\text { All Illnesses \& } \\
\text { Injuries Combined }\end{array}$} & \multicolumn{4}{|c|}{ Rate per 1,000} \\
\hline & Job Category & Age & Men & Women \\
\hline & \multirow{2}{*}{ Professional } & $<50$ & 45 & 81 \\
\hline & & $50+$ & 125 & 327 \\
\hline & \multirow{2}{*}{ Administrative Support } & $<50$ & 294 & 293 \\
\hline & & $50+$ & 188 & 274 \\
\hline & \multirow{2}{*}{ Technical Support } & $<50$ & 226 & 704 \\
\hline & & $50+$ & 255 & 63 \\
\hline & \multirow{2}{*}{ Service } & $<50$ & 819 & 1,129 \\
\hline & & $50+$ & 791 & 1,056 \\
\hline & \multirow{2}{*}{ Security and Fire } & $<50$ & 657 & 1,800 \\
\hline & & $50+$ & 1,000 & 0 \\
\hline & \multirow{2}{*}{ Crafts } & $<50$ & 643 & 0 \\
\hline & & $50+$ & 1,069 & 0 \\
\hline & \multirow{2}{*}{ Line Operators } & $<50$ & 0 & 0 \\
\hline & & $50+$ & 0 & 0 \\
\hline
\end{tabular}

Figure 12. Rates for Selected Diagnostic Categories by Job Category, Gender, and Age

\begin{tabular}{|c|c|c|c|c|}
\hline \multirow{2}{*}{ Cancer } & \multicolumn{4}{|c|}{ Rate per 1,000} \\
\hline & Job Category & Age & Men & Women \\
\hline & \multirow{2}{*}{ Professional } & $<50$ & 4 & 0 \\
\hline & & $50+$ & 10 & 7 \\
\hline & \multirow{2}{*}{ Administrative Support } & $<50$ & 0 & 0 \\
\hline & & $50+$ & 31 & 12 \\
\hline & \multirow{2}{*}{ Technical Support } & $<50$ & 6 & 0 \\
\hline & & $50+$ & 0 & 0 \\
\hline & \multirow{2}{*}{ Service } & $<50$ & 21 & 32 \\
\hline & & $50+$ & 35 & 0 \\
\hline & \multirow{2}{*}{ Security and Fire } & $<50$ & 0 & 0 \\
\hline & & $50+$ & 0 & 0 \\
\hline & \multirow{2}{*}{ Crafts } & $<50$ & 0 & 0 \\
\hline & & $50+$ & 0 & 0 \\
\hline & \multirow{2}{*}{ Line Operators } & $<50$ & 0 & 0 \\
\hline & & $50+$ & 0 & 0 \\
\hline
\end{tabular}


Figure 12. Rates for Selected Diagnostic Categories by Job Category, Gender, and Age (Continued)

\begin{tabular}{|l|l|c|c|c|}
\hline \multirow{2}{*}{ Heart/Circulatory } & \multicolumn{4}{|c|}{ Rate per 1,000 } \\
\cline { 2 - 5 } & \multicolumn{1}{|c|}{ Job Category } & Age & M en & W omen \\
\cline { 2 - 5 } & \multirow{2}{*}{ Professional } & $<50$ & $\mathbf{0}$ & $\mathbf{0}$ \\
\cline { 2 - 5 } & $50+$ & $\mathbf{2 8}$ & $\mathbf{3 9}$ \\
\hline \multirow{2}{*}{ Administrative Support } & $<50$ & $\mathbf{0}$ & $\mathbf{7}$ \\
\cline { 2 - 5 } & $50+$ & $\mathbf{0}$ & $\mathbf{2 4}$ \\
\hline \multirow{2}{*}{ Technical Support } & $<50$ & $\mathbf{1 3}$ & $\mathbf{7 4}$ \\
\cline { 2 - 5 } & $50+$ & $\mathbf{3 0}$ & $\mathbf{0}$ \\
\hline \multirow{2}{*}{ Service } & $<50$ & $\mathbf{0}$ & $\mathbf{0}$ \\
\cline { 2 - 5 } & $50+$ & $\mathbf{9 3}$ & $\mathbf{5 6}$ \\
\cline { 2 - 5 } & \multirow{2}{*}{ Security and Fire } & $<50$ & $\mathbf{0}$ & $\mathbf{0}$ \\
\cline { 2 - 5 } & $50+$ & $\mathbf{1 2 5}$ & $\mathbf{0}$ \\
\cline { 2 - 5 } & \multirow{2}{*}{ Crafts } & $<50$ & $\mathbf{0}$ & $\mathbf{0}$ \\
\cline { 2 - 5 } & $50+$ & $\mathbf{5 2}$ & $\mathbf{0}$ \\
\cline { 2 - 5 } & \multirow{2}{*}{ Line Operators } & $<50$ & $\mathbf{0}$ & $\mathbf{0}$ \\
\cline { 2 - 5 } & $50+$ & $\mathbf{0}$ & $\mathbf{0}$ \\
\hline
\end{tabular}

\begin{tabular}{|c|c|c|c|c|}
\hline \multirow{2}{*}{ Respiratory } & \multicolumn{4}{|c|}{ Rate per 1,000} \\
\hline & Job Category & Age & Men & Women \\
\hline & \multirow{2}{*}{ Professional } & $<50$ & 8 & 0 \\
\hline & & $50+$ & 11 & 26 \\
\hline & \multirow{2}{*}{ Administrative Support } & $<50$ & 59 & 41 \\
\hline & & $50+$ & 94 & 98 \\
\hline & \multirow{2}{*}{ Technical Support } & $<50$ & 58 & 148 \\
\hline & & $50+$ & 40 & 0 \\
\hline & \multirow{2}{*}{ Service } & $<50$ & 128 & 161 \\
\hline & & $50+$ & 93 & 389 \\
\hline & \multirow{2}{*}{ Security and Fire } & $<50$ & 86 & 200 \\
\hline & & $50+$ & 83 & 0 \\
\hline & \multirow{2}{*}{ Crafts } & $<50$ & 114 & 0 \\
\hline & & $50+$ & 241 & 0 \\
\hline & \multirow{2}{*}{ Line Operators } & $<50$ & 0 & 0 \\
\hline & & $50+$ & 0 & 0 \\
\hline
\end{tabular}


Figure 12. Rates for Selected Diagnostic Categories by Job Category, Gender, and Age (Continued)

\begin{tabular}{|c|c|c|c|c|}
\hline \multirow{2}{*}{ Injury } & \multicolumn{4}{|c|}{ Rate per 1,000} \\
\hline & Job Category & Age & Men & Women \\
\hline & \multirow{2}{*}{ Professional } & $<50$ & 7 & 21 \\
\hline & & $50+$ & 16 & 26 \\
\hline & \multirow{2}{*}{ Administrative Support } & $<50$ & 0 & 34 \\
\hline & & $50+$ & 31 & 6 \\
\hline & \multirow{2}{*}{ Technical Support } & $<50$ & 45 & 37 \\
\hline & & $50+$ & 15 & 0 \\
\hline & \multirow{2}{*}{ Service } & $<50$ & 96 & 129 \\
\hline & & $50+$ & 70 & 222 \\
\hline & \multirow{2}{*}{ Security and Fire } & $<50$ & 86 & 0 \\
\hline & & $50+$ & 42 & 0 \\
\hline & \multirow{2}{*}{ Crafts } & $<50$ & 129 & 0 \\
\hline & & $50+$ & 190 & 0 \\
\hline & \multirow{2}{*}{ Line Operators } & $<50$ & 0 & 0 \\
\hline & & $50+$ & 0 & 0 \\
\hline
\end{tabular}

\section{Time Trends}

Figure 13. Age-Adjusted Rates for All Diagnoses Combined Among Women and Men from 2003 to 2008*

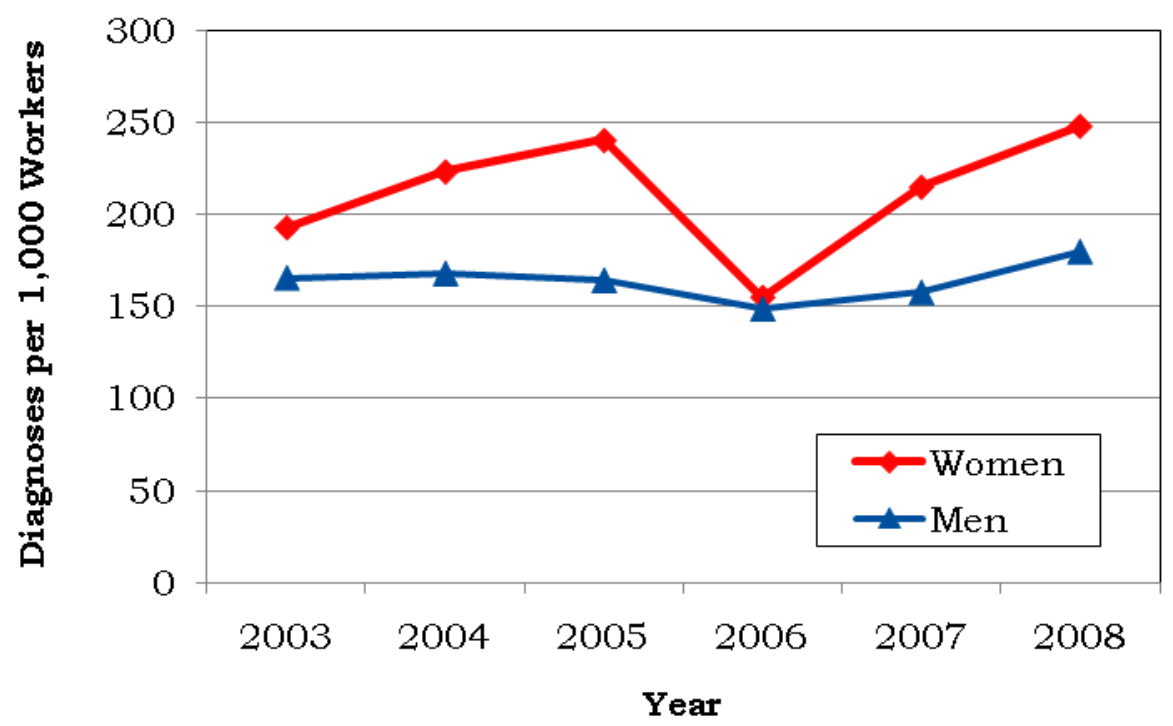

*Standardized to age distribution of 2000 U.S. population. 
Figure 14. Age-Adjusted Rates for Selected Diagnostic Categories Among Women and Men from 2003 to 2008*

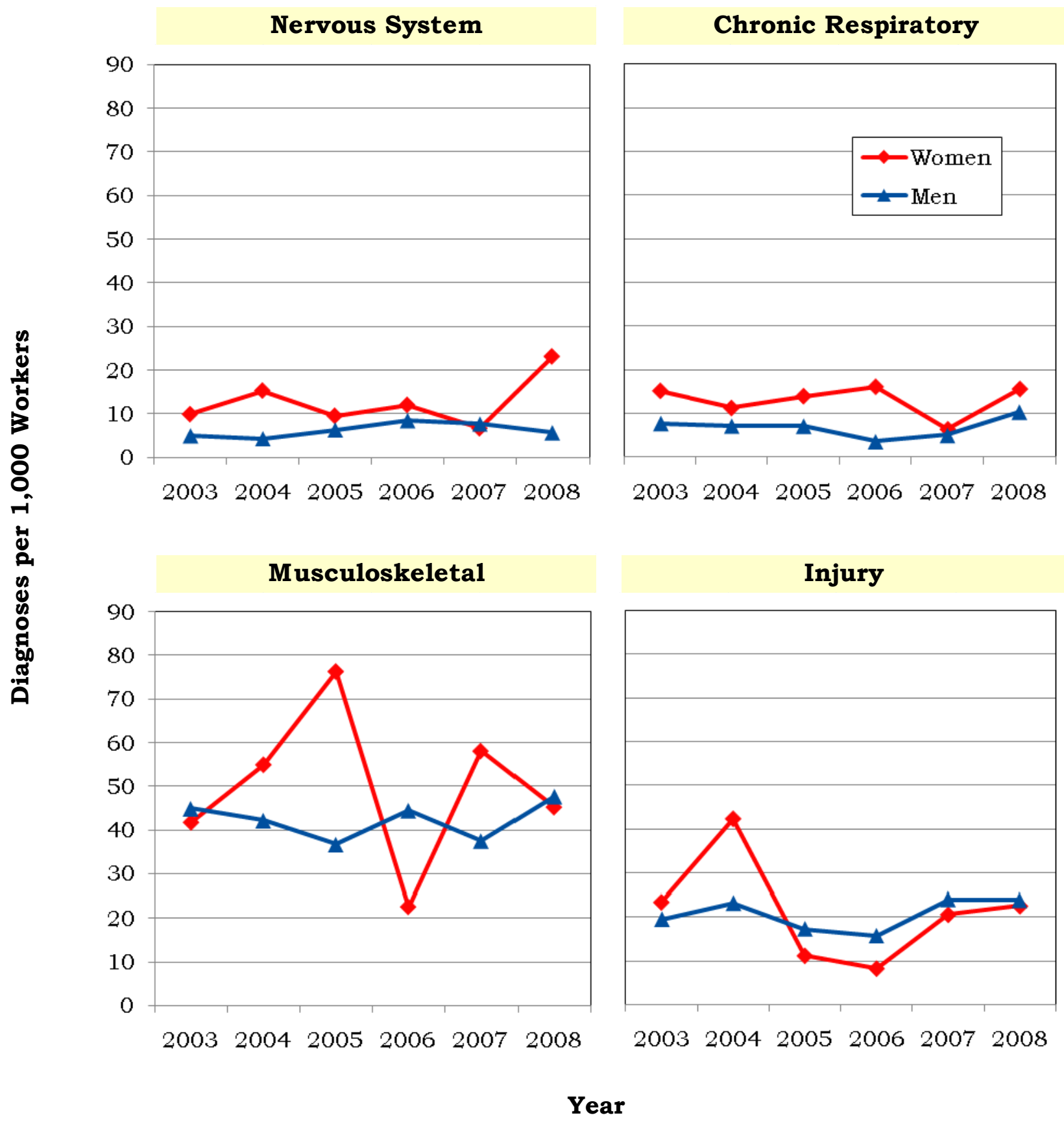

*Standardized to age distribution of 2000 U.S. population. 
Figure 15. Age-Adjusted Rates for All Diagnoses Combined Among Women and Men by Job Category from 2003 to 2008*

Professional

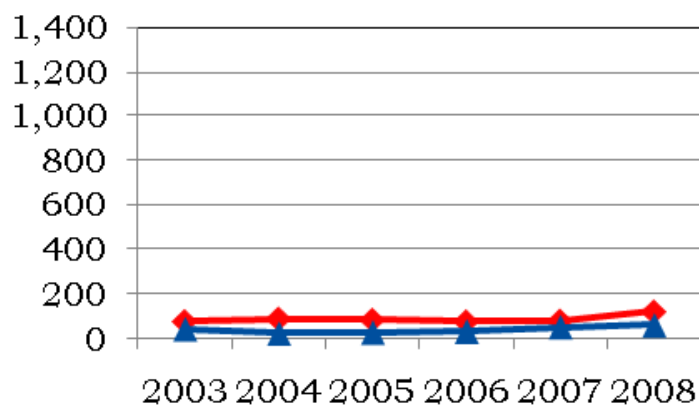

Administrative Support

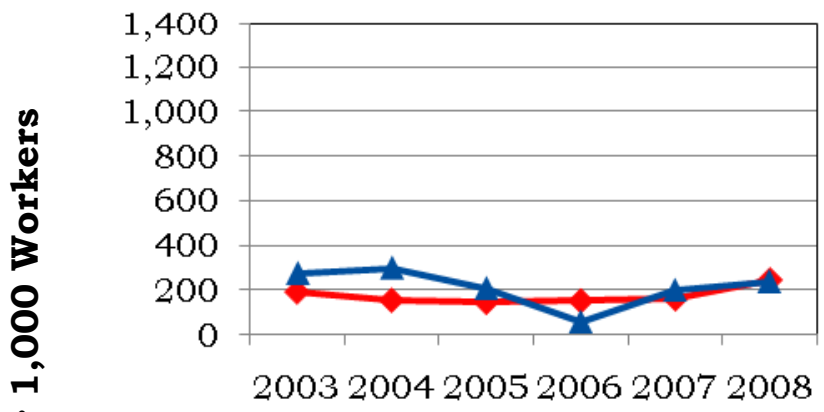

Service

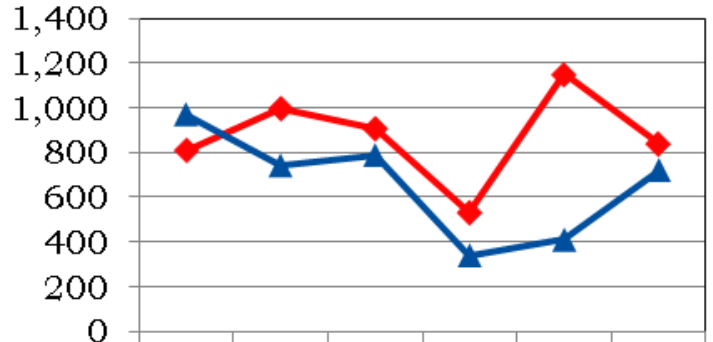

200320042005200620072008

Crafts
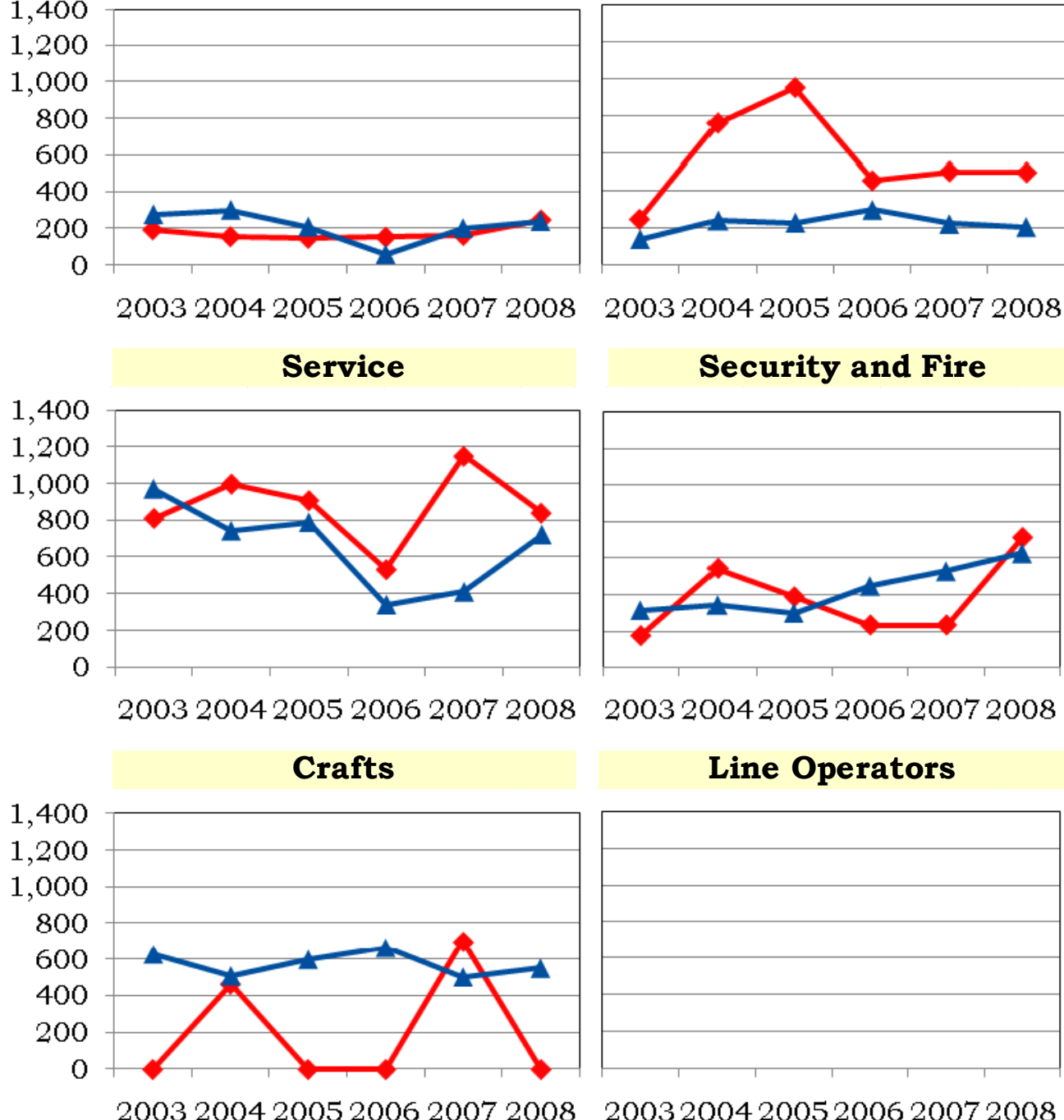

200320042005200620072008

Security and Fire

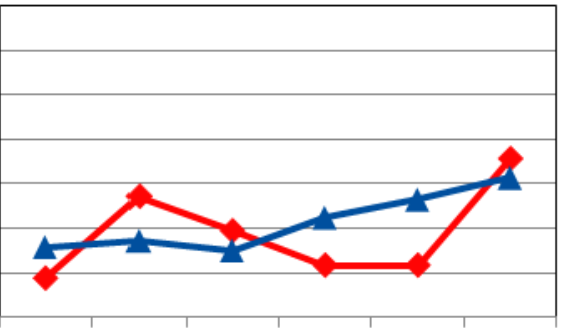

200320042005200620072008

Line Operators

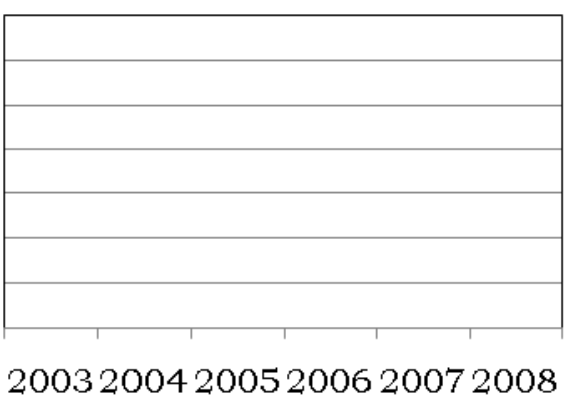

Year

*Standardized to age distribution of 2000 U.S. population. 


\section{Sentinel Health Events for Occupations (SHEOs)}

An occupational sentinel health event (SHEO) is a disease, disability, or death that is likely to be occupationally related. Although sentinel health events may indicate an occupational exposure, many may result from nonoccupational exposures. Sentinel health events are therefore assessed in two categories:

Definite Sentinel Health Events: Diseases that are unlikely to occur in the absence of an occupational exposure (e.g., asbestosis).

Possible Sentinel Health Events: Diseases that may be occupational but can also occur in the absence of an occupational exposure (e.g., lung cancer or carpal tunnel syndrome).

Figure 16. Characteristics of SHEOs by Gender

\begin{tabular}{|l|c|c|c|c|}
\hline \multirow{2}{*}{} & \multicolumn{2}{|c|}{$\begin{array}{c}\text { Total Number of } \\
\text { SHEO Diagnoses }\end{array}$} & \multicolumn{2}{c|}{$\begin{array}{c}\text { Total Number of } \\
\text { Days Absent }\end{array}$} \\
\cline { 2 - 5 } & Men & Women & Men & W omen \\
\hline Definite & 31 & 13 & 658 & 91 \\
\hline Possible & 6 & 4 & 98 & 71 \\
\hline Total & 37 & 17 & 756 & 162 \\
\hline
\end{tabular}

Figure 17. SHEO Diagnoses by Gender

\begin{tabular}{|l|c|c|}
\hline \multirow{2}{*}{ Diagnoses } & \multicolumn{2}{c|}{ Gender } \\
\cline { 2 - 3 } & Women & Men \\
\hline Carpal Tunnel Syndrome & 5 & 1 \\
\hline M usculoskeletal Conditions & 5 & 20 \\
\hline Injuries & 6 & 10 \\
\hline Other Conditions & 1 & 6 \\
\hline
\end{tabular}


Occupational Safety and Health Administration (OSHA)-Recordable Events

Figure 18. OSHA-Recordable Events by Gender and Age

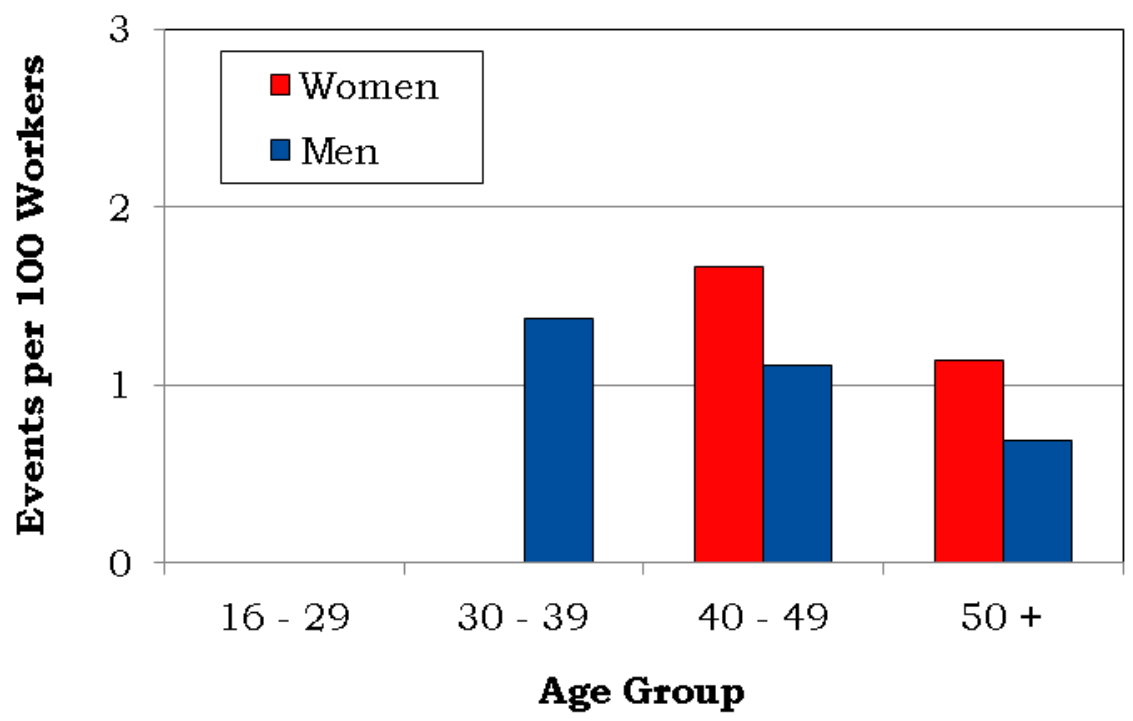

Figure 19. OSHA-Recordable Events by Job Category and Gender

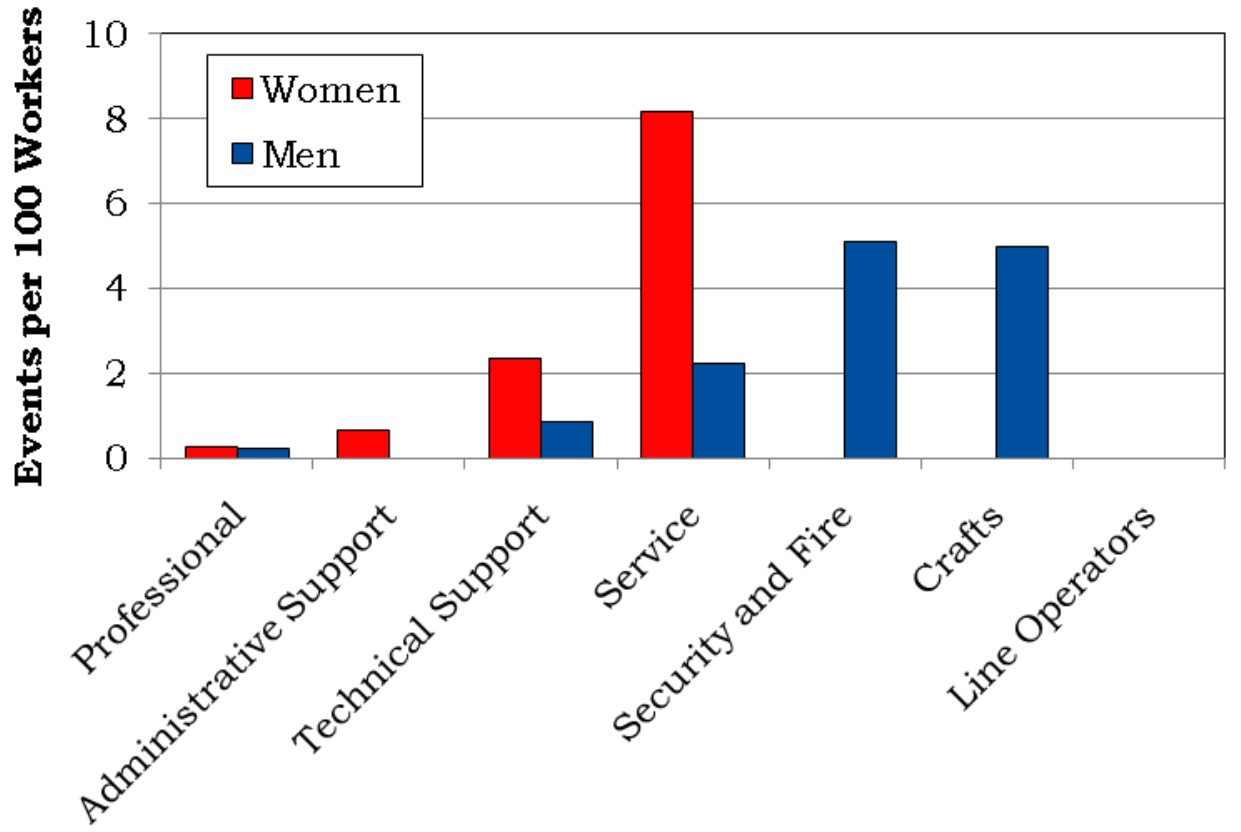

Job Category 


\section{Diagnostic and Accident Categories for OSHA-Recordable Events}

Figure 20. OSHA-Recordable Diagnoses by Diagnostic Category and Gender

\begin{tabular}{|l|c|c|}
\hline \multirow{2}{*}{ Diagnostic Category } & \multicolumn{2}{c|}{ Gender } \\
\cline { 2 - 3 } & Women & M en \\
\hline Musculoskeletal & $\mathbf{4}$ & $\mathbf{4}$ \\
\hline Nervous System & $\mathbf{1}$ & $\mathbf{0}$ \\
\hline Unspecified Symptoms & $\mathbf{7}$ & $\mathbf{0}$ \\
\hline Injury & $\mathbf{7}$ & $\mathbf{1 7}$ \\
\hline Fractures - Lower Limb & $\mathbf{1}$ & $\mathbf{0}$ \\
\hline Open Wounds - Upper Limb & $\mathbf{0}$ & $\mathbf{2}$ \\
\hline Crushing Injuries & $\mathbf{0}$ & $\mathbf{1}$ \\
\hline Unspecified Injuries & $\mathbf{6}$ & $\mathbf{1 4}$ \\
\hline
\end{tabular}

Figure 21. OSHA-Recordable Accidents by Type and Gender

\begin{tabular}{|l|c|c|}
\hline \multirow{2}{*}{ Accident Category } & \multicolumn{2}{|c|}{ Gender } \\
\cline { 2 - 3 } & Women & Men \\
\cline { 2 - 3 } & $\begin{array}{c}\text { Number of } \\
\text { Accidents }\end{array}$ & $\begin{array}{c}\text { Number of } \\
\text { Accidents }\end{array}$ \\
\hline Falls & $\mathbf{2}$ & $\mathbf{5}$ \\
\hline Other Accidents & $\mathbf{5}$ & $\mathbf{1 2}$ \\
\hline Struck by an Object & $\mathbf{2}$ & $\mathbf{2}$ \\
\hline Caught Between Objects & $\mathbf{0}$ & $\mathbf{1}$ \\
\hline Cutting/Piercing Instrument/Object & $\mathbf{0}$ & $\mathbf{1}$ \\
\hline Overexertion/Strenuous Movements & $\mathbf{3}$ & $\mathbf{7}$ \\
\hline Repetitive Trauma & $\mathbf{0}$ & $\mathbf{1}$ \\
\hline Total & $\mathbf{7}$ & $\mathbf{1 7}$ \\
\hline
\end{tabular}




\section{Rates of OSHA-Recordable Events}

Figure 22. OSHA-Recordable Rates by Age and Job Categories Among Women, All Diagnoses Combined

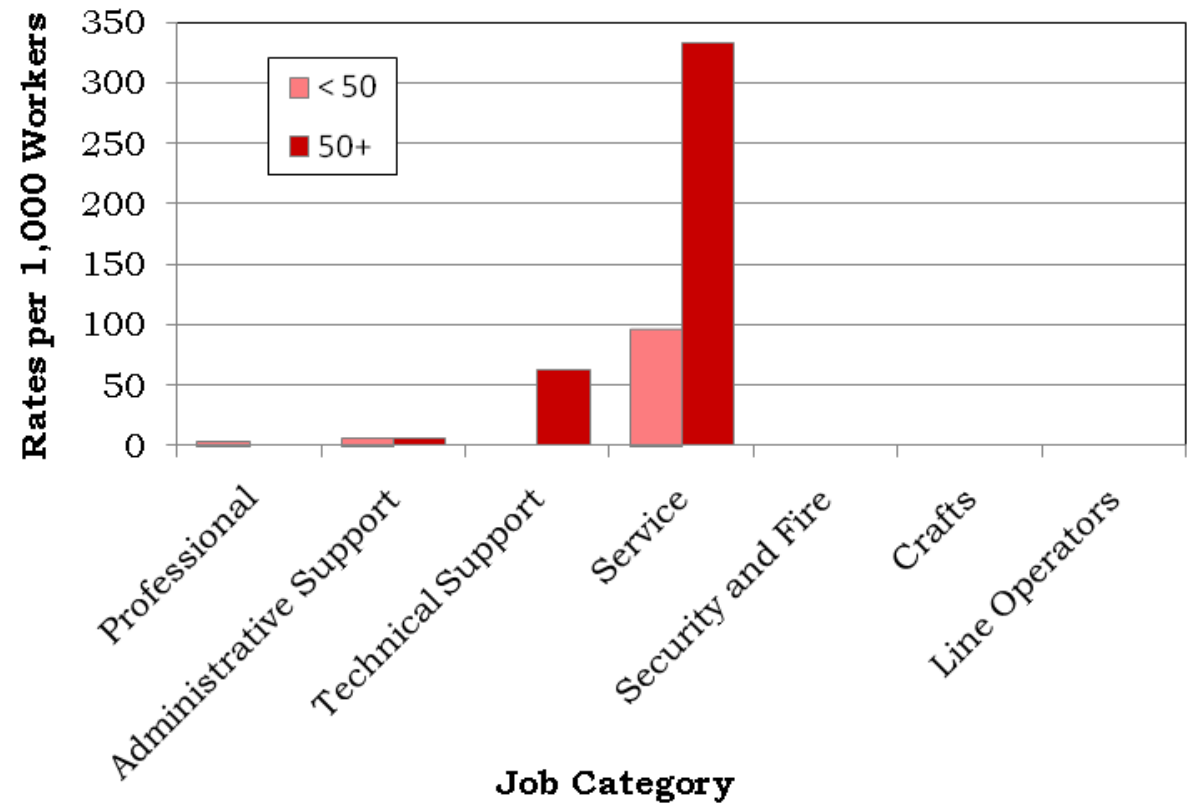

Figure 23. OSHA-Recordable Rates by Age and Job Categories Among Men, All Diagnoses Combined

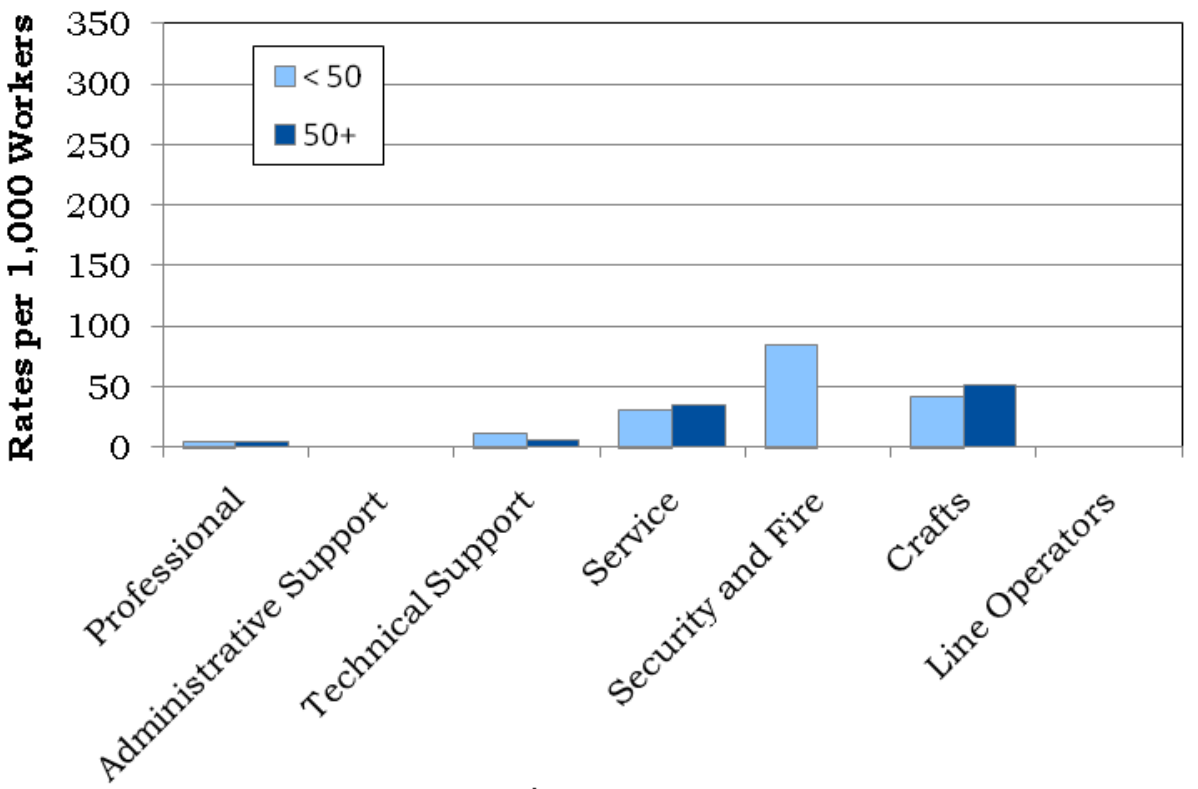

Job Category 


\section{Time Trends for OSHA-Recordable Events}

Figure 24. Age-Adjusted Rates for All OSHA-Recordable Diagnoses Combined Among Women and Men by Job Category from 2003 to 2008*

Professional

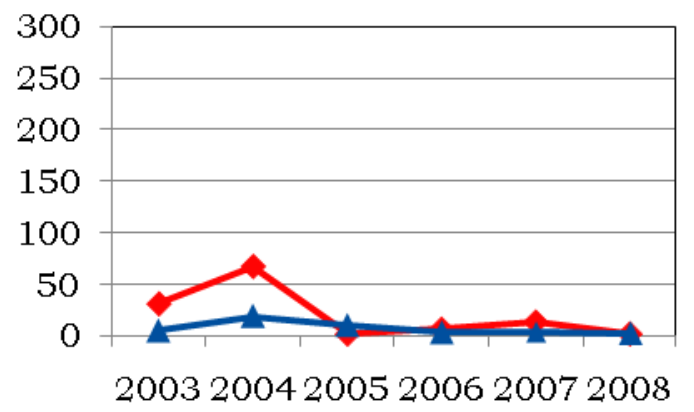

Administrative Support

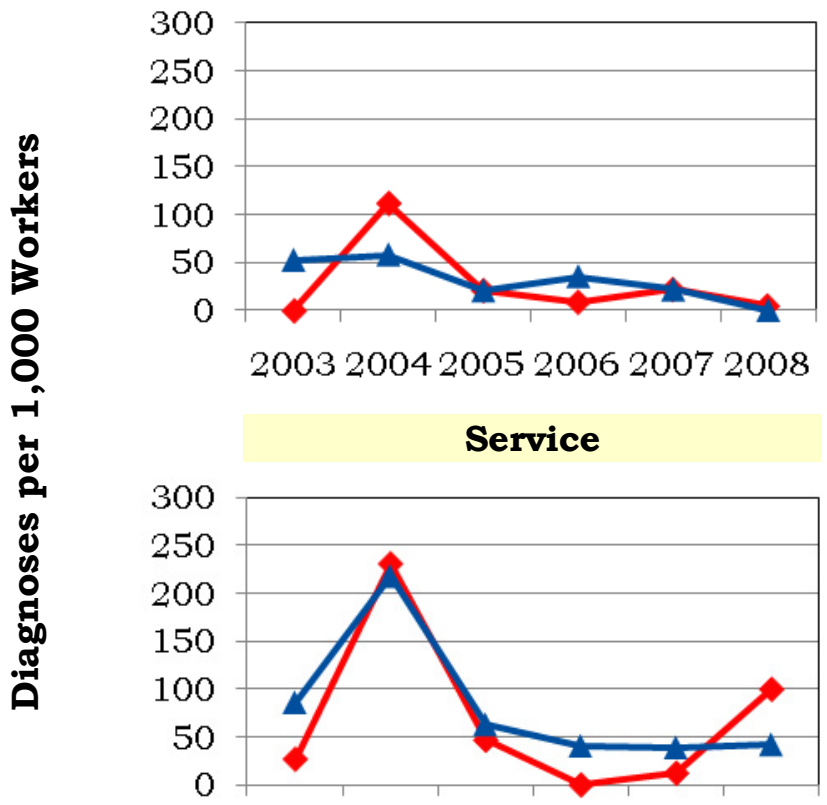

200320042005200620072008

Crafts

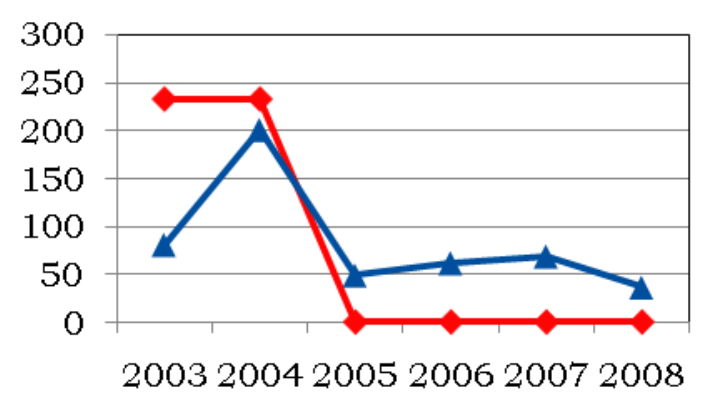

Technical Support

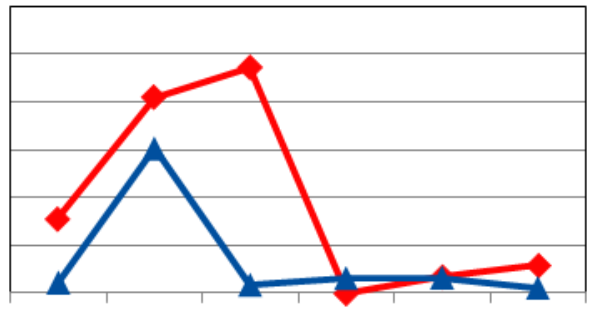

200320042005200620072008

Security and Fire

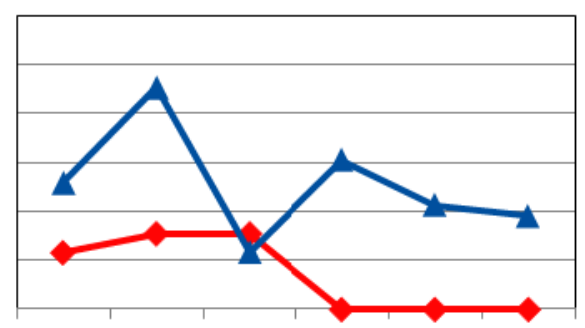

200320042005200620072008

Line Operators

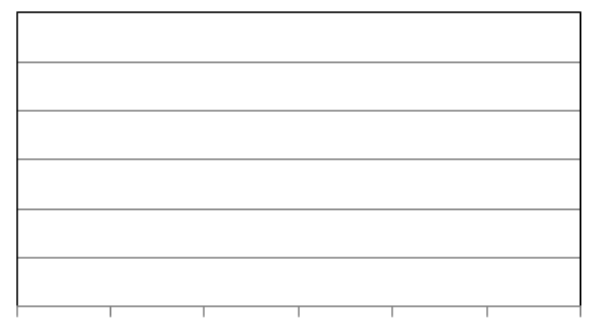

200320042005200620072008

Year

*Standardized to age distribution of 2000 U.S. population. 
Appendices 
Brookhaven National Laboratory 2008

Absence Data

Appendix A. Work Force by Gender, Age, and Job Category

\begin{tabular}{|c|c|c|c|c|c|c|c|c|c|c|c|}
\hline \multirow{3}{*}{ Job Category } & \multicolumn{5}{|c|}{ Women } & \multicolumn{5}{|c|}{ Men } & \multirow[b]{3}{*}{ TOTAL } \\
\hline & \multicolumn{4}{|c|}{ Age Group } & \multirow[b]{2}{*}{ TOTAL } & \multicolumn{4}{|c|}{ Age Group } & \multirow[b]{2}{*}{ TOTAL } & \\
\hline & $16-29$ & $30-39$ & $40-49$ & $50+$ & & $16-29$ & 30 - 39 & $40-49$ & $50+$ & & \\
\hline Professional & 37 & 83 & 114 & 153 & 387 & 88 & 301 & 346 & 615 & 1,350 & 1,737 \\
\hline Administrative Support & 18 & 39 & 90 & 164 & 311 & 5 & 4 & 8 & 32 & 49 & 360 \\
\hline Technical Support & 6 & 6 & 15 & 16 & 43 & 12 & 22 & 121 & 200 & 355 & 398 \\
\hline Service & 1 & 12 & 18 & 18 & 49 & 5 & 21 & 68 & 86 & 180 & 229 \\
\hline Security and Fire & 1 & 0 & 4 & 0 & 5 & 2 & 3 & 30 & 24 & 59 & 64 \\
\hline Crafts & 0 & 0 & 0 & 0 & 0 & 1 & 14 & 55 & 58 & 128 & 128 \\
\hline TOTAL & 63 & 140 & 241 & 351 & 795 & 113 & 365 & 628 & 1,015 & 2,121 & 2,916 \\
\hline
\end{tabular}

Appendix B. Age Distribution of the Work Force by Gender

\begin{tabular}{|l|r|r|r|r|r|r|r|r|}
\hline \multirow{3}{*}{ Year } & \multicolumn{9}{|c|}{ Women } & \multicolumn{4}{c|}{ Men } \\
\cline { 2 - 9 } & \multicolumn{1}{|c|}{ Percent Distribution by Age Group } & \multicolumn{1}{c|}{ Percent Distribution by Age Group } \\
\cline { 2 - 9 } & $\mathbf{1 6}-\mathbf{2 9}$ & $\mathbf{3 0}-\mathbf{3 9}$ & $\mathbf{4 0}-\mathbf{4 9}$ & $\mathbf{5 0}+$ & $\mathbf{1 6}-\mathbf{2 9}$ & $\mathbf{3 0}-\mathbf{3 9}$ & $\mathbf{4 0}-\mathbf{4 9}$ & $\mathbf{5 0}+$ \\
\hline $\mathbf{1 9 9 4}$ & 19.78 & 30.12 & 28.60 & 21.50 & 9.31 & 29.13 & 26.54 & 35.02 \\
\hline $\mathbf{1 9 9 5}$ & 16.30 & 31.02 & 29.13 & 23.55 & 7.77 & 28.63 & 28.31 & 35.29 \\
\hline $\mathbf{1 9 9 6}$ & 14.94 & 31.24 & 29.55 & 24.27 & 7.53 & 27.59 & 30.29 & 34.59 \\
\hline $\mathbf{1 9 9 7}$ & 13.73 & 28.49 & 31.56 & 26.22 & 6.34 & 27.74 & 29.60 & 36.32 \\
\hline $\mathbf{1 9 9 8}$ & 12.57 & 25.62 & 33.25 & 28.55 & 6.55 & 25.61 & 31.19 & 36.65 \\
\hline $\mathbf{1 9 9 9}$ & 10.41 & 24.16 & 33.97 & 31.46 & 5.46 & 23.81 & 32.72 & 38.02 \\
\hline $\mathbf{2 0 0 0}$ & 9.70 & 23.95 & 34.49 & 31.86 & 5.70 & 23.03 & 34.39 & 36.87 \\
\hline $\mathbf{2 0 0 1}$ & 9.61 & 22.63 & 36.01 & 31.75 & 5.93 & 20.97 & 35.70 & 37.40 \\
\hline $\mathbf{2 0 0 2}$ & 8.86 & 22.39 & 36.04 & 32.72 & 5.51 & 20.04 & 36.49 & 37.96 \\
\hline $\mathbf{2 0 0 3}$ & 9.14 & 20.90 & 36.42 & 33.54 & 4.97 & 18.22 & 37.06 & 39.74 \\
\hline $\mathbf{2 0 0 4}$ & 9.64 & 20.05 & 35.55 & 34.77 & 4.96 & 17.70 & 37.07 & 40.27 \\
\hline $\mathbf{2 0 0 5}$ & 7.82 & 18.33 & 34.77 & 39.08 & 5.01 & 16.64 & 34.53 & 43.82 \\
\hline $\mathbf{2 0 0 6}$ & 9.08 & 15.75 & 34.18 & 40.99 & 5.14 & 16.79 & 32.15 & 45.93 \\
\hline $\mathbf{2 0 0 7}$ & 8.38 & 17.53 & 31.19 & 42.91 & 5.23 & 16.96 & 31.49 & 46.32 \\
\hline $\mathbf{2 0 0 8}$ & 7.92 & 17.61 & 30.31 & 44.15 & 5.33 & 17.21 & 29.61 & 47.85 \\
\hline
\end{tabular}


Brookhaven National Laboratory 2008

Absence Data

Appendix C. Total Number of Workers Who Reported at Least One Absence by Gender, Age, and Job Category*

\begin{tabular}{|c|c|c|c|c|c|c|c|c|c|c|c|}
\hline \multirow{3}{*}{ Job Category } & \multicolumn{5}{|c|}{ Women } & \multicolumn{5}{|c|}{ Men } & \multirow[b]{3}{*}{ TOTAL } \\
\hline & \multicolumn{4}{|c|}{ Age Group } & \multirow[b]{2}{*}{ TOTAL } & \multicolumn{4}{|c|}{ Age Group } & \multirow[b]{2}{*}{ TOTAL } & \\
\hline & $16-29$ & 30 - 39 & $40-49$ & $50+$ & & $16-29$ & 30 - 39 & $40-49$ & $50+$ & & \\
\hline Professional & 0 & 2 & 9 & 22 & 33 & 1 & 4 & 15 & 35 & 55 & 88 \\
\hline Administrative Support & 3 & 3 & 14 & 20 & 40 & 1 & 0 & 2 & 4 & 7 & 47 \\
\hline Technical Support & 2 & 1 & 5 & 1 & 9 & 0 & 3 & 14 & 31 & 48 & 57 \\
\hline Service & 0 & 4 & 9 & 11 & 24 & 3 & 6 & 21 & 30 & 60 & 84 \\
\hline Security and Fire & 1 & 0 & 3 & 0 & 4 & 0 & 1 & 7 & 10 & 18 & 22 \\
\hline Crafts & 0 & 0 & 0 & 0 & 0 & 0 & 4 & 23 & 25 & 52 & 52 \\
\hline TOTAL & 6 & 10 & 40 & 54 & 110 & 5 & 18 & 82 & 135 & 240 & 350 \\
\hline
\end{tabular}

*Only those job categories and gender/age combinations with at least one absence appear in this table.

Appendix D. Total Number of Absences by Gender, Age, and Job Category*

\begin{tabular}{|c|c|c|c|c|c|c|c|c|c|c|c|}
\hline \multirow{3}{*}{ Job Category } & \multicolumn{5}{|c|}{ Women } & \multicolumn{5}{|c|}{ Men } & \multirow[b]{3}{*}{ TOTAL } \\
\hline & \multicolumn{4}{|c|}{ Age Group } & \multirow[b]{2}{*}{ TOTAL } & \multicolumn{4}{|c|}{ Age Group } & \multirow[b]{2}{*}{ TOTAL } & \\
\hline & $16-29$ & 30 - 39 & $40-49$ & $50+$ & & $16-29$ & 30 - 39 & $40-49$ & $50+$ & & \\
\hline Professional & 0 & 2 & 10 & 29 & 41 & 1 & 4 & 19 & 39 & 63 & 104 \\
\hline Administrative Support & 3 & 3 & 18 & 28 & 52 & 1 & 0 & 3 & 5 & 9 & 61 \\
\hline Technical Support & 2 & 2 & 7 & 1 & 12 & 0 & 4 & 17 & 34 & 55 & 67 \\
\hline Service & 0 & 7 & 14 & 17 & 38 & 3 & 9 & 36 & 40 & 88 & 126 \\
\hline Security and Fire & 1 & 0 & 5 & 0 & 6 & 0 & 1 & 12 & 16 & 29 & 35 \\
\hline Crafts & 0 & 0 & 0 & 0 & 0 & 0 & 5 & 31 & 40 & 76 & 76 \\
\hline TOTAL & 6 & 14 & 54 & 75 & 149 & 5 & 23 & 118 & 174 & 320 & 469 \\
\hline
\end{tabular}

*Only those job categories and gender/age combinations with at least one absence appear in this table. 
Brookhaven National Laboratory 2008

Absence Data

Appendix E. Distribution of the Number of Calendar Days Missed per Absence by Gender and Age*

\begin{tabular}{|c|c|c|c|c|c|c|c|c|c|c|c|}
\hline \multirow{3}{*}{$\begin{array}{c}\text { Number of } \\
\text { Calendar Days }\end{array}$} & \multicolumn{5}{|c|}{ Women } & \multicolumn{5}{|c|}{ Men } & \multirow[b]{3}{*}{ TOTAL } \\
\hline & \multicolumn{4}{|c|}{ Age Group } & \multirow[b]{2}{*}{ TOTAL } & \multicolumn{4}{|c|}{ Age Group } & \multirow[b]{2}{*}{ TOTAL } & \\
\hline & $16-29$ & $30-39$ & $40-49$ & $50+$ & & $16-29$ & $30-39$ & $40-49$ & $50+$ & & \\
\hline$<15$ & 6 & 10 & 37 & 53 & 106 & 4 & 20 & 86 & 112 & 222 & 328 \\
\hline $15-28$ & 0 & 2 & 10 & 16 & 28 & 0 & 1 & 16 & 32 & 49 & 77 \\
\hline $29-42$ & 0 & 1 & 1 & 4 & 6 & 0 & 1 & 4 & 7 & 12 & 18 \\
\hline $43-56$ & 0 & 0 & 2 & 0 & 2 & 1 & 0 & 3 & 7 & 11 & 13 \\
\hline $57-91$ & 0 & 0 & 2 & 0 & 2 & 0 & 1 & 4 & 8 & 13 & 15 \\
\hline $92-182$ & 0 & 1 & 1 & 2 & 4 & 0 & 0 & 4 & 6 & 10 & 14 \\
\hline $183+$ & 0 & 0 & 1 & 0 & 1 & 0 & 0 & 1 & 2 & 3 & 4 \\
\hline TOTAL & 6 & 14 & 54 & 75 & 149 & 5 & 23 & 118 & 174 & 320 & 469 \\
\hline
\end{tabular}

*Only those gender/age combinations with at least one absence appear in this table. 
Brookhaven National Laboratory 2008

Absence Data

Appendix F. Distribution of the Number of Calendar Days Missed per Absence by Gender and Job Category*

Women

\begin{tabular}{|c|c|c|c|c|c|c|c|}
\hline \multirow{2}{*}{$\begin{array}{c}\text { Number of } \\
\text { Calendar Days }\end{array}$} & \multicolumn{6}{|c|}{ Job Category } & \multirow[b]{2}{*}{ TOTAL } \\
\hline & Professional & $\begin{array}{l}\text { Administrative } \\
\text { Support }\end{array}$ & Technical Support & Service & Security and Fire & Crafts & \\
\hline$<15$ & 25 & 41 & 8 & 27 & 5 & 0 & 106 \\
\hline $15-28$ & 11 & 9 & 3 & 5 & 0 & 0 & 28 \\
\hline $29-42$ & 2 & 1 & 0 & 3 & 0 & 0 & 6 \\
\hline $43-56$ & 1 & 0 & 0 & 1 & 0 & 0 & 2 \\
\hline $57-91$ & 0 & 0 & 1 & 1 & 0 & 0 & 2 \\
\hline $92-182$ & 2 & 1 & 0 & 1 & 0 & 0 & 4 \\
\hline $183+$ & 0 & 0 & 0 & 0 & 1 & 0 & 1 \\
\hline TOTAL & 41 & 52 & 12 & 38 & 6 & 0 & 149 \\
\hline
\end{tabular}

Men

\begin{tabular}{|c|c|c|c|c|c|c|c|}
\hline \multirow{2}{*}{$\begin{array}{c}\text { Number of } \\
\text { Calendar Days }\end{array}$} & \multicolumn{6}{|c|}{ Job Category } & \multirow[b]{2}{*}{ TOTAL } \\
\hline & Professional & $\begin{array}{c}\text { Administrative } \\
\text { Support }\end{array}$ & Technical Support & Service & Security and Fire & Crafts & \\
\hline$<15$ & 39 & 8 & 36 & 63 & 20 & 56 & 222 \\
\hline $15-28$ & 10 & 0 & 11 & 16 & 3 & 9 & 49 \\
\hline $29-42$ & 3 & 0 & 0 & 4 & 2 & 3 & 12 \\
\hline $43-56$ & 2 & 0 & 3 & 1 & 0 & 5 & 11 \\
\hline $57-91$ & 4 & 0 & 2 & 3 & 1 & 3 & 13 \\
\hline $92-182$ & 4 & 1 & 3 & 0 & 2 & 0 & 10 \\
\hline $183+$ & 1 & 0 & 0 & 1 & 1 & 0 & 3 \\
\hline TOTAL & 63 & 9 & 55 & 88 & 29 & 76 & 320 \\
\hline
\end{tabular}

*Only those gender/job category combinations with at least one absence appear in this table. 


\section{Brookhaven National Laboratory 2008}

Absence Data

Appendix G. Number of Diagnoses in Each Diagnostic Category by Gender and Age*

\begin{tabular}{|c|c|c|c|c|c|c|}
\hline & & \multicolumn{5}{|c|}{ Women } \\
\hline & & \multicolumn{4}{|c|}{ Age Group } & \multirow[b]{2}{*}{ TOTAL } \\
\hline & & $16-29$ & $30-39$ & $40-49$ & $50+$ & \\
\hline Diagnostic Category & ICD-9-CM Code & & & & & \\
\hline INFECTIOUS \& PARASITIC DISEASES (DIS) & 001-139 & 1 & 0 & 2 & 5 & 8 \\
\hline -Intestinal Infectious Dis & 001-009 & 0 & 0 & 0 & 0 & 0 \\
\hline -Other Bacterial Dis & 030-041 & 1 & 0 & 0 & 0 & 1 \\
\hline -Viral Dis with Exanthem & $050-057$ & 0 & 0 & 1 & 3 & 4 \\
\hline -Other Viral Dis \& Chlamydiae & 070-079 & 0 & 0 & 1 & 0 & 1 \\
\hline MALIGNANT NEOPLASMS & $140-208,230-234$ & 0 & 0 & 1 & 3 & 4 \\
\hline -Lip, Oral Cavity, Pharynx & $140-149$ & 0 & 0 & 0 & 0 & 0 \\
\hline -Digestive \& Peritoneal & 150-159 & 0 & 0 & 0 & 0 & 0 \\
\hline -Respiratory \& Intrathoracic & $160-165$ & 0 & 0 & 0 & 0 & 0 \\
\hline -Bone, Connective Tissue, Skin & $170-173,176$ & 0 & 0 & 0 & 0 & 0 \\
\hline -Breast & 174-175 & 0 & 0 & 0 & 2 & 2 \\
\hline -Genitourinary & 179-189 & 0 & 0 & 1 & 0 & 1 \\
\hline -Other \& Unspecified Sites & $190,193-199$ & 0 & 0 & 0 & 0 & 0 \\
\hline -Carcinoma in situ & $230-234$ & 0 & 0 & 0 & 1 & 1 \\
\hline BENIGN \& UNCERTAIN NEOPLASMS & 210-229, 235-239 & 0 & 1 & 1 & 1 & 3 \\
\hline ENDOCRINE/METABOLIC/IMMUNITY & $240-279$ & 0 & 0 & 1 & 2 & 3 \\
\hline -Thyroid Gland Disorders & $240-246$ & 0 & 0 & 0 & 0 & 0 \\
\hline -Other Endocrine Gland Dis & $250-259$ & 0 & 0 & 0 & 2 & 2 \\
\hline -Other Metabolic \& Immunity Disorders & $270-279$ & 0 & 0 & 1 & 0 & 1 \\
\hline BLOOD \& BLOOD-FORMING ORGANS & $280-289$ & 0 & 0 & 0 & 0 & 0 \\
\hline MENTAL DISORDERS & 290-319 & 0 & 0 & 1 & 1 & 2 \\
\hline -Psychoses & 290-299 & 0 & 0 & 0 & 0 & 0 \\
\hline -Non-Psychotic Disorders & $300-302,306-316$ & 0 & 0 & 1 & 1 & 2 \\
\hline NERVOUS SYSTEM (NS) \& SENSE ORGANS & $320-389$ & 1 & 3 & 8 & 8 & 20 \\
\hline -Other Disorders of Central NS & $340-349$ & 0 & 0 & 2 & 1 & 3 \\
\hline -Disorders of Peripheral NS & $350-359$ & 0 & 0 & 4 & 4 & 8 \\
\hline -Disorders of Eye & $360-379$ & 0 & 0 & 2 & 1 & 3 \\
\hline -Dis of Ear \& Mastoid & $380-389$ & 1 & 3 & 0 & 2 & 6 \\
\hline CIRCULATORY SYSTEM & $390-459$ & 0 & 0 & 3 & 11 & 14 \\
\hline -Hypertensive Dis & $401-405$ & 0 & 0 & 1 & 4 & 5 \\
\hline -Ischemic Heart Dis & $410-414$ & 0 & 0 & 0 & 2 & 2 \\
\hline -Other Heart Dis & $420-429$ & 0 & 0 & 0 & 3 & 3 \\
\hline -Cerebrovascular Dis & $430-438$ & 0 & 0 & 0 & 1 & 1 \\
\hline -Dis of Arteries \& Capillaries & $440-448$ & 0 & 0 & 0 & 1 & 1 \\
\hline -Dis of Veins, Lymphatics, Other & $451-459$ & 0 & 0 & 2 & 0 & 2 \\
\hline RESPIRATORY SYSTEM & $460-519$ & 3 & 3 & 10 & 27 & 43 \\
\hline -Acute Respiratory Infections & $460-466$ & 0 & 2 & 4 & 9 & 15 \\
\hline
\end{tabular}

(Continued)

*Only those diagnostic categories and gender/age combinations with at least one occurrence appear in this table. 


\section{Brookhaven National Laboratory 2008}

\section{Absence Data}

Appendix G. Number of Diagnoses in Each Diagnostic Category by Gender and Age*

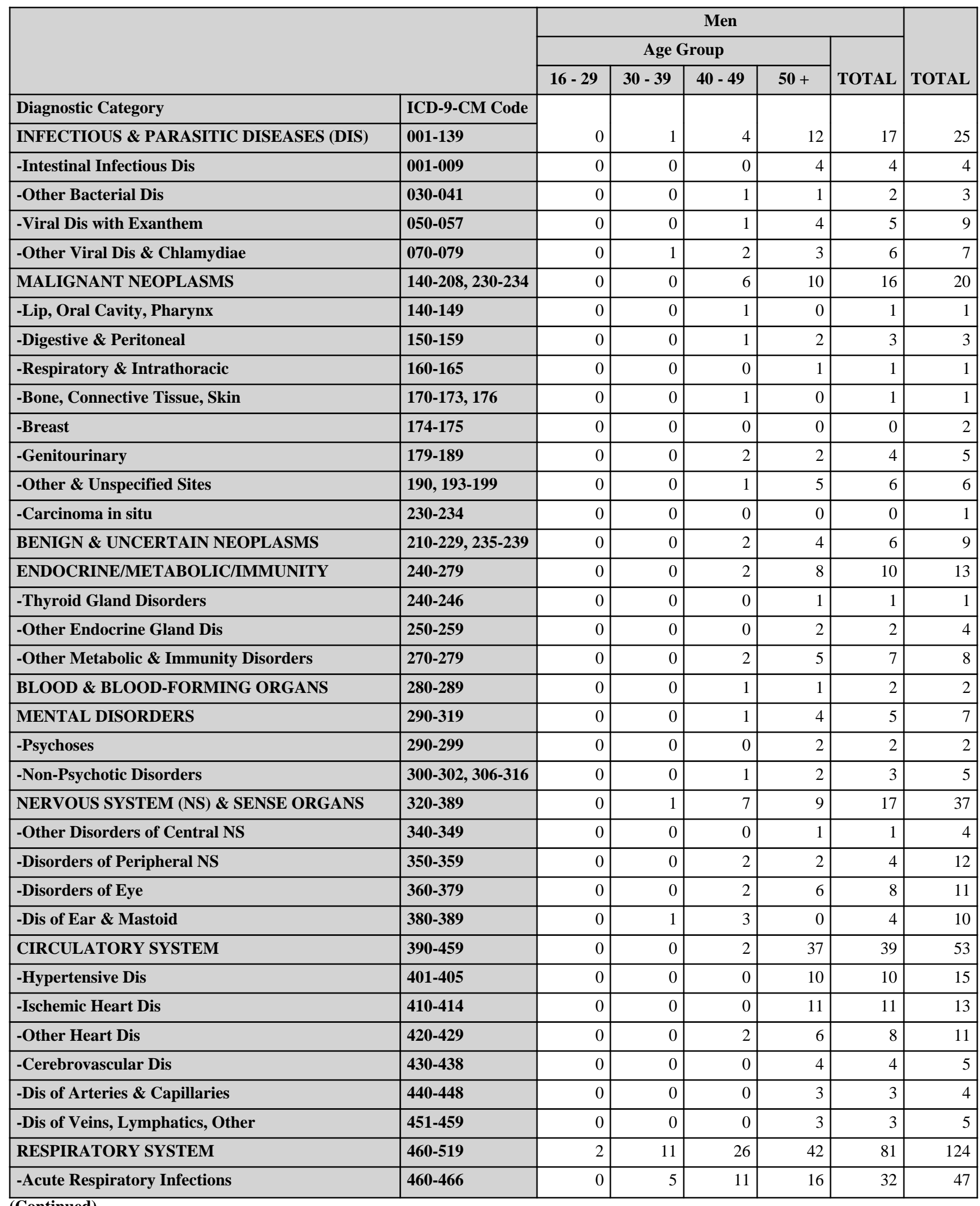

*Only those diagnostic categories and gender/age combinations with at least one occurrence appear in this table. 


\section{Brookhaven National Laboratory 2008}

Absence Data

Appendix G. Number of Diagnoses in Each Diagnostic Category by Gender and Age*

\begin{tabular}{|c|c|c|c|c|c|c|}
\hline & & \multicolumn{5}{|c|}{ Women } \\
\hline & & \multicolumn{4}{|c|}{ Age Group } & \multirow[b]{2}{*}{ TOTAL } \\
\hline & & $16-29$ & 30 - 39 & $40-49$ & $50+$ & \\
\hline Diagnostic Category & ICD-9-CM Code & \multirow[b]{2}{*}{1} & \multirow[b]{2}{*}{1} & \multirow[b]{2}{*}{1} & \multirow[b]{2}{*}{5} & \multirow[b]{2}{*}{8} \\
\hline -Other Dis Upper Respiratory Tract & $470-478$ & & & & & \\
\hline -Pneumonia \& Influenza & $480-487$ & 0 & 0 & 3 & 5 & 8 \\
\hline -Chronic Obstructive Dis & $490-496$ & 2 & 0 & 2 & 7 & 11 \\
\hline -Lung Dis from External Agents & $500-508$ & 0 & 0 & 0 & 0 & 0 \\
\hline -Other Respiratory Dis & $510-519$ & 0 & 0 & 0 & 1 & 1 \\
\hline DIGESTIVE SYSTEM & $520-579$ & 1 & 2 & 7 & 3 & 13 \\
\hline -Oral Cavity, Saliva Glands, Jaw & $520-529$ & 0 & 0 & 4 & 2 & 6 \\
\hline -Esophagus, Stomach, Duodenum & $530-537$ & 0 & 0 & 0 & 0 & 0 \\
\hline -Appendicitis & $540-543$ & 0 & 0 & 0 & 0 & 0 \\
\hline -Hernia & $550-553$ & 0 & 0 & 0 & 0 & 0 \\
\hline -Enteritis, Colitis & $555-558$ & 1 & 0 & 1 & 0 & 2 \\
\hline -Other Intestinal Dis & $560-569$ & 0 & 1 & 2 & 0 & 3 \\
\hline -Other Digestive Dis & $570-579$ & 0 & 1 & 0 & 1 & 2 \\
\hline GENITOURINARY SYSTEM & $580-629$ & 1 & 2 & 4 & 7 & 14 \\
\hline -Other Urinary Dis & $590-599$ & 0 & 0 & 1 & 1 & 2 \\
\hline -Male Genital Organ Dis & $600-608$ & 0 & 0 & 0 & 0 & 0 \\
\hline -Breast Disorders & $610-611$ & 0 & 0 & 1 & 2 & 3 \\
\hline -Other Female Disorders & $617-629$ & 1 & 2 & 2 & 4 & 9 \\
\hline SKIN \& SUBCUTANEOUS TISSUE & $680-709$ & 0 & 0 & 1 & 1 & 2 \\
\hline -Infections & $680-686$ & 0 & 0 & 1 & 0 & 1 \\
\hline -Other Inflammatory Conditions & $690-698$ & 0 & 0 & 0 & 0 & 0 \\
\hline -Other & 700-709 & 0 & 0 & 0 & 1 & 1 \\
\hline $\begin{array}{l}\text { MUSCULOSKELETAL \& CONNECTIVE } \\
\text { TISSUE }\end{array}$ & \begin{tabular}{|l|}
$710-739$ \\
\end{tabular} & 0 & 3 & 20 & 27 & 50 \\
\hline -Arthropathies & $710-719$ & 0 & 0 & 6 & 8 & 14 \\
\hline -Dorsopathies & $720-724$ & 0 & 2 & 6 & 10 & 18 \\
\hline -Rheumatism, Excluding Back & 725-729 & 0 & 1 & 8 & 7 & 16 \\
\hline -Other Dis \& Acquired Deformities & 730-739 & 0 & 0 & 0 & 2 & 2 \\
\hline CONGENITAL ANOMALIES & 740-759 & 0 & 0 & 0 & 0 & 0 \\
\hline $\begin{array}{l}\text { SYMPTOMS, SIGNS, \& ILL-DEFINED } \\
\text { CONDITIONS }\end{array}$ & $780-799$ & 2 & 6 & 22 & 10 & 40 \\
\hline -Symptoms & 780-789 & 2 & 6 & 21 & 9 & 38 \\
\hline -Non-Specific Abnormal Findings & $790-796$ & 0 & 0 & 1 & 1 & 2 \\
\hline INJURY \& POISONING & $800-999$ & 0 & 3 & 12 & 9 & 24 \\
\hline -Fracture - Skull & 800-804 & 0 & 0 & 0 & 0 & 0 \\
\hline -Fracture - Neck, Trunk & $805-809$ & 0 & 0 & 1 & 0 & 1 \\
\hline -Fracture - Upper Limb & $810-819$ & 0 & 0 & 1 & 0 & 1 \\
\hline
\end{tabular}

(Continued)

*Only those diagnostic categories and gender/age combinations with at least one occurrence appear in this table. 


\section{Brookhaven National Laboratory 2008}

\section{Absence Data}

Appendix G. Number of Diagnoses in Each Diagnostic Category by Gender and Age*

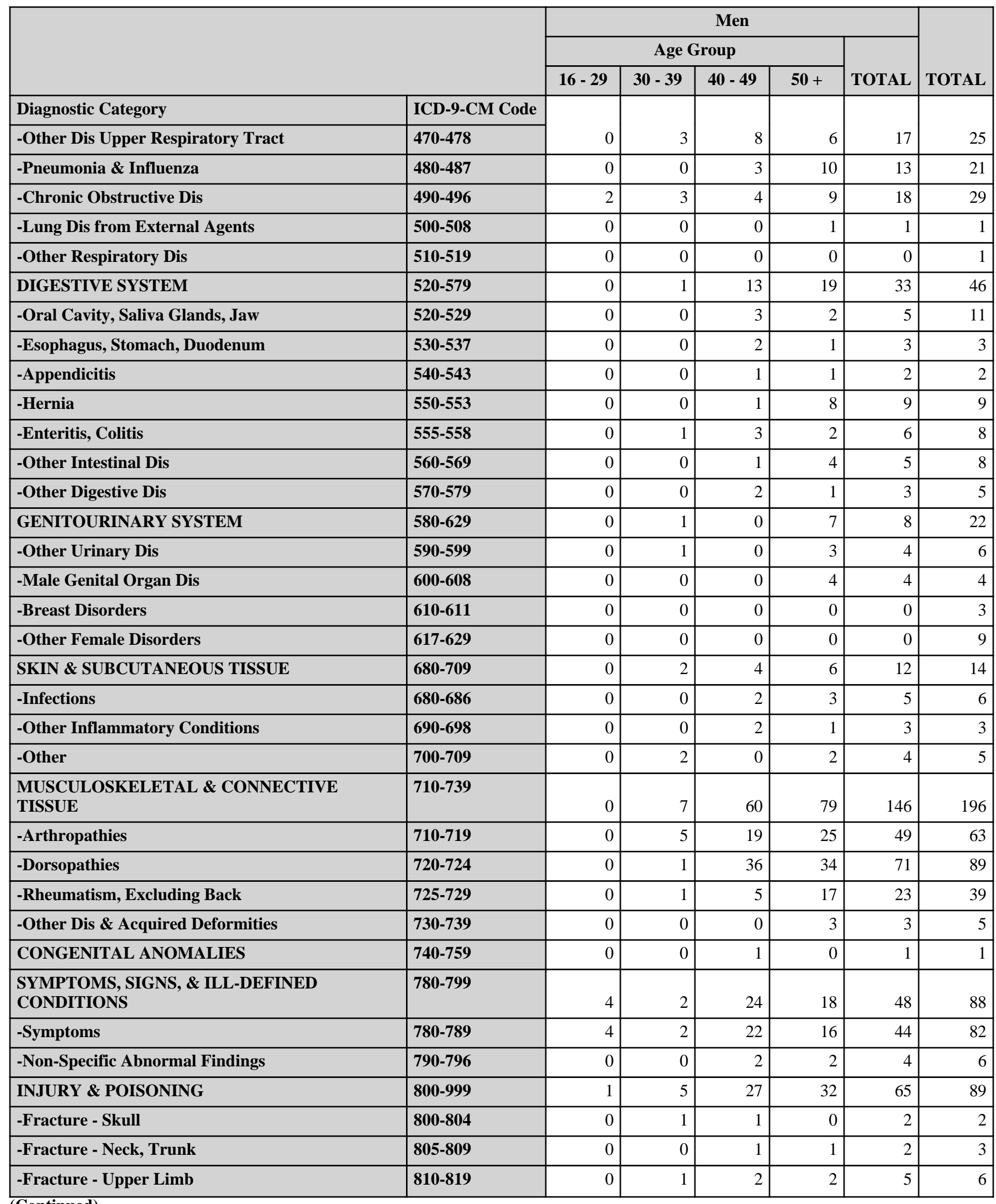

(Continued)

*Only those diagnostic categories and gender/age combinations with at least one occurrence appear in this table. 
Brookhaven National Laboratory 2008

Absence Data

Appendix G. Number of Diagnoses in Each Diagnostic Category by Gender and Age*

\begin{tabular}{|c|c|c|c|c|c|c|}
\hline & & \multicolumn{5}{|c|}{ Women } \\
\hline & & \multicolumn{4}{|c|}{ Age Group } & \multirow[b]{2}{*}{ TOTAL } \\
\hline & & $16-29$ & $30-39$ & $40-49$ & $50+$ & \\
\hline Diagnostic Category & ICD-9-CM Code & \multirow[b]{2}{*}{0} & \multirow[b]{2}{*}{1} & \multirow[b]{2}{*}{1} & \multirow[b]{2}{*}{2} & \multirow[b]{2}{*}{4} \\
\hline -Fracture - Lower Limb & $820-829$ & & & & & \\
\hline -Dislocation & $830-839$ & 0 & 0 & 0 & 0 & 0 \\
\hline -Sprains \& Strains - Back & 846-847 & 0 & 1 & 1 & 0 & 2 \\
\hline -Sprains \& Strains - Other & $840-845,848$ & 0 & 1 & 2 & 2 & 5 \\
\hline -Intracranial Injury & $850-854$ & 0 & 0 & 2 & 0 & 2 \\
\hline -Internal Injury - Thorax, Abdomen, Pelvis & \begin{tabular}{|c|}
$860-869$ \\
\end{tabular} & 0 & 0 & 0 & 0 & 0 \\
\hline -Open Wound - Head, Neck, Trunk & $870-879$ & 0 & 0 & 0 & 0 & 0 \\
\hline -Open Wound - Upper Limb & $880-887$ & 0 & 0 & 0 & 0 & 0 \\
\hline -Open Wound - Lower Limb & 890-897 & 0 & 0 & 0 & 0 & 0 \\
\hline -Superficial Injury & 910-919 & 0 & 0 & 0 & 1 & 1 \\
\hline -Contusion & $920-924$ & 0 & 0 & 3 & 0 & 3 \\
\hline -Foreign Body Entering Orifice & 930-939 & 0 & 0 & 0 & 0 & 0 \\
\hline -Injury to Nerves \& Spinal Cord & $950-957$ & 0 & 0 & 0 & 1 & 1 \\
\hline -Complications \& Unspecified Injuries & 958-959 & 0 & 0 & 0 & 1 & 1 \\
\hline -Unspecified Effects - External Causes & $990-995$ & 0 & 0 & 1 & 1 & 2 \\
\hline -Complications of Surgical/Medical Care & 996-999 & 0 & 0 & 0 & 1 & 1 \\
\hline $\begin{array}{l}\text { HEALTH STATUS/HEALTH SERVICE } \\
\text { CONTACT }\end{array}$ & \begin{tabular}{|l|l} 
V01-V82 \\
\end{tabular} & 3 & 8 & 3 & 0 & 14 \\
\hline -Personal \& Family History & V10-V19 & 0 & 0 & 0 & 0 & 0 \\
\hline -Health Services Reproduction/Development & V20-V29 & 3 & 6 & 1 & 0 & 10 \\
\hline -Specific Procedures/Aftercare & V50-V59 & 0 & 0 & 1 & 0 & 1 \\
\hline -Other Circumstances & V60-V69 & 0 & 2 & 1 & 0 & 3 \\
\hline
\end{tabular}

*Only those diagnostic categories and gender/age combinations with at least one occurrence appear in this table. 


\section{Brookhaven National Laboratory 2008}

Absence Data

Appendix G. Number of Diagnoses in Each Diagnostic Category by Gender and Age*

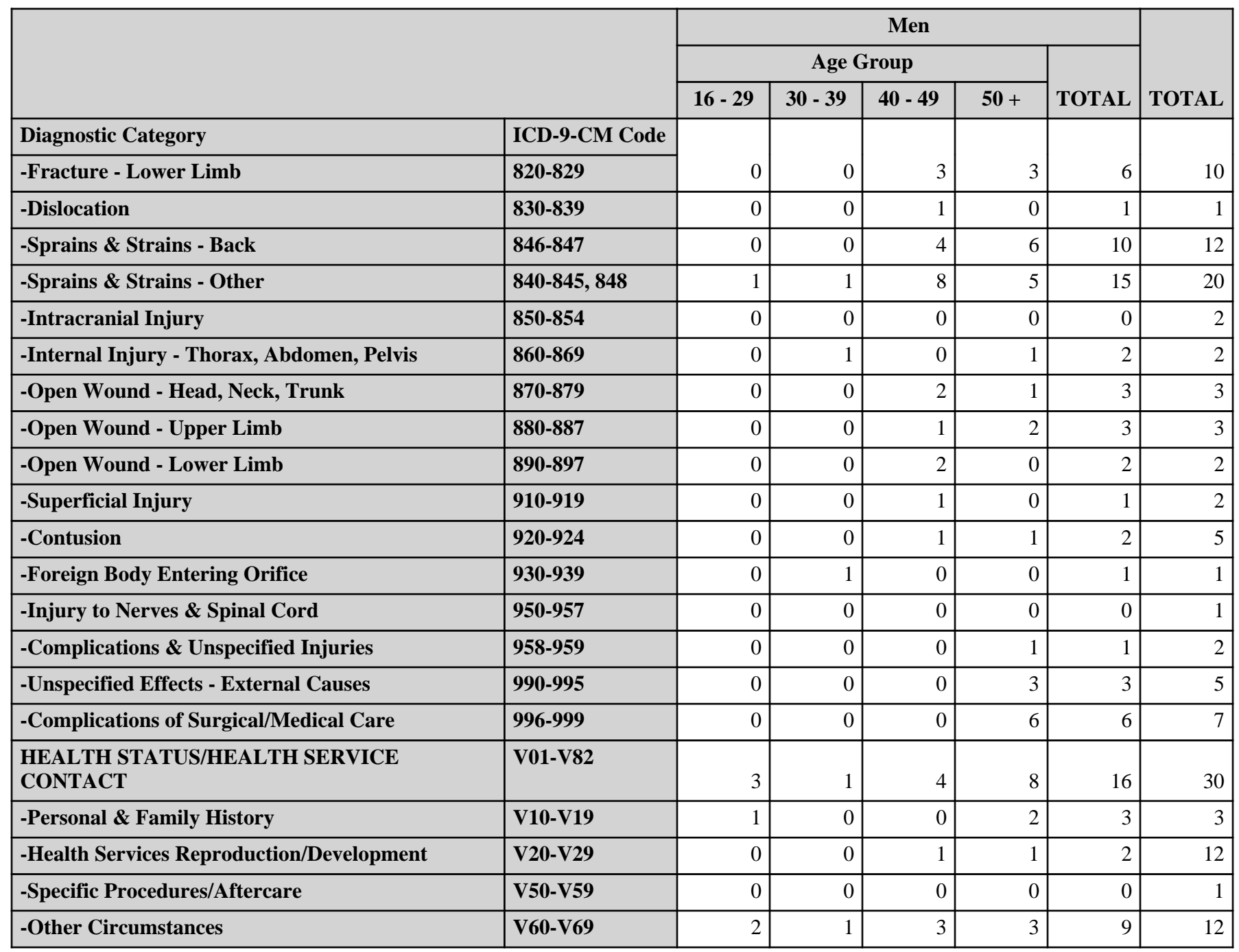

\begin{tabular}{|c|c|c|c|c|c|c|c|c|c|c|c|}
\hline & \multicolumn{5}{|c|}{ Women } & \multicolumn{5}{|c|}{ Men } & \multirow[b]{3}{*}{ TOTAL } \\
\hline & \multicolumn{4}{|c|}{ Age Group } & \multirow[b]{2}{*}{ TOTAL } & \multicolumn{4}{|c|}{ Age Group } & \multirow[b]{2}{*}{ TOTAL } & \\
\hline & $16-29$ & $30-39$ & $40-49$ & $50+$ & & $16-29$ & $30-39$ & $40-49$ & $50+$ & & \\
\hline Diagnostic Category & \multirow[b]{2}{*}{12} & \multirow[b]{2}{*}{31} & \multirow[b]{2}{*}{96} & \multirow[b]{2}{*}{115} & \multirow[b]{2}{*}{254} & \multirow[b]{2}{*}{10} & \multirow[b]{2}{*}{32} & \multirow[b]{2}{*}{184} & \multirow[b]{2}{*}{296} & \multirow[b]{2}{*}{522} & \multirow[b]{2}{*}{776} \\
\hline Total & & & & & & & & & & & \\
\hline
\end{tabular}

*Only those diagnostic categories and gender/age combinations with at least one occurrence appear in this table. 
Brookhaven National Laboratory 2008

Absence Data

Appendix H. Total Number of Calendar Days Absent in Each Diagnostic Category by Gender and Age*

\begin{tabular}{|c|c|c|c|c|c|c|}
\hline & & \multicolumn{5}{|c|}{ Women } \\
\hline & & \multicolumn{4}{|c|}{ Age Group } & \multirow[b]{2}{*}{ TOTAL } \\
\hline & & $16-29$ & $30-39$ & $40-49$ & $50+$ & \\
\hline Diagnostic Category & ICD-9-CM Code & \multirow[b]{2}{*}{4} & \multirow[b]{2}{*}{0} & \multirow[b]{2}{*}{9} & \multirow[b]{2}{*}{75} & \multirow[b]{2}{*}{88} \\
\hline INFECTIOUS \& PARASITIC DISEASES (DIS) & 001-139 & & & & & \\
\hline MALIGNANT NEOPLASMS & 140-208, 230-234 & 0 & 0 & 0 & 27 & 27 \\
\hline BENIGN \& UNCERTAIN NEOPLASMS & 210-229, 235-239 & 0 & 35 & 50 & 14 & 99 \\
\hline ENDOCRINE/METABOLIC/IMMUNITY & $240-279$ & 0 & 0 & 186 & 13 & 199 \\
\hline BLOOD \& BLOOD-FORMING ORGANS & $280-289$ & 0 & 0 & 0 & 0 & 0 \\
\hline MENTAL DISORDERS & $290-319$ & 0 & 0 & 4 & 8 & 12 \\
\hline NERVOUS SYSTEM (NS) \& SENSE ORGANS & $320-389$ & 7 & 49 & 293 & 90 & 439 \\
\hline CIRCULATORY SYSTEM & $390-459$ & 0 & 0 & 86 & 160 & 246 \\
\hline RESPIRATORY SYSTEM & $460-519$ & 10 & 20 & 91 & 189 & 310 \\
\hline DIGESTIVE SYSTEM & $520-579$ & 2 & 130 & 95 & 30 & 257 \\
\hline GENITOURINARY SYSTEM & $580-629$ & 3 & 45 & 68 & 102 & 218 \\
\hline SKIN \& SUBCUTANEOUS TISSUE & 680-709 & 0 & 0 & 3 & 17 & 20 \\
\hline $\begin{array}{l}\text { MUSCULOSKELETAL \& CONNECTIVE } \\
\text { TISSUE }\end{array}$ & $710-739$ & 0 & 16 & 287 & 422 & 725 \\
\hline CONGENITAL ANOMALIES & $740-759$ & 0 & 0 & 0 & 0 & 0 \\
\hline $\begin{array}{l}\text { SYMPTOMS, SIGNS, \& ILL-DEFINED } \\
\text { CONDITIONS }\end{array}$ & 780-799 & 6 & 14 & 48 & 62 & 130 \\
\hline INJURY \& POISONING & $800-999$ & 0 & 58 & 322 & 74 & 454 \\
\hline
\end{tabular}

\footnotetext{
*Absences with >1 ICD-9-CM code in the same diagnostic category were counted only once. Only those diagnostic categories and gender/age combinations with at least one occurrence appear in this table.
} 
Brookhaven National Laboratory 2008

Absence Data

Appendix H. Total Number of Calendar Days Absent in Each Diagnostic Category by Gender and Age*

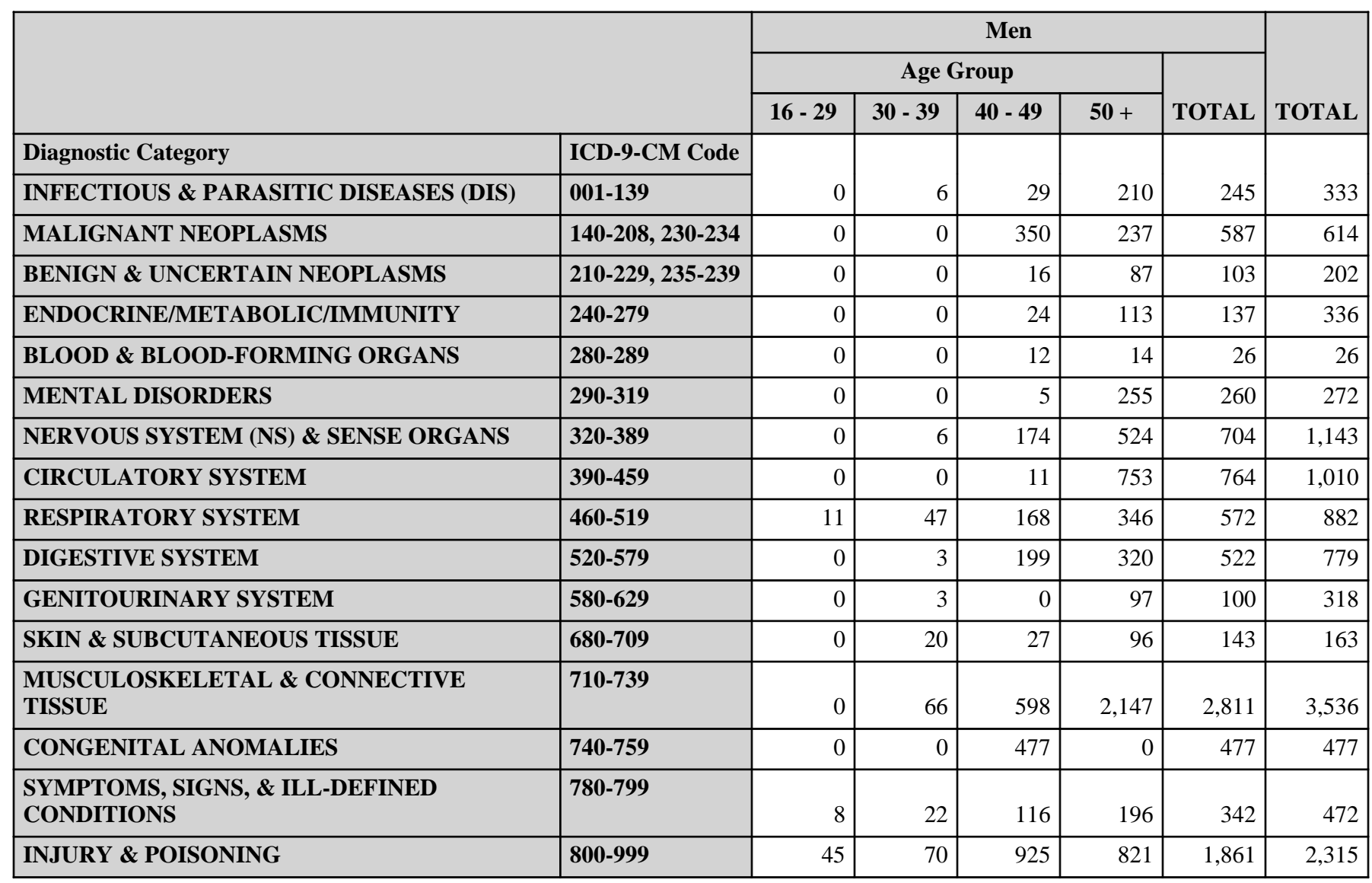

\footnotetext{
*Absences with >1 ICD-9-CM code in the same diagnostic category were counted only once. Only those diagnostic categories and gender/age combinations with at least one occurrence appear in this table.
} 


\section{Brookhaven National Laboratory 2008}

\section{Absence Data}

Appendix I. Number of Diagnoses in Each Diagnostic Category by Gender and Job Category*

\begin{tabular}{|c|c|c|c|c|c|c|}
\hline & & \multicolumn{5}{|c|}{ Women } \\
\hline & & \multicolumn{5}{|c|}{ Job Category } \\
\hline & & Professional & $\begin{array}{c}\text { Administrative } \\
\text { Support }\end{array}$ & $\begin{array}{l}\text { Technical } \\
\text { Support }\end{array}$ & Service & $\begin{array}{l}\text { Security } \\
\text { and Fire }\end{array}$ \\
\hline Diagnostic Category & ICD-9-CM Code & \multirow[b]{2}{*}{4} & \multirow[b]{2}{*}{1} & \multirow[b]{2}{*}{0} & \multirow[b]{2}{*}{3} & \multirow[b]{2}{*}{0} \\
\hline INFECTIOUS \& PARASITIC DISEASES (DIS) & 001-139 & & & & & \\
\hline -Other Bacterial Dis & 030-041 & 0 & 1 & 0 & 0 & 0 \\
\hline -Viral Dis with Exanthem & 050-057 & 2 & 0 & 0 & 2 & 0 \\
\hline -Other Viral Dis \& Chlamydiae & 070-079 & 0 & 0 & 0 & 1 & 0 \\
\hline MALIGNANT NEOPLASMS & $140-208,230-234$ & 1 & 2 & 0 & 1 & 0 \\
\hline -Breast & 174-175 & 1 & 1 & 0 & 0 & 0 \\
\hline -Genitourinary & 179-189 & 0 & 0 & 0 & 1 & 0 \\
\hline -Carcinoma in situ & $230-234$ & 0 & 1 & 0 & 0 & 0 \\
\hline BENIGN \& UNCERTAIN NEOPLASMS & 210-229, 235-239 & 1 & 0 & 0 & 2 & 0 \\
\hline ENDOCRINE/METABOLIC/IMMUNITY & $240-279$ & 1 & 1 & 0 & 0 & 1 \\
\hline -Other Endocrine Gland Dis & $250-259$ & 1 & 1 & 0 & 0 & 0 \\
\hline -Other Metabolic \& Immunity Disorders & $270-279$ & 0 & 0 & 0 & 0 & 1 \\
\hline MENTAL DISORDERS & 290-319 & 1 & 1 & 0 & 0 & 0 \\
\hline -Non-Psychotic Disorders & $300-302,306-316$ & 1 & 1 & 0 & 0 & 0 \\
\hline NERVOUS SYSTEM (NS) \& SENSE ORGANS & 320-389 & 9 & 3 & 3 & 3 & 2 \\
\hline -Other Disorders of Central NS & $340-349$ & 2 & 1 & 0 & 0 & 0 \\
\hline -Disorders of Peripheral NS & $350-359$ & 5 & 1 & 2 & 0 & 0 \\
\hline -Disorders of Eye & $360-379$ & 0 & 1 & 0 & 0 & 2 \\
\hline -Dis of Ear \& Mastoid & $380-389$ & 2 & 0 & 1 & 3 & 0 \\
\hline CIRCULATORY SYSTEM & $390-459$ & 6 & 5 & 2 & 1 & 0 \\
\hline -Hypertensive Dis & $401-405$ & 3 & 2 & 0 & 0 & 0 \\
\hline -Ischemic Heart Dis & $410-414$ & 1 & 0 & 0 & 1 & 0 \\
\hline -Other Heart Dis & $420-429$ & 1 & 2 & 0 & 0 & 0 \\
\hline -Cerebrovascular Dis & $430-438$ & 1 & 0 & 0 & 0 & 0 \\
\hline -Dis of Arteries \& Capillaries & \begin{tabular}{|l|}
$440-448$ \\
\end{tabular} & 0 & 1 & 0 & 0 & 0 \\
\hline -Dis of Veins, Lymphatics, Other & 451-459 & 0 & 0 & 2 & 0 & 0 \\
\hline RESPIRATORY SYSTEM & $460-519$ & 4 & 22 & 4 & 12 & 1 \\
\hline -Acute Respiratory Infections & $460-466$ & 1 & 9 & 2 & 2 & 1 \\
\hline -Other Dis Upper Respiratory Tract & $470-478$ & 0 & 5 & 0 & 3 & 0 \\
\hline -Pneumonia \& Influenza & $480-487$ & 2 & 3 & 0 & 3 & 0 \\
\hline -Chronic Obstructive Dis & $490-496$ & 0 & 5 & 2 & 4 & 0 \\
\hline -Other Respiratory Dis & $510-519$ & 1 & 0 & 0 & 0 & 0 \\
\hline DIGESTIVE SYSTEM & $520-579$ & 5 & 6 & 1 & 1 & 0 \\
\hline -Oral Cavity, Saliva Glands, Jaw & $520-529$ & 5 & 1 & 0 & 0 & 0 \\
\hline -Enteritis, Colitis & $555-558$ & 0 & 2 & 0 & 0 & 0 \\
\hline -Other Intestinal Dis & $560-569$ & 0 & 1 & 1 & 1 & 0 \\
\hline
\end{tabular}

(Continued)

*Only those diagnostic categories and gender/job category combinations with at least one occurrence appear in this table. 


\section{Brookhaven National Laboratory 2008}

Absence Data

Appendix I. Number of Diagnoses in Each Diagnostic Category by Gender and Job Category*

\begin{tabular}{|c|c|c|}
\hline & & Women \\
\hline & & TOTAL \\
\hline Diagnostic Category & ICD-9-CM Code & \\
\hline INFECTIOUS \& PARASITIC DISEASES (DIS) & 001-139 & 8 \\
\hline -Other Bacterial Dis & 030-041 & 1 \\
\hline -Viral Dis with Exanthem & 050-057 & 4 \\
\hline -Other Viral Dis \& Chlamydiae & 070-079 & 1 \\
\hline MALIGNANT NEOPLASMS & $140-208,230-234$ & 4 \\
\hline -Breast & 174-175 & 2 \\
\hline -Genitourinary & 179-189 & 1 \\
\hline -Carcinoma in situ & $230-234$ & 1 \\
\hline BENIGN \& UNCERTAIN NEOPLASMS & 210-229, 235-239 & 3 \\
\hline ENDOCRINE/METABOLIC/IMMUNITY & $240-279$ & 3 \\
\hline -Other Endocrine Gland Dis & $250-259$ & 2 \\
\hline -Other Metabolic \& Immunity Disorders & $270-279$ & 1 \\
\hline MENTAL DISORDERS & $290-319$ & 2 \\
\hline -Non-Psychotic Disorders & $300-302,306-316$ & 2 \\
\hline NERVOUS SYSTEM (NS) \& SENSE ORGANS & 320-389 & 20 \\
\hline -Other Disorders of Central NS & $340-349$ & 3 \\
\hline -Disorders of Peripheral NS & $350-359$ & 8 \\
\hline -Disorders of Eye & $360-379$ & 3 \\
\hline -Dis of Ear \& Mastoid & $380-389$ & 6 \\
\hline CIRCULATORY SYSTEM & $390-459$ & 14 \\
\hline -Hypertensive Dis & $401-405$ & 5 \\
\hline -Ischemic Heart Dis & $410-414$ & 2 \\
\hline -Other Heart Dis & $420-429$ & 3 \\
\hline -Cerebrovascular Dis & $430-438$ & 1 \\
\hline -Dis of Arteries \& Capillaries & $440-448$ & 1 \\
\hline -Dis of Veins, Lymphatics, Other & 451-459 & 2 \\
\hline RESPIRATORY SYSTEM & $460-519$ & 43 \\
\hline -Acute Respiratory Infections & $460-466$ & 15 \\
\hline -Other Dis Upper Respiratory Tract & $470-478$ & 8 \\
\hline -Pneumonia \& Influenza & $480-487$ & 8 \\
\hline -Chronic Obstructive Dis & $490-496$ & 11 \\
\hline -Other Respiratory Dis & $510-519$ & 1 \\
\hline DIGESTIVE SYSTEM & $520-579$ & 13 \\
\hline -Oral Cavity, Saliva Glands, Jaw & $520-529$ & 6 \\
\hline -Enteritis, Colitis & $555-558$ & 2 \\
\hline -Other Intestinal Dis & $560-569$ & 3 \\
\hline
\end{tabular}

(Continued)

*Only those diagnostic categories and gender/job category combinations with at least one occurrence appear in this table. 


\section{Brookhaven National Laboratory 2008}

Absence Data

Appendix I. Number of Diagnoses in Each Diagnostic Category by Gender and Job Category*

\begin{tabular}{|c|c|c|c|c|c|c|}
\hline & & \multicolumn{5}{|c|}{ Women } \\
\hline & & \multicolumn{5}{|c|}{ Job Category } \\
\hline & & Professional & $\begin{array}{l}\text { Administrative } \\
\text { Support }\end{array}$ & $\begin{array}{l}\text { Technical } \\
\text { Support }\end{array}$ & Service & $\begin{array}{l}\text { Security } \\
\text { and Fire }\end{array}$ \\
\hline Diagnostic Category & ICD-9-CM Code & \multirow[b]{2}{*}{0} & \multirow[b]{2}{*}{2} & \multirow[b]{2}{*}{0} & \multirow[b]{2}{*}{0} & \multirow[b]{2}{*}{0} \\
\hline -Other Digestive Dis & \begin{tabular}{|l|}
$570-579$ \\
\end{tabular} & & & & & \\
\hline GENITOURINARY SYSTEM & $580-629$ & 7 & 2 & 1 & 3 & 1 \\
\hline -Other Urinary Dis & 590-599 & 1 & 0 & 1 & 0 & 0 \\
\hline -Breast Disorders & $610-611$ & 2 & 1 & 0 & 0 & 0 \\
\hline -Other Female Disorders & $617-629$ & 4 & 1 & 0 & 3 & 1 \\
\hline SKIN \& SUBCUTANEOUS TISSUE & $680-709$ & 1 & 0 & 0 & 1 & 0 \\
\hline -Infections & $680-686$ & 0 & 0 & 0 & 1 & 0 \\
\hline -Other & 700-709 & 1 & 0 & 0 & 0 & 0 \\
\hline $\begin{array}{l}\text { MUSCULOSKELETAL \& CONNECTIVE } \\
\text { TISSUE }\end{array}$ & 710-739 & 16 & 18 & 1 & 14 & 1 \\
\hline -Arthropathies & $710-719$ & 6 & 4 & 0 & 4 & 0 \\
\hline -Dorsopathies & $720-724$ & 3 & 8 & 0 & 6 & 1 \\
\hline -Rheumatism, Excluding Back & \begin{tabular}{|l|}
$725-729$ \\
\end{tabular} & 6 & 5 & 1 & 4 & 0 \\
\hline -Other Dis \& Acquired Deformities & \begin{tabular}{|l|}
$730-739$ \\
\end{tabular} & 1 & 1 & 0 & 0 & 0 \\
\hline $\begin{array}{l}\text { SYMPTOMS, SIGNS, \& ILL-DEFINED } \\
\text { CONDITIONS }\end{array}$ & \begin{tabular}{|l|}
$780-799$ \\
\end{tabular} & 4 & 21 & 7 & 5 & 3 \\
\hline -Symptoms & 780-789 & 3 & 20 & 7 & 5 & 3 \\
\hline -Non-Specific Abnormal Findings & $790-796$ & 1 & 1 & 0 & 0 & 0 \\
\hline INJURY \& POISONING & $800-999$ & 9 & 6 & 1 & 8 & 0 \\
\hline -Fracture - Neck, Trunk & $805-809$ & 1 & 0 & 0 & 0 & 0 \\
\hline -Fracture - Upper Limb & 810-819 & 1 & 0 & 0 & 0 & 0 \\
\hline -Fracture - Lower Limb & $820-829$ & 4 & 0 & 0 & 0 & 0 \\
\hline -Sprains \& Strains - Back & \begin{tabular}{|l|}
$846-847$ \\
\end{tabular} & 0 & 1 & 0 & 1 & 0 \\
\hline -Sprains \& Strains - Other & $840-845,848$ & 1 & 1 & 1 & 2 & 0 \\
\hline -Intracranial Injury & $850-854$ & 0 & 1 & 0 & 1 & 0 \\
\hline -Superficial Injury & $910-919$ & 0 & 1 & 0 & 0 & 0 \\
\hline -Contusion & $920-924$ & 0 & 1 & 0 & 2 & 0 \\
\hline -Injury to Nerves \& Spinal Cord & $950-957$ & 0 & 0 & 0 & 1 & 0 \\
\hline -Complications \& Unspecified Injuries & 958-959 & 1 & 0 & 0 & 0 & 0 \\
\hline -Unspecified Effects - External Causes & $990-995$ & 0 & 1 & 0 & 1 & $\overline{0}$ \\
\hline -Complications of Surgical/Medical Care & 996-999 & 1 & 0 & 0 & 0 & 0 \\
\hline $\begin{array}{l}\text { HEALTH STATUS/HEALTH SERVICE } \\
\text { CONTACT }\end{array}$ & V01-V82 & 7 & 6 & 0 & 1 & 0 \\
\hline -Health Services Reproduction/Development & V20-V29 & 4 & 6 & 0 & 0 & 0 \\
\hline -Specific Procedures/Aftercare & V50-V59 & 1 & 0 & 0 & 0 & 0 \\
\hline -Other Circumstances & V60-V69 & 2 & 0 & 0 & 1 & 0 \\
\hline
\end{tabular}

*Only those diagnostic categories and gender/job category combinations with at least one occurrence appear in this table. 


\section{Brookhaven National Laboratory 2008}

Absence Data

Appendix I. Number of Diagnoses in Each Diagnostic Category by Gender and Job Category*

\begin{tabular}{|c|c|c|}
\hline & & Women \\
\hline & & TOTAL \\
\hline Diagnostic Category & ICD-9-CM Code & \\
\hline -Other Digestive Dis & $570-579$ & 2 \\
\hline GENITOURINARY SYSTEM & $580-629$ & 14 \\
\hline -Other Urinary Dis & $590-599$ & 2 \\
\hline -Breast Disorders & $610-611$ & 3 \\
\hline -Other Female Disorders & $617-629$ & 9 \\
\hline SKIN \& SUBCUTANEOUS TISSUE & 680-709 & 2 \\
\hline -Infections & $680-686$ & 1 \\
\hline -Other & 700-709 & 1 \\
\hline $\begin{array}{l}\text { MUSCULOSKELETAL \& CONNECTIVE } \\
\text { TISSUE }\end{array}$ & 710-739 & 50 \\
\hline -Arthropathies & 710-719 & 14 \\
\hline -Dorsopathies & $720-724$ & 18 \\
\hline -Rheumatism, Excluding Back & 725-729 & 16 \\
\hline -Other Dis \& Acquired Deformities & $730-739$ & 2 \\
\hline $\begin{array}{l}\text { SYMPTOMS, SIGNS, \& ILL-DEFINED } \\
\text { CONDITIONS }\end{array}$ & 780-799 & 40 \\
\hline -Symptoms & 780-789 & 38 \\
\hline -Non-Specific Abnormal Findings & $790-796$ & 2 \\
\hline INJURY \& POISONING & $800-999$ & 24 \\
\hline -Fracture - Neck, Trunk & 805-809 & 1 \\
\hline -Fracture - Upper Limb & 810-819 & 1 \\
\hline -Fracture - Lower Limb & $820-829$ & 4 \\
\hline -Sprains \& Strains - Back & 846-847 & 2 \\
\hline -Sprains \& Strains - Other & $840-845,848$ & 5 \\
\hline -Intracranial Injury & $850-854$ & 2 \\
\hline -Superficial Injury & $910-919$ & 1 \\
\hline -Contusion & $920-924$ & 3 \\
\hline -Injury to Nerves \& Spinal Cord & $950-957$ & 1 \\
\hline -Complications \& Unspecified Injuries & 958-959 & 1 \\
\hline -Unspecified Effects - External Causes & $990-995$ & 2 \\
\hline -Complications of Surgical/Medical Care & 996-999 & 1 \\
\hline $\begin{array}{l}\text { HEALTH STATUS/HEALTH SERVICE } \\
\text { CONTACT }\end{array}$ & V01-V82 & 14 \\
\hline -Health Services Reproduction/Development & V20-V29 & 10 \\
\hline -Specific Procedures/Aftercare & V50-V59 & 1 \\
\hline -Other Circumstances & V60-V69 & 3 \\
\hline
\end{tabular}

*Only those diagnostic categories and gender/job category combinations with at least one occurrence appear in this table. 
Brookhaven National Laboratory 2008

Absence Data

Appendix I. Number of Diagnoses in Each Diagnostic Category by Gender and Job Category*

\begin{tabular}{|c|c|c|c|c|c|c|}
\hline & \multicolumn{6}{|c|}{ Women } \\
\hline & \multicolumn{5}{|c|}{ Job Category } & \multirow[b]{2}{*}{ TOTAI } \\
\hline & Professional & $\begin{array}{c}\text { Administrative } \\
\text { Support }\end{array}$ & Technical Support & Service & Security and Fire & \\
\hline Diagnostic Category & \multirow[b]{2}{*}{76} & \multirow[b]{2}{*}{94} & \multirow[b]{2}{*}{20} & \multirow[b]{2}{*}{55} & \multirow[b]{2}{*}{9} & \multirow[b]{2}{*}{254} \\
\hline Total & & & & & & \\
\hline
\end{tabular}

*Only those diagnostic categories and gender/job category combinations with at least one occurrence appear in this table. 


\section{Brookhaven National Laboratory 2008}

Absence Data

Appendix I. Number of Diagnoses in Each Diagnostic Category by Gender and Job Category*

\begin{tabular}{|c|c|c|c|c|}
\hline & \multicolumn{3}{|c|}{ Men } \\
\hline & & \multicolumn{3}{|c|}{ Job Category } \\
\hline & & Professional & $\begin{array}{c}\text { Administrative } \\
\text { Support }\end{array}$ & Technical Support \\
\hline Diagnostic Category & ICD-9-CM Code & \multirow[b]{2}{*}{6} & \multirow[b]{2}{*}{0} & \multirow[b]{2}{*}{3} \\
\hline INFECTIOUS \& PARASITIC DISEASES (DIS) & 001-139 & & & \\
\hline -Intestinal Infectious Dis & \begin{tabular}{|c|}
$001-009$ \\
\end{tabular} & 3 & 0 & 1 \\
\hline -Other Bacterial Dis & \begin{tabular}{|c|}
$030-041$ \\
\end{tabular} & 0 & 0 & 1 \\
\hline -Viral Dis with Exanthem & 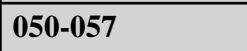 & 2 & 0 & 0 \\
\hline -Other Viral Dis \& Chlamydiae & 070-079 & 1 & 0 & 1 \\
\hline MALIGNANT NEOPLASMS & $140-208,230-234$ & 9 & 1 & 1 \\
\hline -Lip, Oral Cavity, Pharynx & $140-149$ & 0 & 0 & 1 \\
\hline -Digestive \& Peritoneal & $150-159$ & 3 & 0 & 0 \\
\hline -Respiratory \& Intrathoracic & $160-165$ & 1 & 0 & 0 \\
\hline -Bone, Connective Tissue, Skin & $170-173,176$ & 0 & 0 & 0 \\
\hline -Genitourinary & 179-189 & 2 & 1 & 0 \\
\hline -Other \& Unspecified Sites & 190, 193-199 & 3 & 0 & 0 \\
\hline BENIGN \& UNCERTAIN NEOPLASMS & 210-229, 235-239 & 2 & 0 & 2 \\
\hline ENDOCRINE/METABOLIC/IMMUNITY & $240-279$ & 5 & 0 & 2 \\
\hline -Thyroid Gland Disorders & $240-246$ & 0 & 0 & 1 \\
\hline -Other Endocrine Gland Dis & $250-259$ & 1 & 0 & 1 \\
\hline -Other Metabolic \& Immunity Disorders & $270-279$ & 4 & 0 & 0 \\
\hline BLOOD \& BLOOD-FORMING ORGANS & $280-289$ & 0 & 0 & 1 \\
\hline MENTAL DISORDERS & $290-319$ & 3 & 0 & 0 \\
\hline -Psychoses & 290-299 & 1 & 0 & 0 \\
\hline -Non-Psychotic Disorders & $300-302,306-316$ & 2 & 0 & 0 \\
\hline NERVOUS SYSTEM (NS) \& SENSE ORGANS & $320-389$ & 3 & 0 & 1 \\
\hline -Other Disorders of Central NS & $340-349$ & 0 & 0 & 0 \\
\hline -Disorders of Peripheral NS & $350-359$ & 1 & 0 & 0 \\
\hline -Disorders of Eye & $360-379$ & 2 & 0 & 0 \\
\hline -Dis of Ear \& Mastoid & $380-389$ & 0 & 0 & 1 \\
\hline CIRCULATORY SYSTEM & $390-459$ & 17 & 0 & 8 \\
\hline -Hypertensive Dis & $401-405$ & 6 & 0 & 0 \\
\hline -Ischemic Heart Dis & $410-414$ & 6 & 0 & 0 \\
\hline -Other Heart Dis & $420-429$ & 3 & 0 & 5 \\
\hline -Cerebrovascular Dis & $430-438$ & 1 & 0 & 0 \\
\hline -Dis of Arteries \& Capillaries & $440-448$ & 1 & 0 & 2 \\
\hline -Dis of Veins, Lymphatics, Other & \begin{tabular}{|l|}
$451-459$ \\
\end{tabular} & 0 & 0 & 1 \\
\hline RESPIRATORY SYSTEM & $460-519$ & 13 & 4 & 17 \\
\hline -Acute Respiratory Infections & $460-466$ & 4 & 2 & 10 \\
\hline -Other Dis Upper Respiratory Tract & $470-478$ & 1 & 0 & 2 \\
\hline
\end{tabular}

(Continued)

*Only those diagnostic categories and gender/job category combinations with at least one occurrence appear in this table. 


\section{Brookhaven National Laboratory 2008}

Absence Data

Appendix I. Number of Diagnoses in Each Diagnostic Category by Gender and Job Category*

\begin{tabular}{|c|c|c|c|c|c|}
\hline & & \multicolumn{4}{|c|}{ Men } \\
\hline & & \multicolumn{3}{|c|}{ Job Category } & \multirow[b]{2}{*}{ TOTAL } \\
\hline & & Service & Security and Fire & Crafts & \\
\hline Diagnostic Category & ICD-9-CM Code & \multirow[b]{2}{*}{5} & \multirow[b]{2}{*}{0} & \multirow[b]{2}{*}{3} & \multirow[b]{2}{*}{17} \\
\hline INFECTIOUS \& PARASITIC DISEASES (DIS) & 001-139 & & & & \\
\hline -Intestinal Infectious Dis & 001-009 & 0 & 0 & 0 & 4 \\
\hline -Other Bacterial Dis & 030-041 & 1 & 0 & 0 & 2 \\
\hline -Viral Dis with Exanthem & 050-057 & 3 & 0 & 0 & 5 \\
\hline -Other Viral Dis \& Chlamydiae & 070-079 & 1 & 0 & 3 & 6 \\
\hline MALIGNANT NEOPLASMS & 140-208, 230-234 & 5 & 0 & 0 & 16 \\
\hline -Lip, Oral Cavity, Pharynx & $140-149$ & 0 & 0 & 0 & 1 \\
\hline -Digestive \& Peritoneal & $150-159$ & 0 & 0 & 0 & 3 \\
\hline -Respiratory \& Intrathoracic & $160-165$ & 0 & 0 & 0 & 1 \\
\hline -Bone, Connective Tissue, Skin & $170-173,176$ & 1 & 0 & 0 & 1 \\
\hline -Genitourinary & $179-189$ & 1 & 0 & 0 & 4 \\
\hline -Other \& Unspecified Sites & 190, 193-199 & 3 & 0 & 0 & 6 \\
\hline BENIGN \& UNCERTAIN NEOPLASMS & 210-229, 235-239 & 0 & 1 & 1 & $\overline{6}$ \\
\hline ENDOCRINE/METABOLIC/IMMUNITY & $240-279$ & 2 & 0 & 1 & 10 \\
\hline -Thyroid Gland Disorders & $240-246$ & 0 & 0 & 0 & 1 \\
\hline -Other Endocrine Gland Dis & $250-259$ & 0 & 0 & 0 & 2 \\
\hline -Other Metabolic \& Immunity Disorders & $270-279$ & 2 & 0 & 1 & 7 \\
\hline BLOOD \& BLOOD-FORMING ORGANS & $280-289$ & 1 & 0 & 0 & 2 \\
\hline MENTAL DISORDERS & $290-319$ & 1 & 0 & 1 & 5 \\
\hline -Psychoses & 290-299 & 1 & 0 & 0 & 2 \\
\hline -Non-Psychotic Disorders & $300-302,306-316$ & 0 & 0 & 1 & 3 \\
\hline NERVOUS SYSTEM (NS) \& SENSE ORGANS & $320-389$ & 6 & 2 & 5 & 17 \\
\hline -Other Disorders of Central NS & $340-349$ & 1 & 0 & 0 & 1 \\
\hline -Disorders of Peripheral NS & $350-359$ & 2 & 1 & 0 & 4 \\
\hline -Disorders of Eye & $360-379$ & 1 & 1 & 4 & 8 \\
\hline -Dis of Ear \& Mastoid & $380-389$ & 2 & 0 & 1 & 4 \\
\hline CIRCULATORY SYSTEM & $390-459$ & 8 & 3 & 3 & 39 \\
\hline -Hypertensive Dis & $401-405$ & 2 & 1 & 1 & 10 \\
\hline -Ischemic Heart Dis & $410-414$ & 2 & 1 & 2 & 11 \\
\hline -Other Heart Dis & $420-429$ & 0 & 0 & 0 & 8 \\
\hline -Cerebrovascular Dis & $430-438$ & 2 & 1 & 0 & 4 \\
\hline -Dis of Arteries \& Capillaries & $440-448$ & 0 & 0 & 0 & 3 \\
\hline -Dis of Veins, Lymphatics, Other & 451-459 & 2 & 0 & 0 & 3 \\
\hline RESPIRATORY SYSTEM & $460-519$ & 20 & 5 & 22 & 81 \\
\hline -Acute Respiratory Infections & $460-466$ & 8 & 1 & 7 & 32 \\
\hline -Other Dis Upper Respiratory Tract & $470-478$ & 6 & 3 & 5 & 17 \\
\hline
\end{tabular}

(Continued)

*Only those diagnostic categories and gender/job category combinations with at least one occurrence appear in this table. 


\section{Brookhaven National Laboratory 2008}

Absence Data

Appendix I. Number of Diagnoses in Each Diagnostic Category by Gender and Job Category*

\begin{tabular}{|c|c|c|c|c|}
\hline & \multicolumn{3}{|c|}{ Men } \\
\hline & & \multicolumn{3}{|c|}{ Job Category } \\
\hline & & Professional & $\begin{array}{c}\text { Administrative } \\
\text { Support }\end{array}$ & Technical Support \\
\hline Diagnostic Category & ICD-9-CM Code & \multirow[b]{2}{*}{4} & \multirow[b]{2}{*}{1} & \multirow[b]{2}{*}{2} \\
\hline -Pneumonia \& Influenza & $480-487$ & & & \\
\hline -Chronic Obstructive Dis & $490-496$ & 3 & 1 & 3 \\
\hline -Lung Dis from External Agents & $500-508$ & 1 & 0 & 0 \\
\hline DIGESTIVE SYSTEM & \begin{tabular}{|l|}
$520-579$ \\
\end{tabular} & 10 & 1 & 5 \\
\hline -Oral Cavity, Saliva Glands, Jaw & $520-529$ & 1 & 1 & 0 \\
\hline -Esophagus, Stomach, Duodenum & $530-537$ & 2 & 0 & 0 \\
\hline -Appendicitis & $540-543$ & 2 & 0 & 0 \\
\hline -Hernia & $550-553$ & 3 & 0 & 2 \\
\hline -Enteritis, Colitis & $555-558$ & 1 & 0 & 1 \\
\hline -Other Intestinal Dis & $560-569$ & 1 & 0 & 1 \\
\hline -Other Digestive Dis & $570-579$ & 0 & 0 & 1 \\
\hline GENITOURINARY SYSTEM & $580-629$ & 1 & 0 & 1 \\
\hline -Other Urinary Dis & $590-599$ & 1 & 0 & $\overline{0}$ \\
\hline -Male Genital Organ Dis & $600-608$ & 0 & 0 & 1 \\
\hline SKIN \& SUBCUTANEOUS TISSUE & 680-709 & 3 & 0 & 2 \\
\hline -Infections & $680-686$ & 1 & 0 & $\overline{0}$ \\
\hline -Other Inflammatory Conditions & $690-698$ & 1 & 0 & 0 \\
\hline -Other & 700-709 & 1 & 0 & 2 \\
\hline $\begin{array}{l}\text { MUSCULOSKELETAL \& CONNECTIVE } \\
\text { TISSUE }\end{array}$ & 710-739 & 13 & 2 & 26 \\
\hline -Arthropathies & 710-719 & 3 & 0 & 7 \\
\hline -Dorsopathies & $720-724$ & 7 & 1 & 12 \\
\hline -Rheumatism, Excluding Back & 725-729 & 1 & 1 & 6 \\
\hline -Other Dis \& Acquired Deformities & 730-739 & 2 & 0 & 1 \\
\hline CONGENITAL ANOMALIES & 740-759 & 1 & 0 & 0 \\
\hline $\begin{array}{l}\text { SYMPTOMS, SIGNS, \& ILL-DEFINED } \\
\text { CONDITIONS }\end{array}$ & \begin{tabular}{|l|}
$780-799$ \\
\end{tabular} & 9 & 2 & 7 \\
\hline -Symptoms & $780-789$ & 9 & 2 & 7 \\
\hline -Non-Specific Abnormal Findings & $790-796$ & 0 & 0 & 0 \\
\hline INJURY \& POISONING & $800-999$ & 15 & 1 & 10 \\
\hline -Fracture - Skull & $800-804$ & 1 & 0 & 0 \\
\hline -Fracture - Neck, Trunk & $805-809$ & 1 & 0 & 0 \\
\hline -Fracture - Upper Limb & 810-819 & 1 & 0 & 0 \\
\hline -Fracture - Lower Limb & $820-829$ & 2 & 0 & $\overline{0}$ \\
\hline -Dislocation & 830-839 & 0 & 0 & 0 \\
\hline -Sprains \& Strains - Back & $846-847$ & 0 & 0 & 1 \\
\hline -Sprains \& Strains - Other & $840-845,848$ & 4 & 0 & 4 \\
\hline
\end{tabular}

(Continued)

*Only those diagnostic categories and gender/job category combinations with at least one occurrence appear in this table. 


\section{Brookhaven National Laboratory 2008}

Absence Data

Appendix I. Number of Diagnoses in Each Diagnostic Category by Gender and Job Category*

\begin{tabular}{|c|c|c|c|c|c|}
\hline & & \multicolumn{4}{|c|}{ Men } \\
\hline & & \multicolumn{3}{|c|}{ Job Category } & \multirow[b]{2}{*}{ TOTAL } \\
\hline & & Service & Security and Fire & Crafts & \\
\hline Diagnostic Category & ICD-9-CM Code & \multirow[b]{2}{*}{1} & \multirow[b]{2}{*}{0} & \multirow[b]{2}{*}{5} & \multirow[b]{2}{*}{13} \\
\hline -Pneumonia \& Influenza & $480-487$ & & & & \\
\hline -Chronic Obstructive Dis & $490-496$ & 5 & 1 & 5 & 18 \\
\hline -Lung Dis from External Agents & $500-508$ & 0 & 0 & 0 & 1 \\
\hline DIGESTIVE SYSTEM & $520-579$ & 11 & 1 & 5 & 33 \\
\hline -Oral Cavity, Saliva Glands, Jaw & $520-529$ & 1 & 1 & 1 & 5 \\
\hline -Esophagus, Stomach, Duodenum & $530-537$ & 1 & 0 & 0 & 3 \\
\hline -Appendicitis & $540-543$ & 0 & 0 & 0 & 2 \\
\hline -Hernia & $550-553$ & 2 & 0 & 2 & 9 \\
\hline -Enteritis, Colitis & $555-558$ & 3 & 0 & 1 & 6 \\
\hline -Other Intestinal Dis & $560-569$ & 3 & 0 & 0 & 5 \\
\hline -Other Digestive Dis & $570-579$ & 1 & 0 & 1 & 3 \\
\hline GENITOURINARY SYSTEM & $580-629$ & 6 & 0 & 0 & 8 \\
\hline -Other Urinary Dis & $590-599$ & 3 & 0 & 0 & 4 \\
\hline -Male Genital Organ Dis & $600-608$ & 3 & 0 & 0 & 4 \\
\hline SKIN \& SUBCUTANEOUS TISSUE & 680-709 & 1 & 1 & 5 & 12 \\
\hline -Infections & $680-686$ & 1 & 0 & 3 & 5 \\
\hline -Other Inflammatory Conditions & $690-698$ & 0 & 1 & 1 & 3 \\
\hline -Other & 700-709 & 0 & 0 & 1 & 4 \\
\hline $\begin{array}{l}\text { MUSCULOSKELETAL \& CONNECTIVE } \\
\text { TISSUE }\end{array}$ & $710-739$ & 50 & 25 & 30 & 146 \\
\hline -Arthropathies & $710-719$ & 14 & 9 & 16 & 49 \\
\hline -Dorsopathies & $720-724$ & 30 & 10 & 11 & 71 \\
\hline -Rheumatism, Excluding Back & 725-729 & 6 & 6 & 3 & 23 \\
\hline -Other Dis \& Acquired Deformities & $730-739$ & 0 & 0 & 0 & 3 \\
\hline CONGENITAL ANOMALIES & $740-759$ & 0 & 0 & 0 & 1 \\
\hline $\begin{array}{l}\text { SYMPTOMS, SIGNS, \& ILL-DEFINED } \\
\text { CONDITIONS }\end{array}$ & 780-799 & 14 & 5 & 11 & 48 \\
\hline -Symptoms & $780-789$ & 12 & 5 & 9 & 44 \\
\hline -Non-Specific Abnormal Findings & $790-796$ & 2 & 0 & 2 & 4 \\
\hline INJURY \& POISONING & $800-999$ & 15 & 4 & 20 & 65 \\
\hline -Fracture - Skull & $800-804$ & 1 & 0 & 0 & 2 \\
\hline -Fracture - Neck, Trunk & 805-809 & 1 & 0 & 0 & 2 \\
\hline -Fracture - Upper Limb & 810-819 & 0 & 0 & 4 & 5 \\
\hline -Fracture - Lower Limb & $820-829$ & 1 & 1 & 2 & 6 \\
\hline -Dislocation & 830-839 & 1 & 0 & 0 & 1 \\
\hline -Sprains \& Strains - Back & $846-847$ & 3 & 0 & 6 & 10 \\
\hline -Sprains \& Strains - Other & $840-845,848$ & 1 & 3 & 3 & 15 \\
\hline
\end{tabular}

(Continued)

*Only those diagnostic categories and gender/job category combinations with at least one occurrence appear in this table. 
Brookhaven National Laboratory 2008

Absence Data

Appendix I. Number of Diagnoses in Each Diagnostic Category by Gender and Job Category*

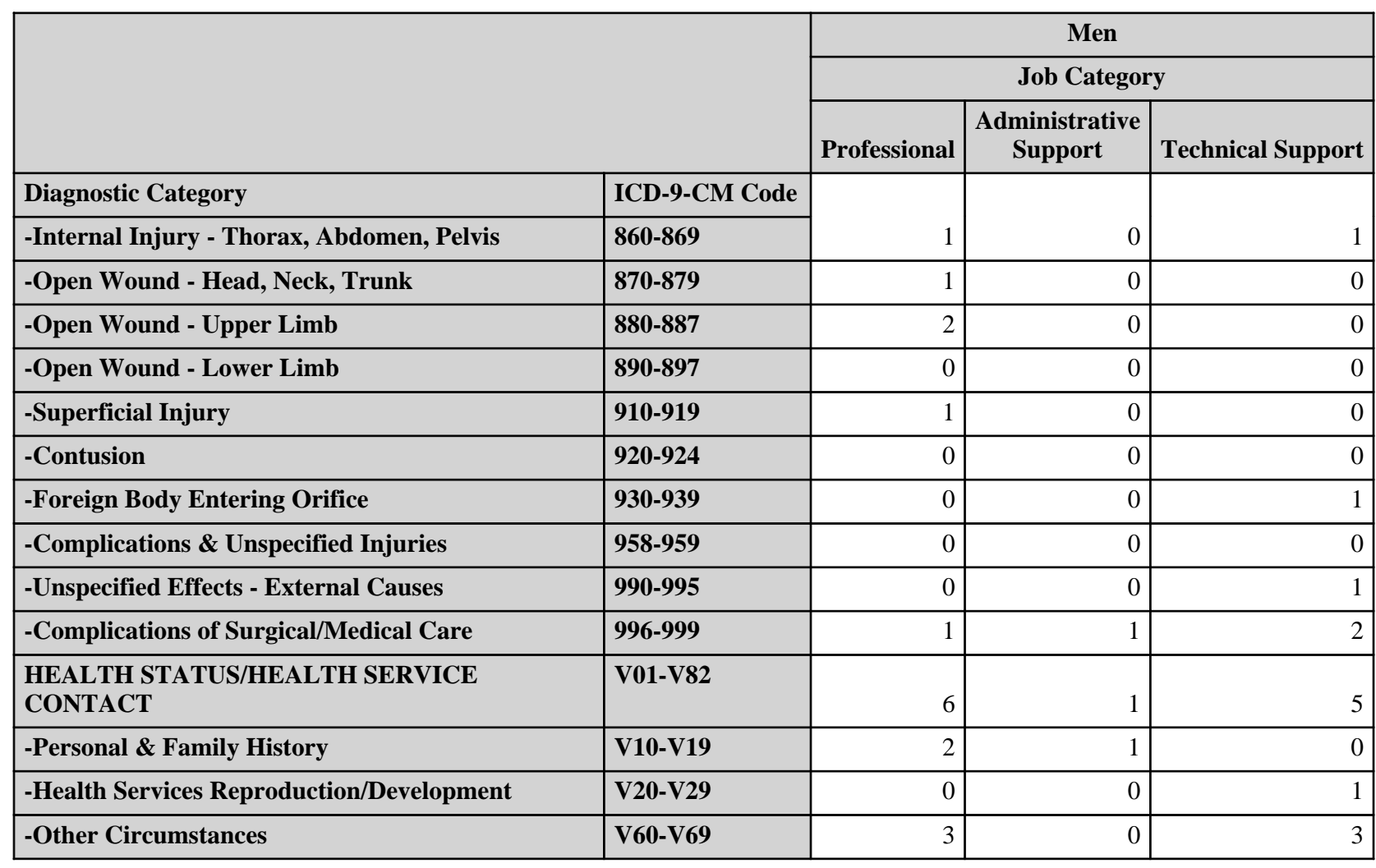

*Only those diagnostic categories and gender/job category combinations with at least one occurrence appear in this table. 
Brookhaven National Laboratory 2008

Absence Data

Appendix I. Number of Diagnoses in Each Diagnostic Category by Gender and Job Category*

\begin{tabular}{|c|c|c|c|c|c|}
\hline & & \multicolumn{4}{|c|}{ Men } \\
\hline & & \multicolumn{3}{|c|}{ Job Category } & \multirow[b]{2}{*}{ TOTAL } \\
\hline & & Service & Security and Fire & Crafts & \\
\hline Diagnostic Category & ICD-9-CM Code & \multirow[b]{2}{*}{0} & \multirow[b]{2}{*}{0} & \multirow[b]{2}{*}{0} & \multirow[b]{2}{*}{2} \\
\hline -Internal Injury - Thorax, Abdomen, Pelvis & $860-869$ & & & & \\
\hline -Open Wound - Head, Neck, Trunk & 870-879 & 2 & 0 & 0 & 3 \\
\hline -Open Wound - Upper Limb & 880-887 & 0 & 0 & 1 & 3 \\
\hline -Open Wound - Lower Limb & 890-897 & 1 & 0 & 1 & 2 \\
\hline -Superficial Injury & $910-919$ & 0 & 0 & 0 & 1 \\
\hline -Contusion & $920-924$ & 2 & 0 & 0 & 2 \\
\hline -Foreign Body Entering Orifice & 930-939 & 0 & 0 & 0 & 1 \\
\hline -Complications \& Unspecified Injuries & $958-959$ & 0 & 0 & 1 & 1 \\
\hline -Unspecified Effects - External Causes & $990-995$ & 0 & 0 & 2 & 3 \\
\hline -Complications of Surgical/Medical Care & 996-999 & 2 & 0 & 0 & 6 \\
\hline $\begin{array}{l}\text { HEALTH STATUS/HEALTH SERVICE } \\
\text { CONTACT }\end{array}$ & V01-V82 & 1 & 1 & 2 & 16 \\
\hline -Personal \& Family History & V10-V19 & 0 & 0 & 0 & 3 \\
\hline -Health Services Reproduction/Development & V20-V29 & 0 & 1 & 0 & 2 \\
\hline -Other Circumstances & V60-V69 & 1 & 0 & 2 & 9 \\
\hline
\end{tabular}

\begin{tabular}{|c|c|c|c|c|c|c|c|}
\hline & \multicolumn{7}{|c|}{ Men } \\
\hline & \multicolumn{6}{|c|}{ Job Category } & \multirow[b]{2}{*}{ TOTAL } \\
\hline & Professional & $\begin{array}{c}\text { Administrative } \\
\text { Support }\end{array}$ & Technical Support & Service & Security and Fire & Crafts & \\
\hline Diagnostic Category & \multirow[b]{2}{*}{116} & \multirow[b]{2}{*}{12} & \multirow[b]{2}{*}{91} & \multirow[b]{2}{*}{146} & \multirow[b]{2}{*}{48} & \multirow[b]{2}{*}{109} & \multirow[b]{2}{*}{522} \\
\hline Total & & & & & & & \\
\hline
\end{tabular}

*Only those diagnostic categories and gender/job category combinations with at least one occurrence appear in this table. 
Brookhaven National Laboratory 2008

Absence Data

Appendix J. Total Number of Calendar Days Absent in Each Diagnostic Category by Gender and Job Category*

\begin{tabular}{|c|c|c|c|c|c|c|}
\hline & & \multicolumn{5}{|c|}{ Women } \\
\hline & & \multicolumn{5}{|c|}{ Job Category } \\
\hline & & Professional & $\begin{array}{l}\text { Administrative } \\
\text { Support }\end{array}$ & $\begin{array}{l}\text { Technical } \\
\text { Support }\end{array}$ & Service & $\begin{array}{l}\text { Security } \\
\text { and Fire }\end{array}$ \\
\hline Diagnostic Category & ICD-9-CM Code & \multirow[b]{2}{*}{41} & \multirow[b]{2}{*}{4} & \multirow[b]{2}{*}{0} & \multirow[b]{2}{*}{43} & \multirow[b]{2}{*}{0} \\
\hline INFECTIOUS \& PARASITIC DISEASES (DIS) & 001-139 & & & & & \\
\hline MALIGNANT NEOPLASMS & $140-208,230-234$ & 0 & 27 & 0 & 0 & 0 \\
\hline BENIGN \& UNCERTAIN NEOPLASMS & 210-229, 235-239 & 14 & 0 & 0 & 85 & 0 \\
\hline ENDOCRINE/METABOLIC/IMMUNITY & $240-279$ & 13 & 0 & 0 & 0 & 186 \\
\hline MENTAL DISORDERS & 290-319 & 4 & 8 & 0 & 0 & 0 \\
\hline NERVOUS SYSTEM (NS) \& SENSE ORGANS & 320-389 & 127 & 31 & 44 & 49 & 188 \\
\hline CIRCULATORY SYSTEM & $390-459$ & 27 & 44 & 70 & 105 & 0 \\
\hline RESPIRATORY SYSTEM & $460-519$ & 27 & 143 & 25 & 103 & 12 \\
\hline DIGESTIVE SYSTEM & $520-579$ & 35 & 117 & 70 & 35 & 0 \\
\hline GENITOURINARY SYSTEM & $580-629$ & 111 & 11 & 6 & 87 & 3 \\
\hline SKIN \& SUBCUTANEOUS TISSUE & $680-709$ & 17 & 0 & 0 & 3 & 0 \\
\hline $\begin{array}{l}\text { MUSCULOSKELETAL \& CONNECTIVE } \\
\text { TISSUE }\end{array}$ & $710-739$ & 325 & 166 & 21 & 207 & 6 \\
\hline $\begin{array}{l}\text { SYMPTOMS, SIGNS, \& ILL-DEFINED } \\
\text { CONDITIONS }\end{array}$ & 780-799 & 30 & 59 & 27 & 8 & 6 \\
\hline INJURY \& POISONING & $800-999$ & 284 & 38 & 28 & 104 & 0 \\
\hline
\end{tabular}

\footnotetext{
*Absences with >1 ICD-9-CM code in the same diagnostic category were counted only once. Only those diagnostic categories and gender/job category combinations with at least one occurrence appear in this table.
} 
Brookhaven National Laboratory 2008

Absence Data

Appendix J. Total Number of Calendar Days Absent in Each Diagnostic Category by Gender and Job Category*

\begin{tabular}{|c|c|c|}
\hline & Women \\
\hline & & TOTAL \\
\hline Diagnostic Category & ICD-9-CM Code & \multirow[b]{2}{*}{88} \\
\hline INFECTIOUS \& PARASITIC DISEASES (DIS) & 001-139 & \\
\hline MALIGNANT NEOPLASMS & $140-208,230-234$ & 27 \\
\hline BENIGN \& UNCERTAIN NEOPLASMS & 210-229, 235-239 & 99 \\
\hline ENDOCRINE/METABOLIC/IMMUNITY & $240-279$ & 199 \\
\hline MENTAL DISORDERS & $290-319$ & 12 \\
\hline NERVOUS SYSTEM (NS) \& SENSE ORGANS & 320-389 & 439 \\
\hline CIRCULATORY SYSTEM & $390-459$ & 246 \\
\hline RESPIRATORY SYSTEM & $460-519$ & 310 \\
\hline DIGESTIVE SYSTEM & 520-579 & 257 \\
\hline GENITOURINARY SYSTEM & 580-629 & 218 \\
\hline SKIN \& SUBCUTANEOUS TISSUE & 680-709 & 20 \\
\hline $\begin{array}{l}\text { MUSCULOSKELETAL \& CONNECTIVE } \\
\text { TISSUE }\end{array}$ & 710-739 & 725 \\
\hline $\begin{array}{l}\text { SYMPTOMS, SIGNS, \& ILL-DEFINED } \\
\text { CONDITIONS }\end{array}$ & 780-799 & 130 \\
\hline INJURY \& POISONING & $800-999$ & 454 \\
\hline
\end{tabular}

\footnotetext{
*Absences with >1 ICD-9-CM code in the same diagnostic category were counted only once. Only those diagnostic categories and gender/job category combinations with at least one occurrence appear in this table.
} 
Brookhaven National Laboratory 2008

Absence Data

Appendix J. Total Number of Calendar Days Absent in Each Diagnostic Category by Gender and Job Category*

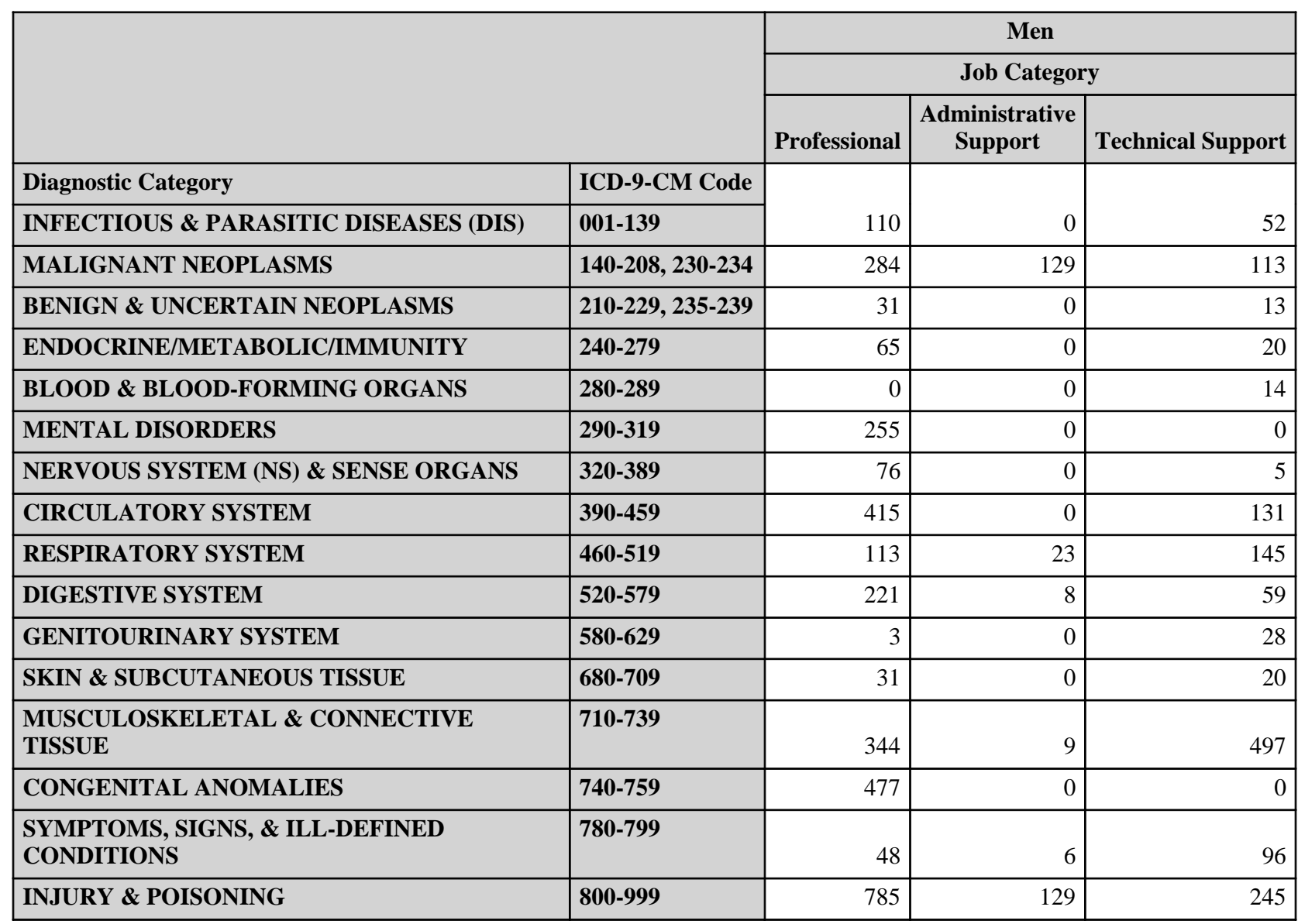

\footnotetext{
*Absences with >1 ICD-9-CM code in the same diagnostic category were counted only once. Only those diagnostic categories and gender/job category combinations with at least one occurrence appear in this table.
} 
Brookhaven National Laboratory 2008

Absence Data

Appendix J. Total Number of Calendar Days Absent in Each Diagnostic Category by Gender and Job Category*

\begin{tabular}{|c|c|c|c|c|c|}
\hline & & \multicolumn{4}{|c|}{ Men } \\
\hline & & \multicolumn{3}{|c|}{ Job Category } & \multirow[b]{2}{*}{ TOTAL } \\
\hline & & Service & Security and Fire & Crafts & \\
\hline Diagnostic Category & ICD-9-CM Code & \multirow[b]{2}{*}{59} & \multirow[b]{2}{*}{0} & \multirow[b]{2}{*}{24} & \multirow[b]{2}{*}{245} \\
\hline INFECTIOUS \& PARASITIC DISEASES (DIS) & 001-139 & & & & \\
\hline MALIGNANT NEOPLASMS & $140-208,230-234$ & 61 & 0 & 0 & 587 \\
\hline BENIGN \& UNCERTAIN NEOPLASMS & 210-229, 235-239 & 0 & 10 & 49 & 103 \\
\hline ENDOCRINE/METABOLIC/IMMUNITY & $240-279$ & 24 & 0 & 28 & 137 \\
\hline BLOOD \& BLOOD-FORMING ORGANS & $280-289$ & 12 & 0 & 0 & 26 \\
\hline MENTAL DISORDERS & 290-319 & 0 & 0 & 5 & 260 \\
\hline NERVOUS SYSTEM (NS) \& SENSE ORGANS & $320-389$ & 90 & 433 & 100 & 704 \\
\hline CIRCULATORY SYSTEM & $390-459$ & 60 & 123 & 35 & 764 \\
\hline RESPIRATORY SYSTEM & $460-519$ & 108 & 30 & 153 & 572 \\
\hline DIGESTIVE SYSTEM & $520-579$ & 97 & 3 & 134 & 522 \\
\hline GENITOURINARY SYSTEM & $580-629$ & 69 & 0 & 0 & 100 \\
\hline SKIN \& SUBCUTANEOUS TISSUE & 680-709 & 9 & 18 & 65 & 143 \\
\hline $\begin{array}{l}\text { MUSCULOSKELETAL \& CONNECTIVE } \\
\text { TISSUE }\end{array}$ & 710-739 & 990 & 612 & 359 & 2,811 \\
\hline CONGENITAL ANOMALIES & $740-759$ & 0 & 0 & 0 & 477 \\
\hline $\begin{array}{l}\text { SYMPTOMS, SIGNS, \& ILL-DEFINED } \\
\text { CONDITIONS }\end{array}$ & 780-799 & 85 & 14 & 93 & 342 \\
\hline INJURY \& POISONING & $800-999$ & 223 & 193 & 286 & 1,861 \\
\hline
\end{tabular}

\footnotetext{
*Absences with >1 ICD-9-CM code in the same diagnostic category were counted only once. Only those diagnostic categories and gender/job category combinations with at least one occurrence appear in this table.
} 


\section{Brookhaven National Laboratory 2008}

Absence Data

Appendix K. Age-Adjusted IIIness and Injury Rates by Diagnostic Category*

Part 1. Men

\begin{tabular}{|c|c|c|c|c|c|}
\hline & & $\begin{array}{l}\text { Number of } \\
\text { Diagnoses }\end{array}$ & $\begin{array}{c}\text { Age-Adjusted } \\
\text { Rate per } 1,000 * *\end{array}$ & $\begin{array}{c}\text { Lower } 95 \% \\
\text { Confidence } \\
\text { Limit per 1,000 }\end{array}$ & $\begin{array}{c}\text { Upper } 95 \% \\
\text { Confidence } \\
\text { Limit per } 1,000\end{array}$ \\
\hline Diagnostic Category & ICD-9-CM Code & \multirow[b]{2}{*}{17} & \multirow[b]{2}{*}{5.5} & \multirow[b]{2}{*}{3.4} & \multirow[b]{2}{*}{9.0} \\
\hline INFECTIOUS \& PARASITIC DISEASES (DIS) & 001-139 & & & & \\
\hline -Intestinal Infectious Dis & 001-009 & 4 & 1.2 & 0.5 & 3.3 \\
\hline -Other Bacterial Dis & 030-041 & 2 & 0.6 & 0.1 & 2.5 \\
\hline -Viral Dis with Exanthem & 050-057 & 5 & 1.5 & 0.6 & 3.6 \\
\hline -Other Viral Dis \& Chlamydiae & 070-079 & 6 & 2.2 & 0.9 & 5.1 \\
\hline MALIGNANT NEOPLASMS & $140-208,230-234$ & 16 & 4.8 & 2.9 & 7.9 \\
\hline -Lip, Oral Cavity, Pharynx & $140-149$ & 1 & 0.4 & 0.1 & 2.6 \\
\hline -Digestive \& Peritoneal & $150-159$ & 3 & 0.9 & 0.3 & 2.9 \\
\hline -Respiratory \& Intrathoracic & $160-165$ & 1 & 0.3 & 0.0 & 2.2 \\
\hline -Bone, Connective Tissue, Skin & $170-173,176$ & 1 & 0.4 & 0.1 & 2.6 \\
\hline -Genitourinary & 179-189 & 4 & 1.2 & 0.5 & 3.3 \\
\hline -Other \& Unspecified Sites & 190, 193-199 & 6 & 1.6 & 0.7 & 3.6 \\
\hline BENIGN \& UNCERTAIN NEOPLASMS & 210-229, 235-239 & 6 & 1.8 & 0.8 & 4.0 \\
\hline ENDOCRINE/METABOLIC/IMMUNITY & $240-279$ & 10 & 2.9 & 1.6 & 5.5 \\
\hline -Thyroid Gland Disorders & $240-246$ & 1 & 0.2 & 0.0 & 1.8 \\
\hline -Other Endocrine Gland Dis & 250-259 & 2 & 0.6 & 0.1 & 2.2 \\
\hline -Other Metabolic \& Immunity Disorders & $270-279$ & 7 & 2.1 & 1.0 & 4.5 \\
\hline BLOOD \& BLOOD-FORMING ORGANS & $280-289$ & 2 & 0.7 & 0.2 & 2.7 \\
\hline MENTAL DISORDERS & 290-319 & 5 & 1.5 & 0.6 & 3.7 \\
\hline -Psychoses & 290-299 & 2 & 0.6 & 0.1 & 2.2 \\
\hline -Non-Psychotic Disorders & $300-302,306-316$ & 3 & 1.0 & 0.3 & 3.0 \\
\hline NERVOUS SYSTEM (NS) \& SENSE ORGANS & 320-389 & 17 & 5.6 & 3.4 & 9.2 \\
\hline -Other Disorders of Central NS & 340-349 & 1 & 0.2 & 0.0 & 1.8 \\
\hline -Disorders of Peripheral NS & $350-359$ & 4 & 1.2 & 0.5 & 3.3 \\
\hline -Disorders of Eye & $360-379$ & 8 & 2.4 & 1.2 & 4.8 \\
\hline -Dis of Ear \& Mastoid & 380-389 & 4 & 1.8 & 0.6 & 4.9 \\
\hline CIRCULATORY SYSTEM & $390-459$ & 39 & 10.8 & 7.8 & 14.8 \\
\hline -Hypertensive Dis & $401-405$ & 10 & 2.6 & 1.4 & 4.9 \\
\hline -Ischemic Heart Dis & $410-414$ & 11 & 3.1 & 1.7 & 5.7 \\
\hline -Other Heart Dis & 420-429 & 8 & 2.3 & 1.2 & 4.7 \\
\hline -Cerebrovascular Dis & $430-438$ & 4 & 1.0 & 0.4 & 2.6 \\
\hline -Dis of Arteries \& Capillaries & $440-448$ & 3 & 0.9 & 0.3 & 2.8 \\
\hline -Dis of Veins, Lymphatics, Other & $451-459$ & 3 & 0.7 & 0.2 & 2.3 \\
\hline RESPIRATORY SYSTEM & $460-519$ & 81 & 32.7 & 24.7 & 43.2 \\
\hline -Acute Respiratory Infections & $460-466$ & 32 & 11.6 & 8.0 & 16.7 \\
\hline
\end{tabular}

(Continued)

*Only those diagnostic categories with at least one occurrence appear in this table.

**Standardized to age distribution of 2000 U.S. population. 


\section{Brookhaven National Laboratory 2008}

Absence Data

Appendix K. Age-Adjusted IIIness and Injury Rates by Diagnostic Category*

Part 1. Men

\begin{tabular}{|c|c|c|c|c|c|}
\hline & & $\begin{array}{c}\text { Number of } \\
\text { Diagnoses }\end{array}$ & $\begin{array}{c}\text { Age-Adjusted } \\
\text { Rate per } 1,000^{* *}\end{array}$ & \begin{tabular}{c|} 
Lower $95 \%$ \\
Confidence \\
Limit per 1,000
\end{tabular} & $\begin{array}{c}\text { Upper } 95 \% \\
\text { Confidence } \\
\text { Limit per 1,000 }\end{array}$ \\
\hline Diagnostic Category & ICD-9-CM Code & & & & \\
\hline -Other Dis Upper Respiratory Tract & $470-478$ & 17 & 6.6 & 4.0 & 10.9 \\
\hline -Pneumonia \& Influenza & $\begin{array}{ll}480-487 \\
4\end{array}$ & 13 & 3.9 & 2.2 & 6.7 \\
\hline -Chronic Obstructive Dis & $490-496$ & 18 & 10.4 & 5.2 & 20.5 \\
\hline -Lung Dis from External Agents & $500-508$ & 1 & 0.2 & 0.0 & 1.8 \\
\hline DIGESTIVE SYSTEM & $520-579$ & 33 & 10.6 & 7.5 & 15.1 \\
\hline -Oral Cavity, Saliva Glands, Jaw & $520-529$ & 5 & 1.7 & 0.7 & 4.0 \\
\hline -Esophagus, Stomach, Duodenum & 530-537 & 3 & 1.0 & 0.3 & 3.2 \\
\hline -Appendicitis & $\begin{array}{l}540-543 \\
\end{array}$ & 2 & 0.6 & 0.1 & 2.5 \\
\hline -Hernia & $550-553$ & 9 & 2.6 & 1.3 & 5.0 \\
\hline -Enteritis, Colitis & $555-558$ & 6 & 2.2 & 1.0 & 5.3 \\
\hline -Other Intestinal Dis & $560-569$ & 5 & 1.5 & 0.6 & 3.6 \\
\hline -Other Digestive Dis & 570-579 & 3 & 1.0 & 0.3 & 3.1 \\
\hline GENITOURINARY SYSTEM & 580-629 & 8 & 2.5 & 1.2 & 5.3 \\
\hline -Other Urinary Dis & 590-599 & 4 & 1.5 & 0.5 & 4.4 \\
\hline -Male Genital Organ Dis & $600-608$ & 4 & 1.0 & 0.4 & 2.6 \\
\hline SKIN \& SUBCUTANEOUS TISSUE & 680-709 & 12 & 4.4 & 2.4 & 8.0 \\
\hline -Infections & 680-686 & 5 & 1.5 & 0.6 & 3.6 \\
\hline -Other Inflammatory Conditions & 690-698 & 3 & 1.0 & 0.3 & 3.2 \\
\hline -Other & 700-709 & 4 & 1.9 & 0.6 & 5.3 \\
\hline $\begin{array}{l}\text { MUSCULOSKELETAL \& CONNECTIVE } \\
\text { TISSUE }\end{array}$ & 710-739 & 146 & 47.7 & 40.3 & 56.5 \\
\hline -Arthropathies & 710-719 & 49 & 17.1 & 12.7 & 22.9 \\
\hline -Dorsopathies & 720-724 & 71 & 23.0 & 18.1 & 29.2 \\
\hline -Rheumatism, Excluding Back & 725-729 & 23 & 6.8 & 4.4 & 10.4 \\
\hline -Other Dis \& Acquired Deformities & 730-739 & 3 & 0.9 & 0.3 & 2.7 \\
\hline CONGENITAL ANOMALIES & 740-759 & 1 & 0.4 & 0.1 & 2.6 \\
\hline $\begin{array}{l}\text { SYMPTOMS, SIGNS, \& ILL-DEFINED } \\
\text { CONDITIONS }\end{array}$ & 780-799 & 48 & 24.1 & 15.9 & 36.7 \\
\hline -Symptoms & 780-789 & 44 & 22.9 & 14.8 & 35.5 \\
\hline -Non-Specific Abnormal Findings & 790-796 & 4 & 1.2 & 0.5 & 3.3 \\
\hline INJURY \& POISONING & $800-999$ & 65 & 23.8 & 17.6 & 32.1 \\
\hline -Fracture - Skull & $800-804$ & 4 & 1.7 & 0.6 & 4.7 \\
\hline -Fracture - Upper Limb & $810-819$ & 5 & 1.9 & 0.7 & 4.8 \\
\hline -Fracture - Lower Limb & $820-829$ & 6 & 1.8 & 0.8 & 4.2 \\
\hline -Dislocation & 830-839 & 1 & 0.4 & 0.1 & 2.6 \\
\hline -Sprains \& Strains - Back & 846-847 & 10 & 3.0 & 1.6 & 5.7 \\
\hline
\end{tabular}

(Continued)

*Only those diagnostic categories with at least one occurrence appear in this table.

**Standardized to age distribution of 2000 U.S. population. 
Brookhaven National Laboratory 2008

Absence Data

Appendix K. Age-Adjusted Illness and Injury Rates by Diagnostic Category*

Part 1. Men

\begin{tabular}{|c|c|c|c|c|c|}
\hline & & $\begin{array}{l}\text { Number of } \\
\text { Diagnoses }\end{array}$ & $\begin{array}{c}\text { Age-Adjusted } \\
\text { Rate per } 1,000 * *\end{array}$ & $\begin{array}{c}\text { Lower } 95 \% \\
\text { Confidence } \\
\text { Limit per 1,000 }\end{array}$ & $\begin{array}{c}\text { Upper } 95 \% \\
\text { Confidence } \\
\text { Limit per 1,000 }\end{array}$ \\
\hline Diagnostic Category & ICD-9-CM Code & \multirow[b]{2}{*}{15} & \multirow[b]{2}{*}{7.2} & \multirow[b]{2}{*}{3.5} & \multirow[b]{2}{*}{14.9} \\
\hline -Sprains \& Strains - Other & $840-845,848$ & & & & \\
\hline -Internal Injury - Thorax, Abdomen, Pelvis & $860-869$ & 2 & 1.0 & 0.2 & 4.2 \\
\hline -Open Wound - Head, Neck, Trunk & 870-879 & 8 & 2.8 & 1.4 & 5.5 \\
\hline -Superficial Injury & $910-919$ & 1 & 0.4 & 0.1 & 2.6 \\
\hline -Contusion & $920-924$ & 2 & 0.6 & 0.1 & 2.5 \\
\hline -Foreign Body Entering Orifice & $930-939$ & 1 & 0.7 & 0.1 & 4.6 \\
\hline -Complications \& Unspecified Injuries & 958-959 & 1 & 0.2 & 0.0 & 1.8 \\
\hline -Unspecified Effects - External Causes & $990-995$ & 3 & 0.7 & 0.2 & 2.3 \\
\hline -Complications of Surgical/Medical Care & 996-999 & 6 & 1.5 & 0.7 & 3.3 \\
\hline Total & & 506 & 179.8 & 161.6 & 200.0 \\
\hline
\end{tabular}

* Only those diagnostic categories with at least one occurrence appear in this table.

**Standardized to age distribution of 2000 U.S. population. 


\section{Brookhaven National Laboratory 2008}

Absence Data

Appendix K. Age-Adjusted Illness and Injury Rates by Diagnostic Category*

Part 2. Women

\begin{tabular}{|c|c|c|c|c|c|}
\hline & & $\begin{array}{l}\text { Number of } \\
\text { Diagnoses }\end{array}$ & $\begin{array}{c}\text { Age-Adjusted } \\
\text { Rate per } 1,000 * *\end{array}$ & $\begin{array}{c}\text { Lower } 95 \% \\
\text { Confidence } \\
\text { Limit per 1,000 }\end{array}$ & $\begin{array}{c}\text { Upper } 95 \% \\
\text { Confidence } \\
\text { Limit per 1,000 }\end{array}$ \\
\hline Diagnostic Category & ICD-9-CM Code & \multirow[b]{2}{*}{8} & \multirow[b]{2}{*}{9.2} & \multirow[b]{2}{*}{3.6} & \multirow[b]{2}{*}{23.5} \\
\hline INFECTIOUS \& PARASITIC DISEASES (DIS) & 001-139 & & & & \\
\hline -Other Bacterial Dis & $030-041$ & 1 & 3.9 & 0.6 & 27.8 \\
\hline -Viral Dis with Exanthem & 050-057 & 4 & 3.0 & 1.1 & 8.0 \\
\hline -Other Viral Dis \& Chlamydiae & 070-079 & 1 & 1.0 & 0.1 & 6.8 \\
\hline MALIGNANT NEOPLASMS & $140-208,230-234$ & 4 & 3.5 & 1.3 & 9.8 \\
\hline -Breast & 174-175 & 2 & 1.9 & 0.4 & 8.1 \\
\hline -Genitourinary & 179-189 & 1 & 1.0 & 0.1 & 6.8 \\
\hline -Carcinoma in situ & $230-234$ & 1 & 0.7 & 0.1 & 4.8 \\
\hline BENIGN \& UNCERTAIN NEOPLASMS & 210-229, 235-239 & 3 & 3.3 & 1.0 & 11.1 \\
\hline ENDOCRINE/METABOLIC/IMMUNITY & $240-279$ & 3 & 2.3 & 0.7 & 7.3 \\
\hline -Other Endocrine Gland Dis & $250-259$ & 2 & 1.3 & 0.3 & 5.4 \\
\hline -Other Metabolic \& Immunity Disorders & $270-279$ & 1 & 1.0 & 0.1 & 6.8 \\
\hline MENTAL DISORDERS & 290-319 & 2 & 1.6 & 0.4 & 6.7 \\
\hline -Non-Psychotic Disorders & $300-302,306-316$ & 2 & 1.6 & 0.4 & 6.7 \\
\hline NERVOUS SYSTEM (NS) \& SENSE ORGANS & 320-389 & 20 & 23.1 & 13.8 & 38.7 \\
\hline -Other Disorders of Central NS & 340-349 & 3 & 2.6 & 0.8 & 8.2 \\
\hline -Disorders of Peripheral NS & $350-359$ & 8 & 7.1 & 3.5 & 14.4 \\
\hline -Disorders of Eye & $360-379$ & 3 & 3.2 & 1.0 & 9.9 \\
\hline -Dis of Ear \& Mastoid & 380-389 & 6 & 10.2 & 4.0 & 26.4 \\
\hline CIRCULATORY SYSTEM & $390-459$ & 14 & 10.8 & 6.3 & 18.5 \\
\hline -Hypertensive Dis & $401-405$ & 5 & 3.6 & 1.5 & 8.8 \\
\hline -Ischemic Heart Dis & $410-414$ & 2 & 1.3 & 0.3 & 5.4 \\
\hline -Other Heart Dis & $420-429$ & 3 & 2.0 & 0.6 & 6.2 \\
\hline -Cerebrovascular Dis & $430-438$ & 1 & 0.7 & 0.1 & 4.8 \\
\hline -Dis of Arteries \& Capillaries & $440-448$ & 1 & 1.2 & 0.2 & 8.8 \\
\hline -Dis of Veins, Lymphatics, Other & 451-459 & 2 & 1.9 & 0.5 & 7.7 \\
\hline RESPIRATORY SYSTEM & $460-519$ & 43 & 47.3 & 32.6 & 68.7 \\
\hline -Acute Respiratory Infections & $460-466$ & 15 & 13.8 & 8.0 & 23.6 \\
\hline -Other Dis Upper Respiratory Tract & $470-478$ & 8 & 10.5 & 4.3 & 25.4 \\
\hline -Pneumonia \& Influenza & $480-487$ & 8 & 6.8 & 3.3 & 13.9 \\
\hline -Chronic Obstructive Dis & $490-496$ & 11 & 15.6 & 7.2 & 33.8 \\
\hline -Other Respiratory Dis & $510-519$ & 1 & 0.7 & 0.1 & 4.8 \\
\hline DIGESTIVE SYSTEM & $520-579$ & 13 & 16.6 & 8.7 & 31.6 \\
\hline -Oral Cavity, Saliva Glands, Jaw & $520-529$ & 6 & 5.8 & 2.6 & 13.0 \\
\hline -Enteritis, Colitis & $555-558$ & 2 & 4.9 & 1.0 & 24.6 \\
\hline
\end{tabular}

(Continued)

*Only those diagnostic categories with at least one occurrence appear in this table.

**Standardized to age distribution of 2000 U.S. population. 


\section{Brookhaven National Laboratory 2008}

Absence Data

Appendix K. Age-Adjusted Illness and Injury Rates by Diagnostic Category*

Part 2. Women

\begin{tabular}{|c|c|c|c|c|c|}
\hline & & $\begin{array}{c}\text { Number of } \\
\text { Diagnoses }\end{array}$ & \begin{tabular}{|l} 
Age-Adjusted \\
Rate per 1,000**
\end{tabular} & \begin{tabular}{|c|} 
Lower $95 \%$ \\
Confidence \\
Limit per 1,000
\end{tabular} & $\begin{array}{c}\text { Upper } 95 \% \\
\text { Confidence } \\
\text { Limit per 1,000 }\end{array}$ \\
\hline Diagnostic Category & ICD-9-CM Code & & & & \\
\hline -Other Intestinal Dis & $560-569$ & 3 & 3.6 & 1.1 & 11.6 \\
\hline -Other Digestive Dis & 570-579 & 2 & 2.3 & 0.5 & 10.5 \\
\hline GENITOURINARY SYSTEM & $580-629$ & 14 & 15.8 & 8.2 & 30.3 \\
\hline -Other Urinary Dis & $590-599$ & 2 & 1.6 & 0.4 & 6.7 \\
\hline -Breast Disorders & 610-611 & 3 & 2.3 & 0.7 & 7.3 \\
\hline -Other Female Disorders & $617-629$ & 9 & 11.8 & 5.2 & 26.9 \\
\hline SKIN \& SUBCUTANEOUS TISSUE & 680-709 & 2 & 1.6 & 0.4 & 6.7 \\
\hline -Infections & $680-686$ & 1 & 1.0 & 0.1 & 6.8 \\
\hline -Other & 700-709 & 1 & 0.7 & 0.1 & 4.8 \\
\hline $\begin{array}{l}\text { MUSCULOSKELETAL \& CONNECTIVE } \\
\text { TISSUE }\end{array}$ & 710-739 & 50 & 45.2 & 33.8 & 60.3 \\
\hline -Arthropathies & 710-719 & 14 & 12.3 & 7.2 & 21.0 \\
\hline -Dorsopathies & 720-724 & 18 & 16.9 & 10.4 & 27.6 \\
\hline -Rheumatism, Excluding Back & 725-729 & 16 & 14.1 & 8.4 & 23.4 \\
\hline -Other Dis \& Acquired Deformities & 730-739 & 2 & 1.9 & 0.4 & 8.1 \\
\hline $\begin{array}{l}\text { SYMPTOMS, SIGNS, \& ILL-DEFINED } \\
\text { CONDITIONS }\end{array}$ & 780-799 & 40 & 45.7 & 31.7 & 65.8 \\
\hline -Symptoms & 780-789 & 38 & 44.1 & 30.3 & 64.0 \\
\hline -Non-Specific Abnormal Findings & $790-796$ & 2 & 1.6 & 0.4 & 6.7 \\
\hline INJURY \& POISONING & $800-999$ & 24 & 22.6 & 14.8 & 34.4 \\
\hline -Fracture - Skull & $800-804$ & 1 & 1.0 & 0.1 & 6.8 \\
\hline -Fracture - Upper Limb & $810-819$ & 1 & 1.0 & 0.1 & 6.8 \\
\hline -Fracture - Lower Limb & 820-829 & 4 & 4.0 & 1.4 & 11.4 \\
\hline -Sprains \& Strains - Back & $846-847$ & 2 & 2.6 & 0.6 & 11.0 \\
\hline -Sprains \& Strains - Other & $840-845,848$ & 5 & 4.9 & 1.9 & 12.5 \\
\hline -Intracranial Injury & $850-854$ & 2 & 1.9 & 0.5 & 7.7 \\
\hline -Superficial Injury & $910-919$ & 1 & 0.7 & 0.1 & 4.8 \\
\hline -Contusion & $920-924$ & 3 & 2.9 & 0.9 & 9.0 \\
\hline -Injury to Nerves \& Spinal Cord & $950-957$ & 1 & 0.7 & 0.1 & 4.8 \\
\hline -Complications \& Unspecified Injuries & 958-959 & 1 & 0.7 & 0.1 & 4.8 \\
\hline -Unspecified Effects - External Causes & $990-995$ & 2 & 1.6 & 0.4 & 6.7 \\
\hline -Complications of Surgical/Medical Care & 996-999 & 1 & 0.7 & 0.1 & 4.8 \\
\hline Total & & 240 & 248.6 & 214.2 & 288.4 \\
\hline
\end{tabular}

*Only those diagnostic categories with at least one occurrence appear in this table.

**Standardized to age distribution of 2000 U.S. population. 


\section{Brookhaven National Laboratory 2008}

\section{Absence Data}

Appendix K. Age-Adjusted IIIness and Injury Rates by Diagnostic Category*

Part 3. Men and Women

\begin{tabular}{|c|c|c|c|c|c|}
\hline & & $\begin{array}{l}\text { Number of } \\
\text { Diagnoses }\end{array}$ & $\begin{array}{c}\text { Age-Adjusted } \\
\text { Rate per } 1,000 * *\end{array}$ & $\begin{array}{c}\text { Lower } 95 \% \\
\text { Confidence } \\
\text { Limit per 1,000 }\end{array}$ & $\begin{array}{c}\text { Upper } 95 \% \\
\text { Confidence } \\
\text { Limit per 1,000 }\end{array}$ \\
\hline Diagnostic Category & ICD-9-CM Code & & & & \\
\hline INFECTIOUS \& PARASITIC DISEASES (DIS) & 001-139 & 25 & 7.1 & 4.2 & 11.9 \\
\hline -Intestinal Infectious Dis & 001-009 & 4 & 1.0 & 0.4 & 2.7 \\
\hline -Other Bacterial Dis & 030-041 & 3 & 1.9 & 0.4 & 8.7 \\
\hline -Viral Dis with Exanthem & 050-057 & 9 & 1.9 & 1.0 & 3.8 \\
\hline -Other Viral Dis \& Chlamydiae & 070-079 & 7 & 1.9 & 0.9 & 4.1 \\
\hline MALIGNANT NEOPLASMS & $140-208,230-234$ & 20 & 4.4 & 2.8 & 6.9 \\
\hline -Lip, Oral Cavity, Pharynx & 140-149 & 1 & 0.3 & 0.0 & 1.9 \\
\hline -Digestive \& Peritoneal & $150-159$ & 3 & 0.7 & 0.2 & 2.2 \\
\hline -Respiratory \& Intrathoracic & $160-165$ & 1 & 0.3 & 0.0 & 1.8 \\
\hline -Bone, Connective Tissue, Skin & $170-173,176$ & 1 & 0.3 & 0.0 & 1.9 \\
\hline -Breast & 174-175 & 2 & 0.4 & 0.1 & 1.8 \\
\hline -Genitourinary & 179-189 & 5 & 1.2 & 0.5 & 2.8 \\
\hline -Other \& Unspecified Sites & $190,193-199$ & 6 & 1.2 & 0.5 & 2.6 \\
\hline -Carcinoma in situ & $230-234$ & 1 & 0.2 & 0.0 & 1.3 \\
\hline BENIGN \& UNCERTAIN NEOPLASMS & $210-229,235-239$ & 9 & 2.2 & 1.1 & 4.5 \\
\hline ENDOCRINE/METABOLIC/IMMUNITY & $240-279$ & 13 & 2.9 & 1.7 & 5.0 \\
\hline -Thyroid Gland Disorders & $240-246$ & 1 & 0.2 & 0.0 & 1.3 \\
\hline -Other Endocrine Gland Dis & $250-259$ & 4 & 0.8 & 0.3 & 2.2 \\
\hline -Other Metabolic \& Immunity Disorders & $270-279$ & 8 & 1.9 & 1.0 & 3.9 \\
\hline BLOOD \& BLOOD-FORMING ORGANS & $280-289$ & 2 & 0.5 & 0.1 & 2.1 \\
\hline MENTAL DISORDERS & 290-319 & 7 & 1.7 & 0.8 & 3.5 \\
\hline -Psychoses & 290-299 & 2 & 0.4 & 0.1 & 1.8 \\
\hline -Non-Psychotic Disorders & $300-302,306-316$ & 5 & 1.2 & 0.5 & 3.0 \\
\hline NERVOUS SYSTEM (NS) \& SENSE ORGANS & 320-389 & 37 & 10.8 & 7.2 & 16.0 \\
\hline -Other Disorders of Central NS & 340-349 & 4 & 0.9 & 0.3 & 2.4 \\
\hline -Disorders of Peripheral NS & 350-359 & 12 & 2.8 & 1.6 & 4.9 \\
\hline -Disorders of Eye & $360-379$ & 11 & 2.6 & 1.4 & 4.8 \\
\hline -Dis of Ear \& Mastoid & 380-389 & 10 & 4.5 & 2.0 & 9.8 \\
\hline CIRCULATORY SYSTEM & $390-459$ & 53 & 11.2 & 8.5 & 14.7 \\
\hline -Hypertensive Dis & 401-405 & 15 & 3.0 & 1.8 & 5.1 \\
\hline -Ischemic Heart Dis & $410-414$ & 13 & 2.9 & 1.7 & 5.0 \\
\hline -Other Heart Dis & 420-429 & 11 & 2.3 & 1.3 & 4.2 \\
\hline -Cerebrovascular Dis & $430-438$ & 5 & 0.9 & 0.4 & 2.2 \\
\hline -Dis of Arteries \& Capillaries & \begin{tabular}{|l|}
$440-448$ \\
\end{tabular} & 4 & 1.0 & 0.4 & 2.7 \\
\hline -Dis of Veins, Lymphatics, Other & 451-459 & 5 & 1.1 & 0.4 & 2.6 \\
\hline
\end{tabular}

(Continued)

*Only those diagnostic categories with at least one occurrence appear in this table.

**Standardized to age distribution of 2000 U.S. population. 


\section{Brookhaven National Laboratory 2008}

\section{Absence Data}

Appendix K. Age-Adjusted Illness and Injury Rates by Diagnostic Category*

Part 3. Men and Women

\begin{tabular}{|c|c|c|c|c|c|}
\hline & & $\begin{array}{l}\text { Number of } \\
\text { Diagnoses }\end{array}$ & $\begin{array}{l}\text { Age-Adjusted } \\
\text { Rate per } 1,000 * *\end{array}$ & $\begin{array}{c}\text { Lower } 95 \% \\
\text { Confidence } \\
\text { Limit per 1,000 }\end{array}$ & $\begin{array}{c}\text { Upper } 95 \% \\
\text { Confidence } \\
\text { Limit per 1,000 }\end{array}$ \\
\hline Diagnostic Category & ICD-9-CM Code & \multirow[b]{2}{*}{124} & \multirow[b]{2}{*}{37.4} & \multirow[b]{2}{*}{29.8} & \multirow[b]{2}{*}{46.9} \\
\hline RESPIRATORY SYSTEM & $460-519$ & & & & \\
\hline -Acute Respiratory Infections & $460-466$ & 47 & 12.2 & 9.0 & 16.6 \\
\hline -Other Dis Upper Respiratory Tract & $470-478$ & 25 & 8.1 & 4.9 & 13.2 \\
\hline -Pneumonia \& Influenza & $480-487$ & 21 & 4.8 & 3.1 & 7.3 \\
\hline -Chronic Obstructive Dis & $490-496$ & 29 & 12.0 & 7.1 & 20.1 \\
\hline -Lung Dis from External Agents & $500-508$ & 1 & 0.2 & 0.0 & 1.3 \\
\hline -Other Respiratory Dis & $510-519$ & 1 & 0.2 & 0.0 & $\overline{1.3}$ \\
\hline DIGESTIVE SYSTEM & $520-579$ & 46 & 12.8 & 9.1 & 18.1 \\
\hline -Oral Cavity, Saliva Glands, Jaw & $520-529$ & 11 & 2.7 & 1.5 & 5.0 \\
\hline -Esophagus, Stomach, Duodenum & $530-537$ & 3 & 0.8 & 0.3 & 2.4 \\
\hline -Appendicitis & $540-543$ & 2 & 0.4 & 0.1 & 1.8 \\
\hline -Hernia & $550-553$ & 9 & 2.0 & 1.0 & 3.9 \\
\hline -Enteritis, Colitis & $555-558$ & 8 & 3.3 & 1.3 & 8.7 \\
\hline -Other Intestinal Dis & $560-569$ & 8 & 2.1 & 1.0 & 4.4 \\
\hline -Other Digestive Dis & $570-579$ & 5 & 1.4 & 0.5 & 3.5 \\
\hline GENITOURINARY SYSTEM & $580-629$ & 22 & 6.6 & 3.8 & 11.5 \\
\hline -Other Urinary Dis & $590-599$ & 6 & 1.6 & 0.7 & 3.7 \\
\hline -Male Genital Organ Dis & $600-608$ & 4 & 0.7 & 0.3 & 1.9 \\
\hline -Breast Disorders & $610-611$ & 3 & 0.6 & 0.2 & 2.0 \\
\hline -Other Female Disorders & 617-629 & 9 & 3.6 & 1.5 & 8.9 \\
\hline SKIN \& SUBCUTANEOUS TISSUE & $680-709$ & 14 & 3.7 & 2.1 & 6.4 \\
\hline -Infections & $680-686$ & 6 & 1.3 & 0.6 & 3.0 \\
\hline -Other Inflammatory Conditions & $690-698$ & 3 & 0.8 & 0.3 & 2.4 \\
\hline -Other & 700-709 & 5 & 1.5 & 0.6 & 4.0 \\
\hline $\begin{array}{l}\text { MUSCULOSKELETAL \& CONNECTIVE } \\
\text { TISSUE }\end{array}$ & $710-739$ & 196 & 47.6 & 41.1 & 55.0 \\
\hline -Arthropathies & $710-719$ & 63 & 15.9 & 12.3 & 20.6 \\
\hline -Dorsopathies & $720-724$ & 89 & 21.6 & 17.4 & 26.7 \\
\hline -Rheumatism, Excluding Back & $725-729$ & 39 & 8.9 & 6.4 & 12.4 \\
\hline -Other Dis \& Acquired Deformities & $730-739$ & 5 & 1.1 & 0.5 & 2.7 \\
\hline CONGENITAL ANOMALIES & $740-759$ & 1 & 0.3 & 0.0 & 1.9 \\
\hline $\begin{array}{l}\text { SYMPTOMS, SIGNS, \& ILL-DEFINED } \\
\text { CONDITIONS }\end{array}$ & 780-799 & 88 & 30.1 & 22.8 & 39.9 \\
\hline -Symptoms & $780-789$ & 82 & 28.8 & 21.5 & 38.5 \\
\hline -Non-Specific Abnormal Findings & 790-796 & 6 & 1.3 & 0.6 & 3.0 \\
\hline INJURY \& POISONING & 800-999 & 89 & 23.5 & 18.5 & 29.8 \\
\hline
\end{tabular}

(Continued)

*Only those diagnostic categories with at least one occurrence appear in this table.

**Standardized to age distribution of 2000 U.S. population. 
Brookhaven National Laboratory 2008

Absence Data

Appendix K. Age-Adjusted Illness and Injury Rates by Diagnostic Category*

Part 3. Men and Women

\begin{tabular}{|c|c|c|c|c|c|}
\hline & & $\begin{array}{c}\text { Number of } \\
\text { Diagnoses }\end{array}$ & $\begin{array}{c}\text { Age-Adjusted } \\
\text { Rate per 1,000** }\end{array}$ & $\begin{array}{c}\text { Lower } 95 \% \\
\text { Confidence } \\
\text { Limit per 1,000 }\end{array}$ & $\begin{array}{c}\text { Upper 95\% } \\
\text { Confidence } \\
\text { Limit per 1,000 }\end{array}$ \\
\hline Diagnostic Category & ICD-9-CM Code & \multirow[b]{2}{*}{5} & \multirow[b]{2}{*}{1.5} & \multirow[b]{2}{*}{0.6} & \multirow[b]{2}{*}{3.8} \\
\hline -Fracture - Skull & $800-804$ & & & & \\
\hline -Fracture - Upper Limb & 810-819 & 6 & 1.6 & 0.7 & 3.8 \\
\hline -Fracture - Lower Limb & 820-829 & 10 & 2.4 & 1.3 & 4.7 \\
\hline -Dislocation & 830-839 & 1 & 0.3 & 0.0 & 1.9 \\
\hline -Sprains \& Strains - Back & 846-847 & 12 & 3.0 & 1.6 & 5.4 \\
\hline -Sprains \& Strains - Other & $840-845,848$ & 20 & 6.4 & 3.6 & 11.3 \\
\hline -Intracranial Injury & $850-854$ & 2 & 0.5 & 0.1 & 2.1 \\
\hline -Internal Injury - Thorax, Abdomen, Pelvis & $860-869$ & 2 & 0.7 & 0.2 & 3.1 \\
\hline -Open Wound - Head, Neck, Trunk & 870-879 & 8 & 2.1 & 1.0 & 4.2 \\
\hline -Superficial Injury & $910-919$ & 2 & 0.4 & 0.1 & 1.8 \\
\hline -Contusion & $920-924$ & 5 & 1.2 & 0.5 & 3.0 \\
\hline -Foreign Body Entering Orifice & $930-939$ & 1 & 0.5 & 0.1 & 3.3 \\
\hline -Injury to Nerves \& Spinal Cord & $950-957$ & 1 & 0.2 & 0.0 & 1.3 \\
\hline -Complications \& Unspecified Injuries & 958-959 & 2 & 0.4 & 0.1 & 1.5 \\
\hline -Unspecified Effects - External Causes & $990-995$ & 5 & 1.0 & 0.4 & 2.4 \\
\hline -Complications of Surgical/Medical Care & 996-999 & 7 & 1.3 & 0.6 & 2.7 \\
\hline Total & & 746 & 202.8 & 185.9 & 221.2 \\
\hline
\end{tabular}

* Only those diagnostic categories with at least one occurrence appear in this table.

**Standardized to age distribution of 2000 U.S. population. 
Brookhaven National Laboratory 2008

OSHA Data

Appendix L. Number of Workers with at Least One OSHA Event by Gender, Age, and Job Category*

\begin{tabular}{|c|c|c|c|c|c|c|c|c|}
\hline \multirow{3}{*}{ Job Category } & \multicolumn{3}{|c|}{ Women } & \multicolumn{4}{|c|}{ Men } & \multirow[b]{3}{*}{ TOTAL } \\
\hline & \multicolumn{2}{|c|}{ Age Group } & \multirow[b]{2}{*}{ TOTAL } & \multicolumn{3}{|c|}{ Age Group } & \multirow[b]{2}{*}{ TOTAL } & \\
\hline & $40-49$ & $50+$ & & $30-39$ & $40-49$ & $50+$ & & \\
\hline Professional & 1 & 0 & 1 & 1 & 1 & 1 & 3 & 4 \\
\hline Administrative Support & 1 & 1 & 2 & 0 & 0 & 0 & 0 & 2 \\
\hline Technical Support & 0 & 1 & 1 & 0 & 2 & 1 & 3 & 4 \\
\hline Service & 2 & 2 & 4 & 2 & 0 & 2 & 4 & 8 \\
\hline Security and Fire & 0 & 0 & 0 & 1 & 2 & 0 & 3 & 3 \\
\hline Crafts & 0 & 0 & 0 & 1 & 2 & 3 & 6 & 6 \\
\hline TOTAL & 4 & 4 & 8 & 5 & 7 & 7 & 19 & 27 \\
\hline
\end{tabular}

*Only those job categories and gender/age combinations with at least one OSHA event appear in this table.

Appendix M. Total Number of Workdays Lost or with Restricted Activity from OSHA Events by Gender and Age

\begin{tabular}{|c|c|c|c|c|c|c|c|c|c|}
\hline \multirow[b]{2}{*}{ Age Group } & \multicolumn{3}{|c|}{ Women } & \multicolumn{3}{|c|}{ Men } & \multicolumn{3}{|c|}{ TOTAL } \\
\hline & $\begin{array}{c}\text { Number of } \\
\text { Events }\end{array}$ & \begin{tabular}{|c} 
Days \\
Restricted
\end{tabular} & Days Lost & $\begin{array}{l}\text { Number of } \\
\text { Events }\end{array}$ & $\begin{array}{c}\text { Days } \\
\text { Restricted }\end{array}$ & Days Lost & $\begin{array}{l}\text { Number of } \\
\text { Events }\end{array}$ & $\begin{array}{c}\text { Days } \\
\text { Restricted }\end{array}$ & Days Lost \\
\hline $30-39$ & 0 & 0 & 0 & 5 & 39 & 43 & 5 & 39 & 43 \\
\hline $40-49$ & 4 & 189 & 157 & 7 & 79 & 143 & 11 & 268 & 300 \\
\hline $50+$ & 4 & 45 & 7 & 7 & 103 & 365 & 11 & 148 & 372 \\
\hline TOTAL & 8 & 234 & 164 & 19 & 221 & 551 & 27 & 455 & 715 \\
\hline
\end{tabular}

Appendix N. Total Number of Workdays Lost or with Restricted Activity from OSHA Events by Gender and Job Category*

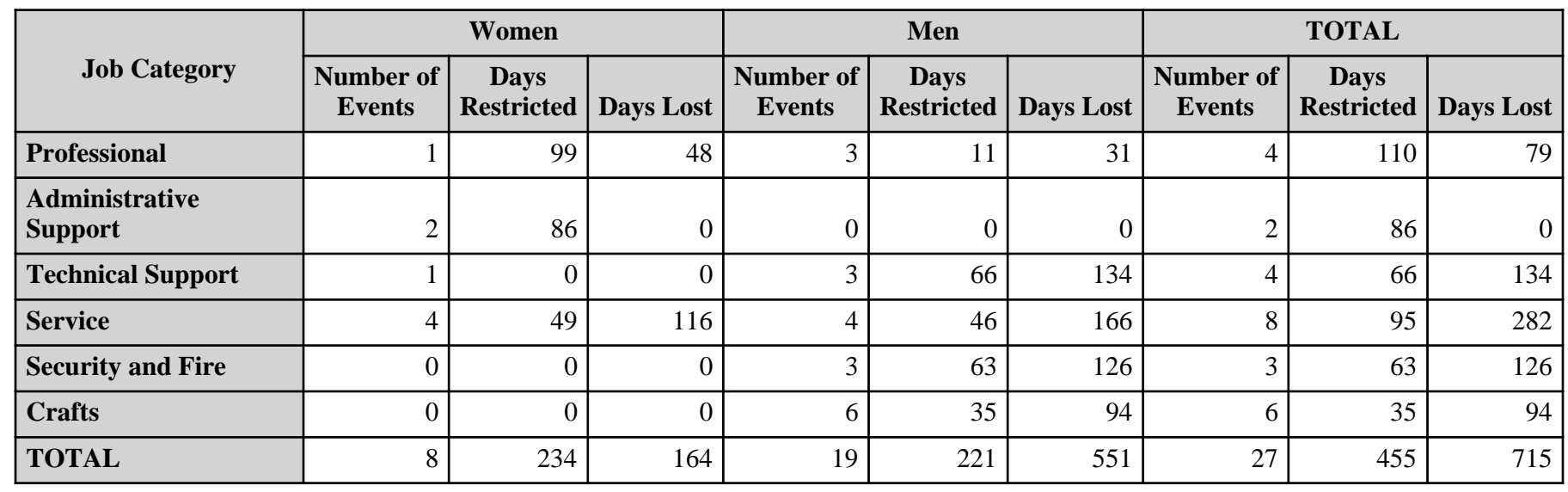

*Only those job categories with at least one OSHA event appear in this table. 
Brookhaven National Laboratory 2008

OSHA Data

Appendix O. Number of Diagnoses in Each Diagnostic Category by Gender and Age*

\begin{tabular}{|c|c|c|c|c|c|c|c|c|c|}
\hline & & \multicolumn{3}{|c|}{ Women } & \multicolumn{4}{|c|}{ Men } & \multirow[b]{3}{*}{ TOTAL } \\
\hline & & \multicolumn{2}{|c|}{ Age Group } & \multirow[b]{2}{*}{ TOTAL } & \multicolumn{3}{|c|}{ Age Group } & \multirow[b]{2}{*}{ TOTAL } & \\
\hline & & $40-49$ & $\begin{array}{l}50 \\
+\end{array}$ & & $30-39$ & $40-49$ & $\begin{array}{l}50 \\
+\end{array}$ & & \\
\hline Diagnostic Category & ICD-9-CM code & & & & & & & & \\
\hline NERVOUS SYSTEM (NS) \& SENSE ORGANS & 320-389 & 0 & 1 & 1 & 0 & 0 & 0 & 0 & 1 \\
\hline -Disorders of Peripheral NS & 350-359 & 0 & 1 & 1 & 0 & 0 & 0 & 0 & 1 \\
\hline $\begin{array}{l}\text { MUSCULOSKELETAL \& CONNECTIVE } \\
\text { TISSUE }\end{array}$ & 710-739 & 1 & 3 & 4 & 0 & 0 & 4 & 4 & 8 \\
\hline -Arthropathies & $710-719$ & 0 & 2 & 2 & 0 & 0 & 2 & 2 & 4 \\
\hline -Rheumatism, Excluding Back & 725-729 & 1 & 1 & 2 & 0 & 0 & 2 & 2 & 4 \\
\hline $\begin{array}{l}\text { SYMPTOMS, SIGNS, \& ILL-DEFINED } \\
\text { CONDITIONS }\end{array}$ & $780-799$ & 0 & 1 & 1 & 0 & 0 & 0 & 0 & 1 \\
\hline -Symptoms & $780-789$ & 0 & 1 & 1 & 0 & 0 & 0 & 0 & 1 \\
\hline INJURY \& POISONING & $800-999$ & 4 & 3 & 7 & 6 & 7 & 4 & 17 & 24 \\
\hline -Fracture - Lower Limb & $820-829$ & 1 & 0 & 1 & 0 & 0 & 0 & 0 & 1 \\
\hline -Open Wound - Upper Limb & 880-887 & 0 & 0 & 0 & 1 & 1 & 0 & 2 & 2 \\
\hline -Crushing Injury & $925-929$ & 0 & 0 & 0 & 1 & 0 & 0 & 1 & 1 \\
\hline -Complications \& Unspecified Injuries & 958-959 & 3 & 3 & 6 & 4 & 6 & 4 & 14 & 20 \\
\hline
\end{tabular}

\begin{tabular}{|c|c|c|c|c|c|c|c|c|}
\hline & \multicolumn{3}{|c|}{ Women } & \multicolumn{4}{|c|}{ Men } & \multirow[b]{3}{*}{ TOTAL } \\
\hline & \multicolumn{2}{|c|}{ Age Group } & \multirow[b]{2}{*}{ TOTAL } & \multicolumn{3}{|c|}{ Age Group } & \multirow[b]{2}{*}{ TOTAL } & \\
\hline & $40-49$ & $50+$ & & $30-39$ & $40-49$ & $50+$ & & \\
\hline Diagnostic Category & \multirow[b]{2}{*}{5} & \multirow[b]{2}{*}{8} & \multirow[b]{2}{*}{13} & \multirow[b]{2}{*}{6} & \multirow[b]{2}{*}{7} & \multirow[b]{2}{*}{8} & \multirow[b]{2}{*}{21} & \multirow[b]{2}{*}{34} \\
\hline Total & & & & & & & & \\
\hline
\end{tabular}

*Only those diagnostic categories and gender/age combinations with at least one OSHA event appear in this table. 
Brookhaven National Laboratory 2008

OSHA Data

Appendix P. Number of Workdays Lost or with Restricted Activity in Each Diagnostic Category by Gender and Age*

\begin{tabular}{|c|c|c|c|c|c|}
\hline & & \multicolumn{4}{|c|}{ Women } \\
\hline & & \multicolumn{4}{|c|}{ Age Group } \\
\hline & & \multicolumn{2}{|c|}{$40-49$} & \multicolumn{2}{|c|}{$50+$} \\
\hline & & $\begin{array}{c}\text { Days } \\
\text { Restricted }\end{array}$ & Days Lost & $\begin{array}{c}\text { Days } \\
\text { Restricted }\end{array}$ & Days Lost \\
\hline Diagnostic Category & ICD-9-CM Codes & \multirow[b]{2}{*}{0} & \multirow[b]{2}{*}{0} & \multirow[b]{2}{*}{0} & \multirow[b]{2}{*}{1} \\
\hline -Disorders of Peripheral NS & $350-359$ & & & & \\
\hline -Arthropathies & $710-719$ & 0 & 0 & 0 & 1 \\
\hline -Rheumatism, Excluding Back & $725-729$ & 86 & 0 & 0 & 1 \\
\hline -Symptoms & $780-789$ & 0 & 0 & 0 & 1 \\
\hline -Fracture - Lower Limb & $820-829$ & 99 & 48 & 0 & 0 \\
\hline $\begin{array}{l}\text {-Complications \& Unspecified } \\
\text { Injuries }\end{array}$ & 958-959 & 4 & 109 & 45 & 6 \\
\hline
\end{tabular}

\begin{tabular}{|c|c|c|c|c|c|c|c|}
\hline & & \multicolumn{6}{|c|}{ Men } \\
\hline & & \multicolumn{6}{|c|}{ Age Group } \\
\hline & & \multicolumn{2}{|c|}{$30-39$} & \multicolumn{2}{|c|}{$40-49$} & \multicolumn{2}{|c|}{$50+$} \\
\hline & & $\begin{array}{c}\text { Days } \\
\text { Restricted }\end{array}$ & Days Lost & \begin{tabular}{c|} 
Days \\
Restricted
\end{tabular} & Days Lost & \begin{tabular}{|c|} 
Days \\
Restricted
\end{tabular} & Days Lost \\
\hline Diagnostic Category & ICD-9-CM Codes & \multirow[b]{2}{*}{0} & \multirow[b]{2}{*}{0} & \multirow[b]{2}{*}{0} & \multirow[b]{2}{*}{0} & \multirow[b]{2}{*}{31} & \multirow[b]{2}{*}{163} \\
\hline -Arthropathies & $710-719$ & & & & & & \\
\hline -Rheumatism, Excluding Back & $725-729$ & 0 & 0 & 0 & 0 & 6 & 28 \\
\hline -Open Wound - Upper Limb & 880-887 & 0 & 0 & 29 & 1 & 0 & 0 \\
\hline -Crushing Injury & 925-929 & 15 & 1 & 0 & 0 & 0 & 0 \\
\hline $\begin{array}{l}\text {-Complications \& Unspecified } \\
\text { Injuries }\end{array}$ & 958-959 & 24 & 42 & 50 & 142 & 66 & 174 \\
\hline
\end{tabular}

*OSHA events with >1 ICD-9-CM code in the same diagnostic category were counted only once. Only those diagnostic categories and gender/age combinations with at least one occurrence appear in this table. 
Brookhaven National Laboratory 2008

OSHA Data

Appendix Q. Number of Occurrences in Each Accident Category by Gender and Age*

\begin{tabular}{|c|c|c|c|c|c|c|c|c|c|}
\hline & & \multicolumn{3}{|c|}{ Women } & \multicolumn{4}{|c|}{ Men } & \multirow[b]{3}{*}{ TOTAL } \\
\hline & & \multicolumn{2}{|c|}{ Age Group } & \multirow[b]{2}{*}{ TOTAL } & \multicolumn{3}{|c|}{ Age Group } & \multirow[b]{2}{*}{ TOTAL } & \\
\hline & & $40-49$ & $50+$ & & 30 - 39 & $40-49$ & $50+$ & & \\
\hline Type of Accident & E Codes & & & & & & & & \\
\hline Falls & E880-E888 & 2 & 0 & 2 & 1 & 1 & 3 & 5 & 7 \\
\hline Other Accidents & E916-E928 & 1 & 4 & 5 & 4 & 4 & 4 & 12 & 17 \\
\hline
\end{tabular}

*Only those accident types and gender/age combinations with at least one occurrence appear in this table. 
Brookhaven National Laboratory 2008

OSHA Data

Appendix R. Number of Workdays Lost or with Restricted Activity in Each Accident Category by Gender and Age*

\begin{tabular}{|c|c|c|c|c|c|}
\hline & & \multicolumn{4}{|c|}{ Women } \\
\hline & & \multicolumn{4}{|c|}{ Age Group } \\
\hline & & \multicolumn{2}{|c|}{$40-49$} & \multicolumn{2}{|c|}{$50+$} \\
\hline & & $\begin{array}{c}\text { Days } \\
\text { Restricted }\end{array}$ & Days Lost & $\begin{array}{c}\text { Days } \\
\text { Restricted }\end{array}$ & Days Lost \\
\hline Type of Accident & E Codes & \multirow[b]{2}{*}{99} & \multirow[b]{2}{*}{157} & \multirow[b]{2}{*}{0} & \multirow[b]{2}{*}{0} \\
\hline Falls & E880-E888 & & & & \\
\hline Other Accidents & E916-E928 & 4 & 0 & 45 & 7 \\
\hline
\end{tabular}

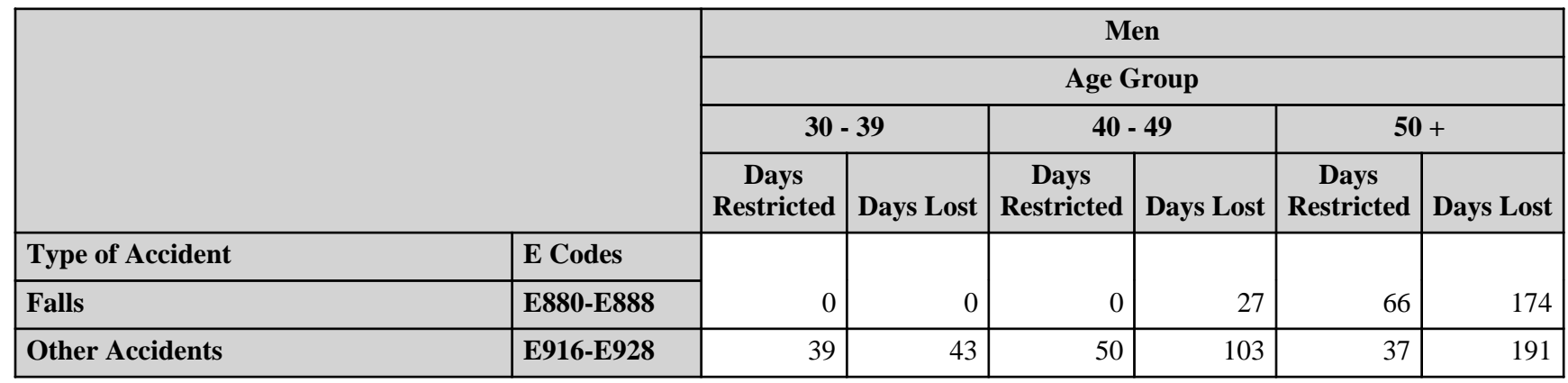

*OSHA events with $>1 \mathrm{E}$ code in the same accident type were counted only once. Only those accident types and gender/age combinations with at least one occurrence appear in this table. 
Brookhaven National Laboratory 2008

OSHA Data

Appendix S. Number of Diagnoses in Each Diagnostic Category by Gender and Job Category*

\begin{tabular}{|c|c|c|c|c|c|c|}
\hline & & \multicolumn{5}{|c|}{ Women } \\
\hline & & \multicolumn{4}{|c|}{ Job Category } & \multirow[b]{2}{*}{ TOTAL } \\
\hline & & Professional & $\begin{array}{c}\text { Administrative } \\
\text { Support }\end{array}$ & Technical Support & Service & \\
\hline Diagnostic Category & ICD-9-CM Code & & & & & \\
\hline $\begin{array}{l}\text { NERVOUS SYSTEM } \\
\text { (NS) \& SENSE ORGANS }\end{array}$ & $320-389$ & 0 & 0 & 0 & 1 & 1 \\
\hline $\begin{array}{l}\text {-Disorders of Peripheral } \\
\text { NS }\end{array}$ & $350-359$ & 0 & 0 & 0 & 1 & 1 \\
\hline $\begin{array}{l}\text { MUSCULOSKELETAL } \\
\text { \& CONNECTIVE } \\
\text { TISSUE }\end{array}$ & $710-739$ & 0 & 1 & 0 & 3 & 4 \\
\hline -Arthropathies & $710-719$ & 0 & 0 & 0 & 2 & 2 \\
\hline $\begin{array}{l}\text {-Rheumatism, Excluding } \\
\text { Back }\end{array}$ & $725-729$ & 0 & 1 & 0 & 1 & 2 \\
\hline $\begin{array}{l}\text { SYMPTOMS, } \\
\text { SIGNS, \& ILL-DEFINED } \\
\text { CONDITIONS }\end{array}$ & $780-799$ & 0 & 0 & 0 & 1 & 1 \\
\hline -Symptoms & $780-789$ & 0 & 0 & 0 & 1 & 1 \\
\hline INJURY \& POISONING & $800-999$ & 1 & 1 & 1 & 4 & 7 \\
\hline -Fracture - Lower Limb & $820-829$ & 1 & 0 & 0 & 0 & 1 \\
\hline $\begin{array}{l}\text {-Complications \& } \\
\text { Unspecified Injuries }\end{array}$ & $958-959$ & 0 & 1 & 1 & 4 & 6 \\
\hline
\end{tabular}

\begin{tabular}{|c|c|c|c|c|c|}
\hline & \multicolumn{5}{|c|}{ Women } \\
\hline & \multicolumn{4}{|c|}{ Job Category } & \multirow[b]{2}{*}{ TOTAL } \\
\hline & Professional & $\begin{array}{c}\text { Administrative } \\
\text { Support }\end{array}$ & Technical Support & Service & \\
\hline Diagnostic Category & \multirow[b]{2}{*}{1} & \multirow[b]{2}{*}{2} & \multirow[b]{2}{*}{1} & \multirow[b]{2}{*}{9} & \multirow[b]{2}{*}{13} \\
\hline Total & & & & & \\
\hline
\end{tabular}

\begin{tabular}{|c|c|c|c|c|c|c|c|}
\hline & & \multicolumn{6}{|c|}{ Men } \\
\hline & & \multicolumn{5}{|c|}{ Job Category } & \multirow[b]{2}{*}{ TOTAL } \\
\hline & & Professional & \begin{tabular}{|l|} 
Technical Support \\
\end{tabular} & Service & Security and Fire & Crafts & \\
\hline Diagnostic Category & ICD-9-CM Code & & & & & & \\
\hline $\begin{array}{l}\text { MUSCULOSKELETAL } \\
\text { \& CONNECTIVE } \\
\text { TISSUE }\end{array}$ & $710-739$ & 0 & 0 & 3 & 0 & 1 & 4 \\
\hline -Arthropathies & $710-719$ & 0 & 0 & 2 & 0 & 0 & 2 \\
\hline $\begin{array}{l}\text {-Rheumatism, Excluding } \\
\text { Back }\end{array}$ & $725-729$ & 0 & 0 & 1 & 0 & 1 & 2 \\
\hline INJURY \& POISONING & 800-999 & 3 & 3 & 3 & 3 & 5 & 17 \\
\hline $\begin{array}{l}\text {-Open Wound - Upper } \\
\text { Limb }\end{array}$ & 880-887 & 1 & 0 & 0 & 0 & 1 & 2 \\
\hline
\end{tabular}

(Continued)

*Only those diagnostic categories and gender/job category combinations with at least one occurrence appear in this table. 
Brookhaven National Laboratory 2008

OSHA Data

Appendix S. Number of Diagnoses in Each Diagnostic Category by Gender and Job Category*

\begin{tabular}{|c|c|c|c|c|c|c|c|}
\hline & & \multicolumn{6}{|c|}{ Men } \\
\hline & & \multicolumn{5}{|c|}{ Job Category } & \multirow[b]{2}{*}{ TOTAL } \\
\hline & & Professional & Technical Support & Service & Security and Fire & Crafts & \\
\hline Diagnostic Category & ICD-9-CM Code & \multirow[b]{2}{*}{0} & \multirow[b]{2}{*}{0} & \multirow[b]{2}{*}{1} & \multirow[b]{2}{*}{0} & \multirow[b]{2}{*}{0} & \multirow[b]{2}{*}{1} \\
\hline -Crushing Injury & 925-929 & & & & & & \\
\hline $\begin{array}{l}\text {-Complications \& } \\
\text { Unspecified Injuries }\end{array}$ & 958-959 & 2 & 3 & 2 & 3 & 4 & 14 \\
\hline
\end{tabular}

\begin{tabular}{|l|r|r|r|r|r|r|}
\hline \multirow{4}{*}{} & \multicolumn{7}{|c|}{ Men } & \\
\cline { 2 - 7 } & \multicolumn{5}{|c|}{ Job Category } & \\
\cline { 2 - 8 } & Professional & Technical Support & Service & Security and Fire & Crafts & TOTAL \\
\hline Diagnostic Category & & & & & & \\
\cline { 1 - 8 } Total & 3 & 3 & 6 & 3 & 6 \\
\hline
\end{tabular}

*Only those diagnostic categories and gender/job category combinations with at least one occurrence appear in this table. 
Brookhaven National Laboratory 2008

OSHA Data

Appendix T. Number of Workdays Lost or with Restricted Activity in Each Diagnostic Category by Gender and Job Category*

\begin{tabular}{|c|c|c|c|c|c|c|c|c|c|}
\hline & & \multicolumn{8}{|c|}{ Women } \\
\hline & & \multicolumn{8}{|c|}{ Job Category } \\
\hline & & \multicolumn{2}{|c|}{ Professional } & \multicolumn{2}{|c|}{$\begin{array}{l}\text { Administrative } \\
\text { Support }\end{array}$} & \multicolumn{2}{|c|}{$\begin{array}{l}\text { Technical } \\
\text { Support }\end{array}$} & \multicolumn{2}{|c|}{ Service } \\
\hline & & $\begin{array}{c}\text { Days } \\
\text { Restricted }\end{array}$ & $\begin{array}{l}\text { Days } \\
\text { Lost }\end{array}$ & \begin{tabular}{c|} 
Days \\
Restricted
\end{tabular} & $\begin{array}{l}\text { Days } \\
\text { Lost }\end{array}$ & \begin{tabular}{c|} 
Days \\
Restricted
\end{tabular} & $\begin{array}{l}\text { Days } \\
\text { Lost }\end{array}$ & $\begin{array}{c}\text { Days } \\
\text { Restricted }\end{array}$ & $\begin{array}{l}\text { Days } \\
\text { Lost }\end{array}$ \\
\hline Diagnostic Category & ICD-9-CM Codes & & & & & & & & \\
\hline -Disorders of Peripheral NS & $350-359$ & 0 & 0 & 0 & 0 & 0 & 0 & 0 & 1 \\
\hline -Arthropathies & $710-719$ & 0 & 0 & 0 & 0 & 0 & 0 & 0 & 1 \\
\hline -Rheumatism, Excluding Back & $725-729$ & 0 & 0 & 86 & 0 & 0 & 0 & 0 & 1 \\
\hline -Symptoms & $780-789$ & 0 & 0 & 0 & 0 & 0 & 0 & 0 & 1 \\
\hline -Fracture - Lower Limb & 820-829 & 99 & 48 & 0 & 0 & 0 & 0 & 0 & 0 \\
\hline $\begin{array}{l}\text {-Complications \& Unspecified } \\
\text { Injuries }\end{array}$ & 958-959 & 0 & 0 & 0 & 0 & 0 & 0 & 49 & 115 \\
\hline
\end{tabular}

\begin{tabular}{|c|c|c|c|c|c|c|c|}
\hline & & \multicolumn{6}{|c|}{ Men } \\
\hline & & \multicolumn{6}{|c|}{ Job Category } \\
\hline & & \multicolumn{2}{|c|}{ Professional } & \multicolumn{2}{|c|}{ Technical Support } & \multicolumn{2}{|c|}{ Service } \\
\hline & & $\begin{array}{c}\text { Days } \\
\text { Restricted }\end{array}$ & Days Lost & $\begin{array}{c}\text { Days } \\
\text { Restricted }\end{array}$ & Days Lost & $\begin{array}{c}\text { Days } \\
\text { Restricted }\end{array}$ & Days Lost \\
\hline Diagnostic Category & ICD-9-CM Codes & \multirow[b]{2}{*}{0} & \multirow[b]{2}{*}{0} & \multirow[b]{2}{*}{0} & \multirow[b]{2}{*}{0} & \multirow[b]{2}{*}{31} & \multirow[b]{2}{*}{163} \\
\hline -Arthropathies & $710-719$ & & & & & & \\
\hline -Rheumatism, Excluding Back & 725-729 & 0 & 0 & 0 & 0 & 0 & 2 \\
\hline -Open Wound - Upper Limb & 880-887 & 0 & 0 & 0 & 0 & 0 & 0 \\
\hline -Crushing Injury & $925-929$ & 0 & 0 & 0 & 0 & 15 & 1 \\
\hline $\begin{array}{l}\text {-Complications \& Unspecified } \\
\text { Injuries }\end{array}$ & 958-959 & 11 & 31 & 66 & 134 & 0 & 0 \\
\hline
\end{tabular}

\begin{tabular}{|c|c|c|c|c|c|}
\hline & & \multicolumn{4}{|c|}{ Men } \\
\hline & & \multicolumn{4}{|c|}{ Job Category } \\
\hline & & \multicolumn{2}{|c|}{ Security and Fire } & \multicolumn{2}{|c|}{ Crafts } \\
\hline & & $\begin{array}{c}\text { Days } \\
\text { Restricted }\end{array}$ & Days Lost & $\begin{array}{c}\text { Days } \\
\text { Restricted }\end{array}$ & Days Lost \\
\hline Diagnostic Category & ICD-9-CM Codes & \multirow[b]{2}{*}{0} & \multirow[b]{2}{*}{0} & \multirow[b]{2}{*}{0} & \multirow[b]{2}{*}{0} \\
\hline -Arthropathies & 710-719 & & & & \\
\hline -Rheumatism, Excluding Back & $725-729$ & 0 & 0 & 6 & 26 \\
\hline -Open Wound - Upper Limb & 880-887 & 0 & 0 & 29 & 1 \\
\hline -Crushing Injury & $925-929$ & 0 & 0 & 0 & 0 \\
\hline $\begin{array}{l}\text {-Complications \& Unspecified } \\
\text { Injuries }\end{array}$ & 958-959 & 63 & 126 & 0 & 67 \\
\hline
\end{tabular}

*OSHA events with >1 ICD-9-CM code in the same diagnostic category were counted only once. Only those diagnostic categories and gender/job category combinations with at least one occurrence appear in this table. 
Brookhaven National Laboratory 2008

OSHA Data

Appendix U. Number of Occurrences in Each Accident Category by Gender and Job Category*

\begin{tabular}{|c|c|c|c|c|c|c|}
\hline & & \multicolumn{5}{|c|}{ Women } \\
\hline & & \multicolumn{4}{|c|}{ Job Category } & \multirow[b]{2}{*}{ TOTAL } \\
\hline & & Professional & $\begin{array}{c}\text { Administrative } \\
\text { Support }\end{array}$ & $\begin{array}{c}\text { Technical } \\
\text { Support }\end{array}$ & Service & \\
\hline Type of Accident & E CODES & \multirow[b]{2}{*}{1} & \multirow[b]{2}{*}{0} & \multirow[b]{2}{*}{0} & \multirow[b]{2}{*}{1} & \multirow[b]{2}{*}{2} \\
\hline Falls & E880-E888 & & & & & \\
\hline Other Accidents & E916-E928 & 0 & 1 & 1 & 3 & 5 \\
\hline
\end{tabular}

\begin{tabular}{|c|c|c|c|c|c|c|c|}
\hline & & \multicolumn{6}{|c|}{ Men } \\
\hline & & \multicolumn{5}{|c|}{ Job Category } & \multirow[b]{2}{*}{ TOTAL } \\
\hline & & Professional & $\begin{array}{c}\text { Technical } \\
\text { Support }\end{array}$ & Service & $\begin{array}{c}\text { Security and } \\
\text { Fire }\end{array}$ & Crafts & \\
\hline Type of Accident & E CODES & \multirow[b]{2}{*}{1} & \multirow[b]{2}{*}{1} & \multirow[b]{2}{*}{1} & \multirow[b]{2}{*}{0} & \multirow[b]{2}{*}{2} & \multirow[b]{2}{*}{5} \\
\hline Falls & E880-E888 & & & & & & \\
\hline Other Accidents & E916-E928 & 2 & 2 & 3 & 2 & 3 & 12 \\
\hline
\end{tabular}

*Only those accident types and gender/job category combinations with at least one occurrence appear in this table. 
Brookhaven National Laboratory 2008

OSHA Data

Appendix V. Number of Workdays Lost or with Restricted Activity in Each Accident Category by Gender and Job Category*

\begin{tabular}{|c|c|c|c|c|c|c|c|c|c|}
\hline & & \multicolumn{8}{|c|}{ Women } \\
\hline & & \multicolumn{8}{|c|}{ Job Category } \\
\hline & & \multicolumn{2}{|c|}{ Professional } & \multicolumn{2}{|c|}{$\begin{array}{l}\text { Administrative } \\
\text { Support }\end{array}$} & \multicolumn{2}{|c|}{$\begin{array}{c}\text { Technical } \\
\text { Support }\end{array}$} & \multicolumn{2}{|c|}{ Service } \\
\hline & & $\begin{array}{c}\text { Days } \\
\text { Restricted }\end{array}$ & $\begin{array}{l}\text { Days } \\
\text { Lost }\end{array}$ & \begin{tabular}{c|} 
Days \\
Restricted
\end{tabular} & $\begin{array}{l}\text { Days } \\
\text { Lost }\end{array}$ & $\begin{array}{c}\text { Days } \\
\text { Restricted }\end{array}$ & $\begin{array}{l}\text { Days } \\
\text { Lost }\end{array}$ & \begin{tabular}{c|} 
Days \\
Restricted
\end{tabular} & $\begin{array}{l}\text { Days } \\
\text { Lost }\end{array}$ \\
\hline Type of Accident & E Codes & \multirow[b]{2}{*}{99} & \multirow[b]{2}{*}{48} & \multirow[b]{2}{*}{0} & \multirow[b]{2}{*}{0} & \multirow[b]{2}{*}{0} & \multirow[b]{2}{*}{0} & \multirow[b]{2}{*}{0} & \multirow[b]{2}{*}{109} \\
\hline Falls & E880-E888 & & & & & & & & \\
\hline Other Accidents & E916-E928 & 0 & 0 & 0 & 0 & 0 & 0 & 49 & 7 \\
\hline
\end{tabular}

\begin{tabular}{|c|c|c|c|c|c|c|c|}
\hline & & \multicolumn{6}{|c|}{ Men } \\
\hline & & \multicolumn{6}{|c|}{ Job Category } \\
\hline & & \multicolumn{2}{|c|}{ Professional } & \multicolumn{2}{|c|}{ Technical Support } & \multicolumn{2}{|c|}{ Service } \\
\hline & & $\begin{array}{c}\text { Days } \\
\text { Restricted }\end{array}$ & Days Lost & $\begin{array}{c}\text { Days } \\
\text { Restricted }\end{array}$ & Days Lost & $\begin{array}{c}\text { Days } \\
\text { Restricted }\end{array}$ & Days Lost \\
\hline Type of Accident & E Codes & \multirow[b]{2}{*}{0} & \multirow[b]{2}{*}{0} & \multirow[b]{2}{*}{66} & \multirow[b]{2}{*}{134} & \multirow[b]{2}{*}{0} & \multirow[b]{2}{*}{0} \\
\hline Falls & E880-E888 & & & & & & \\
\hline Other Accidents & E916-E928 & 11 & 31 & 0 & 0 & 46 & 166 \\
\hline
\end{tabular}

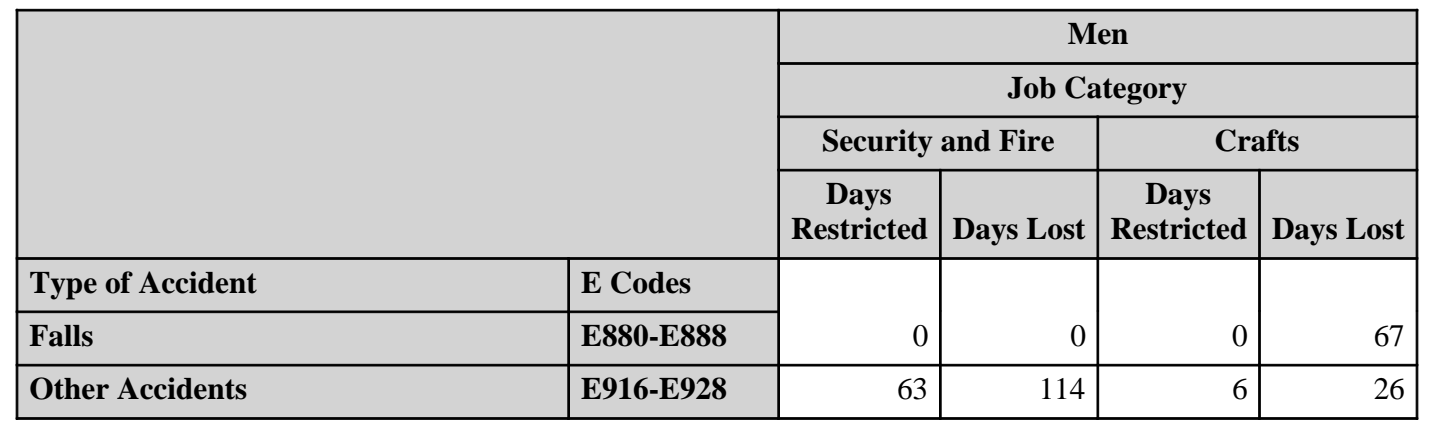

*OSHA events with >1 E code in the same accident type were counted only once. Only those accident types and gender/job category combinations with at least one occurrence appear in this table. 
Brookhaven National Laboratory 2008

OSHA Data

Appendix W. Age-Adjusted OSHA Illness and Injury Rates by Diagnostic Category*

Part 1. Men

\begin{tabular}{|c|c|c|c|c|c|}
\hline & & $\begin{array}{l}\text { Number of } \\
\text { Diagnoses }\end{array}$ & $\begin{array}{c}\text { Age-Adjusted } \\
\text { Rate per } 1,000 * *\end{array}$ & $\begin{array}{c}\text { Lower } 95 \% \\
\text { Confidence } \\
\text { Limit per 1,000 }\end{array}$ & $\begin{array}{c}\text { Upper } 95 \% \\
\text { Confidence } \\
\text { Limit per } 1,000\end{array}$ \\
\hline Diagnostic Category & ICD-9-CM Code & & & & \\
\hline $\begin{array}{l}\text { MUSCULOSKELETAL \& CONNECTIVE } \\
\text { TISSUE }\end{array}$ & $710-739$ & 4 & 1.0 & 0.4 & 2.6 \\
\hline -Arthropathies & $710-719$ & 2 & 0.5 & 0.1 & 2.0 \\
\hline -Rheumatism, Excluding Back & 725-729 & 2 & 0.5 & 0.1 & 2.0 \\
\hline INJURY \& POISONING & $800-999$ & 17 & 7.5 & 4.5 & 12.5 \\
\hline -Open Wound - Upper Limb & $880-887$ & 2 & 1.0 & 0.2 & 4.3 \\
\hline -Complications of Surgical/Medical Care & 996-999 & 15 & 6.5 & 3.8 & 11.2 \\
\hline Total & & 21 & 8.5 & 5.4 & 13.5 \\
\hline
\end{tabular}

*Only those diagnostic categories with at least one occurrence appear in this table.

**Standardized to age distribution of 2000 U.S. population. 
Brookhaven National Laboratory 2008

OSHA Data

Appendix W. Age-Adjusted OSHA Illness and Injury Rates by Diagnostic Category*

Part 2. Women

\begin{tabular}{|c|c|c|c|c|c|}
\hline & & $\begin{array}{l}\text { Number of } \\
\text { Diagnoses }\end{array}$ & $\begin{array}{c}\text { Age-Adjusted } \\
\text { Rate per } 1,000 * *\end{array}$ & $\begin{array}{c}\text { Lower } 95 \% \\
\text { Confidence } \\
\text { Limit per 1,000 }\end{array}$ & $\begin{array}{c}\text { Upper } 95 \% \\
\text { Confidence } \\
\text { Limit per 1,000 }\end{array}$ \\
\hline Diagnostic Category & ICD-9-CM Code & \multirow[b]{2}{*}{1} & \multirow[b]{2}{*}{0.7} & \multirow[b]{2}{*}{0.1} & \multirow[b]{2}{*}{4.8} \\
\hline NERVOUS SYSTEM (NS) \& SENSE ORGANS & 320-389 & & & & \\
\hline -Disorders of Peripheral NS & 350-359 & 1 & 0.7 & 0.1 & 4.8 \\
\hline $\begin{array}{l}\text { MUSCULOSKELETAL \& CONNECTIVE } \\
\text { TISSUE }\end{array}$ & 710-739 & 4 & 3.0 & 1.1 & 8.0 \\
\hline -Arthropathies & 710-719 & 2 & 1.3 & 0.3 & 5.4 \\
\hline -Rheumatism, Excluding Back & 725-729 & 2 & 1.6 & 0.4 & 6.7 \\
\hline $\begin{array}{l}\text { SYMPTOMS, SIGNS, \& ILL-DEFINED } \\
\text { CONDITIONS }\end{array}$ & 780-799 & 1 & 0.7 & 0.1 & 4.8 \\
\hline -Symptoms & $780-789$ & 1 & 0.7 & 0.1 & 4.8 \\
\hline INJURY \& POISONING & $800-999$ & 7 & 7.0 & 3.3 & 14.9 \\
\hline -Fracture - Lower Limb & $820-829$ & 1 & 1.0 & 0.1 & 6.8 \\
\hline -Complications of Surgical/Medical Care & 996-999 & 6 & 6.0 & 2.7 & 13.6 \\
\hline Total & & 13 & 11.3 & 6.5 & 19.8 \\
\hline
\end{tabular}

* Only those diagnostic categories with at least one occurrence appear in this table.

**Standardized to age distribution of 2000 U.S. population. 
Brookhaven National Laboratory 2008

OSHA Data

Appendix W. Age-Adjusted OSHA Illness and Injury Rates by Diagnostic Category*

Part 3. Men and Women

\begin{tabular}{|c|c|c|c|c|c|}
\hline & & $\begin{array}{l}\text { Number of } \\
\text { Diagnoses }\end{array}$ & $\begin{array}{c}\text { Age-Adjusted } \\
\text { Rate per } 1,000^{* *}\end{array}$ & $\begin{array}{c}\text { Lower } 95 \% \\
\text { Confidence } \\
\text { Limit per 1,000 }\end{array}$ & $\begin{array}{c}\text { Upper } 95 \% \\
\text { Confidence } \\
\text { Limit per 1,000 }\end{array}$ \\
\hline Diagnostic Category & ICD-9-CM Code & \multirow[b]{2}{*}{1} & \multirow[b]{2}{*}{0.2} & \multirow[b]{2}{*}{0.0} & \multirow[b]{2}{*}{1.3} \\
\hline NERVOUS SYSTEM (NS) \& SENSE ORGANS & 320-389 & & & & \\
\hline -Disorders of Peripheral NS & $350-359$ & 1 & 0.2 & 0.0 & 1.3 \\
\hline $\begin{array}{l}\text { MUSCULOSKELETAL \& CONNECTIVE } \\
\text { TISSUE }\end{array}$ & 710-739 & 8 & 1.5 & 0.8 & 3.1 \\
\hline -Arthropathies & 710-719 & 4 & 0.7 & 0.3 & 1.9 \\
\hline -Rheumatism, Excluding Back & $725-729$ & 4 & 0.8 & 0.3 & 2.2 \\
\hline $\begin{array}{l}\text { SYMPTOMS, SIGNS, \& ILL-DEFINED } \\
\text { CONDITIONS }\end{array}$ & 780-799 & 1 & 0.2 & 0.0 & 1.3 \\
\hline- Symptoms & 780-789 & 1 & 0.2 & 0.0 & 1.3 \\
\hline INJURY \& POISONING & $800-999$ & 24 & 7.2 & 4.7 & 11.0 \\
\hline -Fracture - Lower Limb & 820-829 & 1 & 0.3 & 0.0 & 1.9 \\
\hline -Open Wound - Upper Limb & $880-887$ & 2 & 0.7 & 0.2 & 3.1 \\
\hline -Complications of Surgical/Medical Care & 996-999 & 21 & 6.2 & 4.0 & 9.8 \\
\hline Total & & 34 & 9.1 & 6.4 & 13.0 \\
\hline
\end{tabular}

* Only those diagnostic categories with at least one occurrence appear in this table.

**Standardized to age distribution of 2000 U.S. population. 